University of Rhode Island

\title{
DigitalCommons@URI
}

Open Access Dissertations

2019

\section{Health Information Campaigns and Genetically Modified Food Labels in the Seafood Market}

Michael Joseph Weir

University of Rhode Island, weir.michaelj@gmail.com

Follow this and additional works at: https://digitalcommons.uri.edu/oa_diss

Terms of Use

All rights reserved under copyright.

\section{Recommended Citation}

Weir, Michael Joseph, "Health Information Campaigns and Genetically Modified Food Labels in the Seafood Market" (2019). Open Access Dissertations. Paper 840.

https://digitalcommons.uri.edu/oa_diss/840

This Dissertation is brought to you for free and open access by DigitalCommons@URI. It has been accepted for inclusion in Open Access Dissertations by an authorized administrator of DigitalCommons@URI. For more information, please contact digitalcommons@etal.uri.edu. 


\author{
HEALTH INFORMATION CAMPAIGNS AND \\ GENETICALLY MODIFIED FOOD LABELS IN THE \\ SEAFOOD MARKET \\ BY \\ MICHAEL JOSEPH WEIR
}

\title{
A DISSERTATION SUBMITTED IN PARTIAL FULFILLMENT OF THE REQUIREMENTS FOR THE DEGREE OF DOCTOR OF PHILOSOPHY
}

IN

ENVIRONMENTAL AND NATURAL RESOURCE ECONOMICS

UNIVERSITY OF RHODE ISLAND

2019 


\title{
DOCTOR OF PHILOSOPHY DISSERTATION
}

OF

MICHAEL JOSEPH WEIR

\section{APPROVED:}

Dissertation Committee:

\author{
Major Professor Hirotsugu Uchida \\ Thomas W. Sproul \\ Maya Vadiveloo \\ Nasser H. Zawia \\ DEAN OF THE GRADUATE SCHOOL
}




\begin{abstract}
In this dissertation I investigate consumer responses to two forms of information provision in the seafood market: health information campaigns and genetically modified food labels. Using data from a seafood auction experiment, I explore sources of heterogeneity among auction participants and their responses to health information in the context of current United States Departments of Agriculture and Health and Human Services policy goals using a mixed effects finite mixture model. My second and third chapters explore the potential effect of the forthcoming National Bioengineered Food Disclosure Standard on demand for genetically modified seafood. Considering the new labeling standard and the development of a genetically modified fish I collect data using an online choice experiment to investigate 1) consumer preferences and willingness to pay for Atlantic Salmon fillets with labels denoting the presence or absence of GM technology and 2) influence of behavioral measures on consumer preference for GM seafood using an application of machine learning techniques. The use of these techniques allows for rigorous identification of treatment effects that hold important implications for policy makers in the ever adapting "Information Age."
\end{abstract}




\section{ACKNOWLEDGMENTS}

I wish to thank my advisor, Dr. Hirotsugu Uchida. The opportunities I have been afforded under your mentorship have undoubtedly shaped my perspectives on life and have made possible my pursuit of a career as an applied economist. The same could be said of my committee member Dr. Thomas Sproul. I am forever thankful for your enthusiastic encouragement and support throughout my career. I am particularly grateful for your (strong) nudges that convinced me working at a café while trying to finish a dissertation is not the best use of time. To my committee member, Dr. Maya Vadiveloo, thank you for pushing me to think more deeply about my work and consider its implications from an outside perspective.

I also want to thank all the other faculty that have supported me during my time at URI. I specifically want to thank Dr. Todd Guilfoos, Dr.Tracey Dalton, and Dr. Stephen Atlas for inviting me to work with them on a variety of projects over the past few years.

To all the past and current graduate students in Coastal Institute Room 222, I am most certain this dissertation would not have been written without your help. Thank you in particular to Jason Walsh, Ben Blachly, Vasu Gaur, Clayton Michaud, Carrie Gill, and Kyle Montanio. It has been an honor sharing the last five years with all of you.

To the Buccheri, Smith, and Akers families, I am not sure it is possible to put into words how truly grateful I am for your love and support during my time in Rhode Island. David and Rebecca, you are the reason I even considered applying to URI and I cannot thank you enough.

To my parents, Joe and Julie, and my sister Caroline: I love you. Thank you for believing in me and helping me to believe in myself. 


\section{PREFACE}

I use manuscript format for this dissertation. There are three independent chapters which constitute the entire work. The goal of this dissertation is to build understanding of consumer choice in the context of seafood. The first manuscript is co-authored with Hirotsugu Uchida, Cathy Roheim, and Robert Johnston. It is being prepared for submission to the American Journal of Agricultural Economics. The second manuscript is co-authored with Hirotsugu Uchida and Maya Vadiveloo. It is being prepared for submission to Food Policy. The third manuscript is co-authored with Thomas Sproul. It is being prepared for submission to Sustainability. 


\section{TABLE OF CONTENTS}

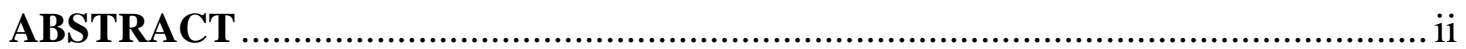

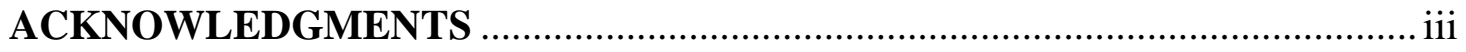

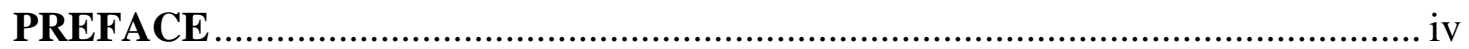

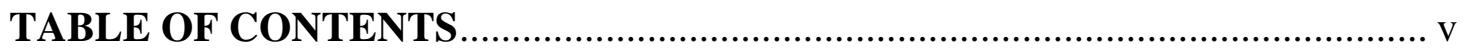

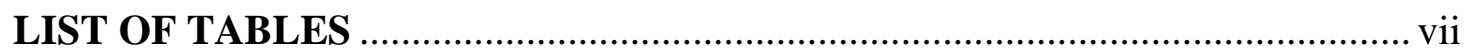

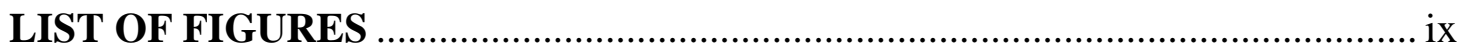

PURCHASE BEHAVIOR, TRUST OF ACADEMIC SOURCED

INFORMATION AND AGGREGATION EFFECTS IN CONSUMER

RESPONSE TO HEALTH INFORMATION CAMPAIGNS .......................... 1

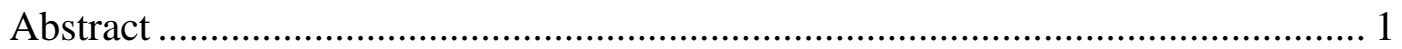

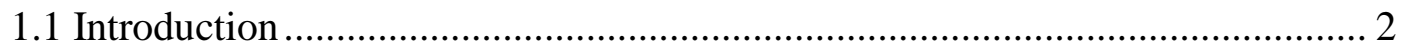

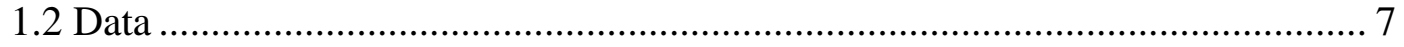

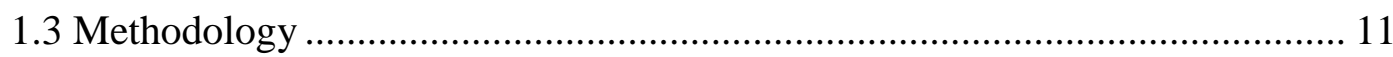

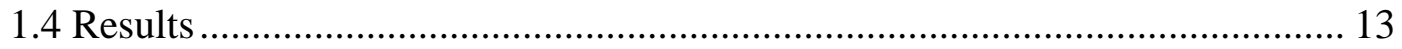

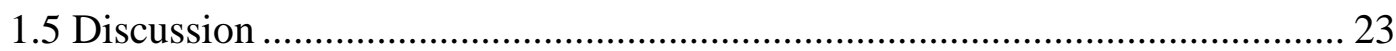

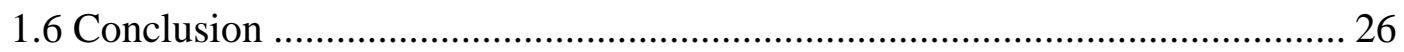

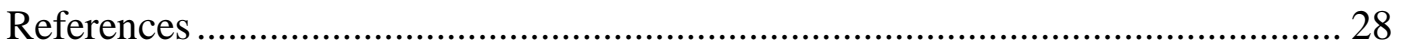

NATIONAL BIOENGINEERED FOOD DISCLOSURE STANDARD AND THE POLARIZING EFFECT OF MARKET INFORMATION ON DEMAND FOR GENETICALLY MODIFIED SEAFOOD ........................................... 56

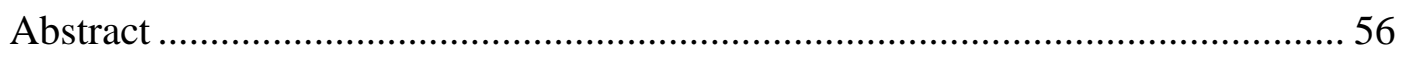

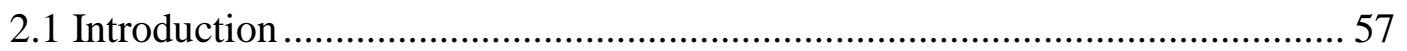




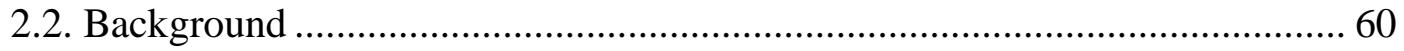

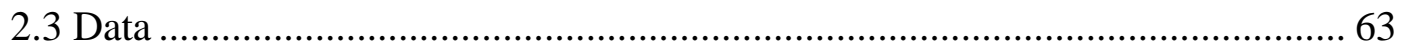

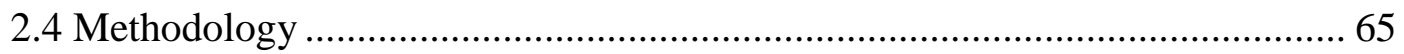

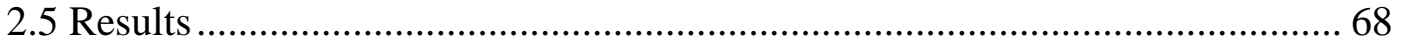

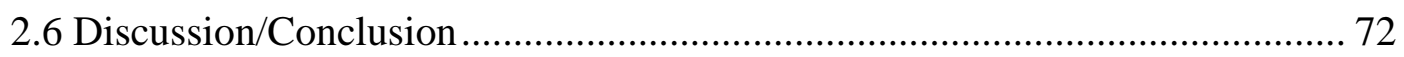

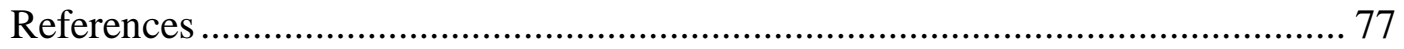

INCORPORATING INDIVIDUAL-LEVEL BEHAVIORAL MEASURES TO

PREDICT CONSUMER PURCHASES IN THE GENETICALLY

MODIFIED SEAFOOD MARKET: AN APPLICATION OF LASSO

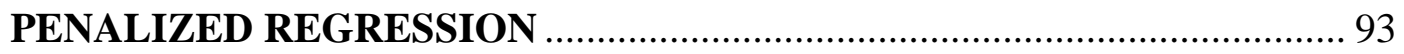

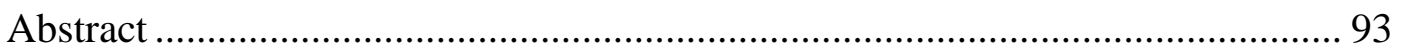

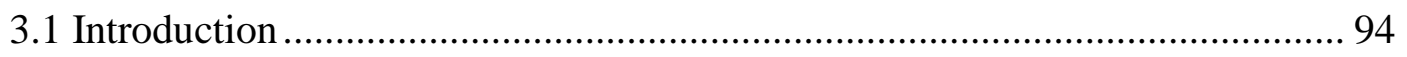

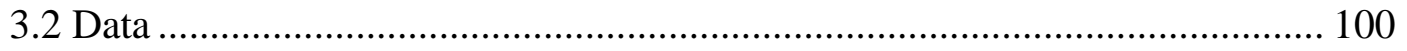

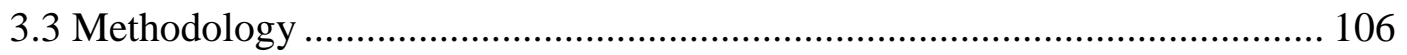

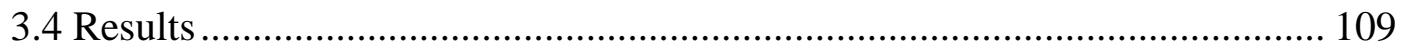

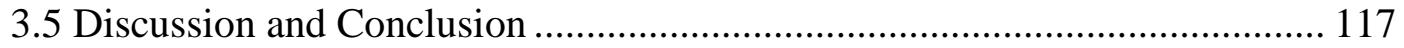

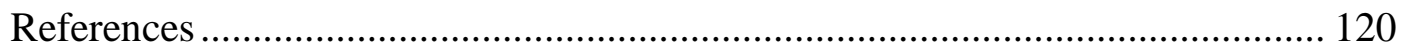

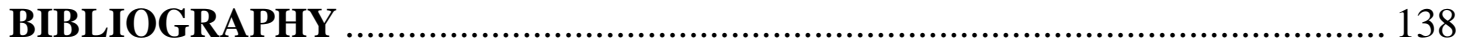




\section{LIST OF TABLES}

TABLE

PAGE

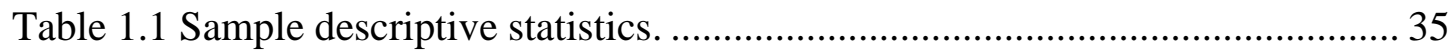

Table 1.2 Summary of experimental information treatments ..................................... 36

Table 1.3 Summary of information premium by quantile......................................... 37

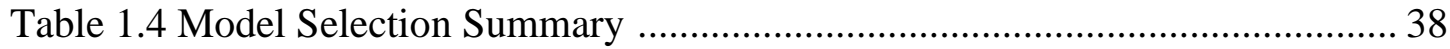

Table 1.5 Sample descriptive statistics by class ........................................................ 39

Table 1.6 Rotated factor loadings - seafood purchase behavior................................... 40

Table 1.7 Rotated factor loadings - seafood lifestyle ................................................ 41

Table 1.8 Rotated factor loadings - seafood health perceptions.................................. 42

Table 1.9 Rotated factor loadings - seafood information trust................................... 44

Table 1.10 Multinomial logit summary …………………...................................... 45

Table 1.11 Effect of information on information premium by class............................ 47

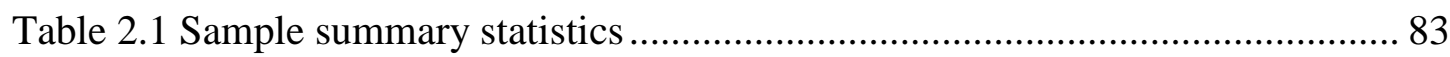

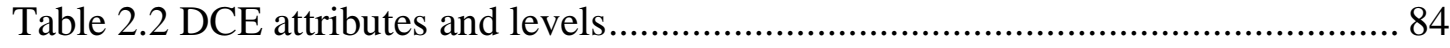

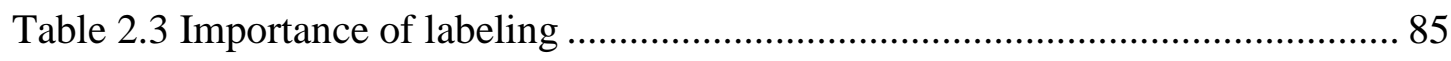

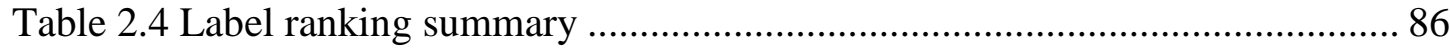

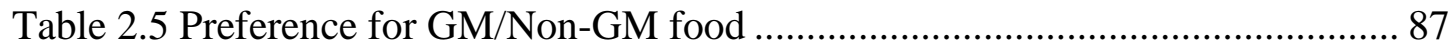

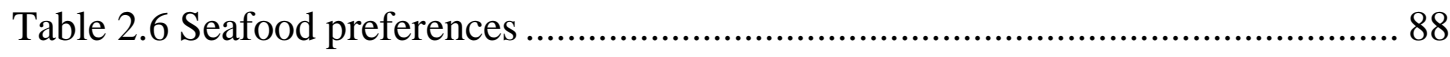

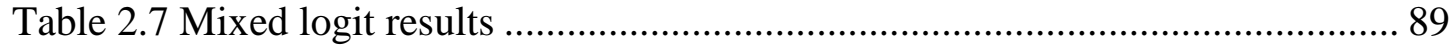

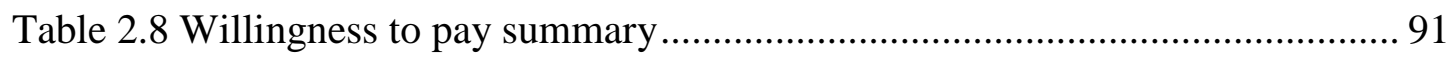

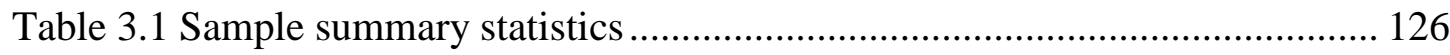

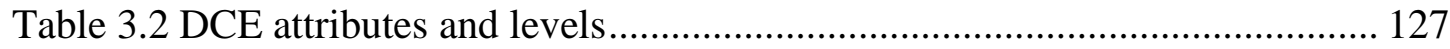


Table 3.3 Covariates selected by lasso regularization ......................................... 128

Table 3.4 Significant covariates (99\% level), Lasso* fit on full sample .................. 130

Table 3.5 Significant covariates (99\% level), Intersection model fit on full sample 131 


\section{LIST OF FIGURES}

FIGURE

PAGE

Figure 1.1 Summary of information premium by product and information treatment 51

Figure 1.2 Scree plots for prior seafood consumption by profile factors.................. 52

Figure 1.3 Quantile plot of information premium by class .................................. 53

Figure 1.4 Margins plot by class for information-product combination ................... 54

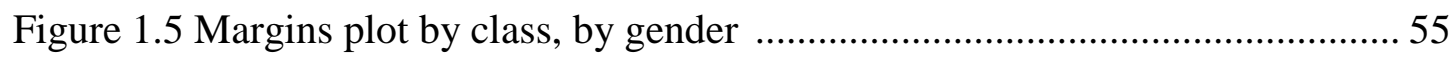

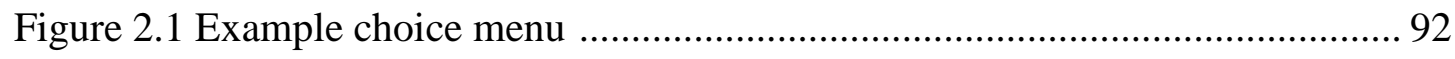

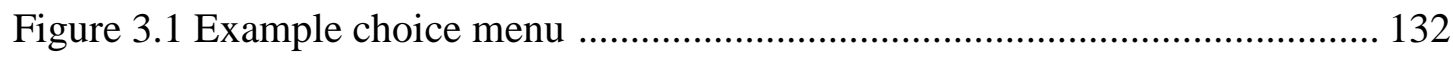

Figure 3.2 Hierarchy of Concern framework .................................................... 133

Figure 3.3 Example ambiguity aversion elicitation menu .................................. 134

Figure 3.4 Histogram and smoothed density plot of ambiguity aversion parameter 135

Figure 3.5 Mean out of sample log-likelihood ............................................... 136

Figure 3.6 Mean out of sample prediction accuracy ......................................... 137 


\title{
PURCHASE BEHAVIOR, TRUST OF ACADEMIC SOURCED INFORMATION AND AGGREGATION EFFECTS IN CONSUMER RESPONSE TO HEALTH INFORMATION CAMPAIGNS
}

(To be submitted to American Journal of Agricultural Economics)

By

\author{
Michael J. Weir ${ }^{\mathrm{a}}$, Hirotsugu Uchida ${ }^{\mathrm{a}}$, Cathy Roheim ${ }^{\mathrm{b}}$, and Robert J. Johnston ${ }^{\mathrm{c}}$ \\ ${ }^{a}$ Department of Environmental and Natural Resource Economics, University of Rhode \\ Island, Kingston, RI \\ ${ }^{b}$ Department of Agricultural Economics and Rural Sociology, University of Idaho, \\ Moscow, Idaho \\ ${ }^{c}$ Department of Economics, Clark University, Worcester Massachusetts
}

\begin{abstract}
Using data from a seafood auction experiment, we use a mixed-effects finite mixture model to explore sources of heterogeneity among participants and their responses to health information in the context of current United States Departments of Agriculture and Health and Human Services policy goals. We identify two distinct groups of consumers based on seafood purchase behavior, seafood lifestyle, and trust in seafood information sources. The majority of our sample is classified as "trust academics" and respond to both health benefit and risk information. The remaining portion of our sample is classified as "specialty store shoppers" and significantly respond to seafood health risk campaigns. We find evidence that female auction participants drive the significant information effects in each class. We highlight how these findings may be used in future seafood health information campaigns.
\end{abstract}




\subsection{Introduction}

While global consumption of seafood continues to exhibit strong growth (FAO 2016), the recommended intake of fish is generally not achieved by consumers in the United States, and while many consumers perceive seafood as healthy, they lack specific knowledge of health benefits (Carlucci et al. 2015; Jahns et al. 2014). To combat this, the U.S. market for seafood has been flooded with both public and private sources of information related to health risks and benefits of seafood consumption. The consensus from the medical literature on these health risk/benefit tradeoffs related to seafood is that greater consumption of seafood is warranted for most groups (Nesheim and Yaktine 2007). The U.S. Department of Agriculture (USDA) and U.S. Department of Health and Human Services (HHS) recently recommended that pregnant and nursing women consume at least 8 to 12 ounces of a variety of seafood per week as part of a well-balanced diet, with a similar recommendation for other adults, and less for young children (USDA and HHS 2010).

It is unclear, however, whether these information help consumers make more informed choices based on balancing the health benefits and risks associated with various seafood products (Shimshack, Ward, and Beatty 2007; Marette et al. 2008; Nesheim and Yaktine 2007; Sha et al. 2015). In recent years, economists have focused their efforts on evaluating the impact of both consumer health risk and benefit perceptions on food demand (Shogren et al. 1999; Lusk et al. 2004; Lusk and Coble 2005; Rousu and Shogren 2006; Huffman et al. 2007; Teisl and Roe 2010; Heiman and Lowengart 2011). While there have been studies on consumer preferences, knowledge, and behavior related to other food products, with particular focus on meat 
products, the application of these results to seafood is limited (Verbeke et al. 2008; Johnston and Roheim 2006). In fact, a National Academies study concluded that "research is needed to develop and evaluate more effective communication tools for use when conveying the health benefits and risks of seafood consumption" (Nesheim and Yaktine 2007). We answer this call by not only evaluating the effectiveness of information campaigns, but by also highlighting how differences in demographics may mediate information's effectiveness.

Uchida, Roheim, and Johnston (2017) conducted a series of experiments with the goal of understanding whether the health-related information currently provided to the public are effective at motivating changes in seafood consumption. Consumer choices were elicited through an experimental auction that simulated actual market purchase decisions, in which respondents could bid for different types of seafood characterized by distinct risk and benefit profiles. These bids were then used to estimate consumers' changes in willingness to pay (WTP) for seafood products given the different information treatments. Their study found, among other things, that there is significant heterogeneity among individual preferences for seafood and how auction participants react to the information treatment. Specifically, all random parameters in their linear mixed model were statistically significant. Further investigation on the nature of heterogeneity, however, was not conducted and is the main objective of the current article.

Using the experimental auction data from Uchida, Roheim, and Johnston (2017), this article analyzes the nature and characteristics of preference heterogeneity found by that study. It explores factors which may explain heterogeneous responses to 
information treatments to better understand the components influencing these demand shifts. Unlike most latent class analyses in the literature, which typically use discrete dependent variables, our dependent variable is a bid-difference (i.e., continuous) and as such employs the more general finite mixture model to explain heterogeneity in WTP changes (Boxall and Adamowicz 2002). This framework models heterogeneity within a finite number of classes based on responses to information related to the health risks and benefits of seafood consumption. We classify two consumer groups based on the premium ${ }^{1}$ assigned to information provided during the auction experiment and identify defining characteristics of these groups based on demographics, prior beliefs, and behavioral intentions collected in a pre-auction survey. The analyses reveal primary seafood purchase location and trust in seafood information sources as the defining characteristics of the two classes and thus their response to the information provided. We find that health benefit information does have an influence in promoting healthy seafood consumption once we account for the identified preference heterogeneity. This result adds nuance to the findings of Uchida, Roheim, and Johnston (2017) by incorporating individual-level seafood preference data. This allows for targeting future information campaigns to specific sub-groups of the population. Our results also highlight the effect aggregation can have on model results by masking important sub-sample differences.

The rest of the article is outlined as follows: Section 2 reviews the literature on seafood consumer heterogeneity. Section 3 discusses the general set up and execution of the auction experiment from which the data was collected. Section 4 provides the

\footnotetext{
${ }^{1}$ We are using the term 'premium' simply as a shorthand for 'difference in WTP before and after the information treatment,' which can be both positive or negative.
} 
motivation for exploring the heterogeneity of participants. Section 5 introduces the estimated model. Section 6 presents findings. In section 7 we further discuss our findings and provide some concluding remarks in section 8.

\subsubsection{Food choices and preference heterogeneity}

Empirical analysis on consumer preferences often assumes homogeneous preferences within a sample due to the complexity of properly accounting for preference heterogeneity. McFadden (1986) recognized the value in controlling for perceptions, beliefs, preferences, behavioral intentions, and socioeconomic factors in consumer research. In the context of food choice, understanding preference heterogeneity is an important issue in examining consumer behavior, particularly in development of marketing strategies (Onozaka, Hansen, and Sørvig 2014). Preference heterogeneity also plays an important role in how consumers interpret information about food products (Verbeke et al. 2008; Carlucci et al. 2015).

Aside from differences in consumer perceptions and attitudes, demographic characteristics can also influence food choice. In particular, age, gender, educational attainment, household size, age of children, and income all have been identified to influence seafood consumption as well as other foods deemed healthy in the medical literature (Samoggia and Castellini 2018; Dolgopolova and Teuber 2018). Using data from the 2005 - 2010 National Health and Nutrition Examinations Surveys (NHANES), Jahns et al. (2014) report that while 80\% of survey respondents consumed seafood within thirty days of survey completion, respondents that were younger, earned lower income, and attained lower education levels had statistically significant lower odds of being a seafood consumer. Of those considered seafood 
consumers, respondents that were women, younger aged, and less educated ate less seafood relative to other seafood consumers.

The majority of work on consumer heterogeneity and food choice has come in the realm of meat deriving from livestock, with results that may not directly apply to seafood choice (Johnston and Roheim 2006). Meat and seafood products are markedly different in relation to general perceptions; meat products are often the subject of scrutiny in the media due to controversial production and/or processing techniques (Fox, Hayes, and Shogren 2002), food safety incidents (Gellynck, Verbeke, and Vermeire 2006), and more recently issues of animal welfare (Tonsor and Olynk 2011; Lusk and Norwood 2011). Seafood, on the other hand, is generally viewed in a positive light and is considered healthy (Verbeke et al. 2008; Carlucci et al. 2015), although farmed seafood does receive its fair share of criticisms and negative press (Sha et al. 2015).

In this article, we investigate the factors associated with heterogeneity in consumer preferences for seafood. Using a classification approach, such as a finite mixture model, we can further the research on consumer heterogeneity focusing on those key perception and demographic differences previously identified. This will add to our understanding of how different consumer groups respond to information meant to promote healthful food consumption. Understanding of how information campaigns are effective for different types of consumers is important for the development of marketing and pricing policies related to healthy foods (Dolgopolova and Teuber 2018). Given that seafood intake in the U.S. population is still below recommended levels, particularly in low-income consumers and women (Mancino et al. 2018; U.S. 
Department of Health and Human Services and U.S. Department of Agriculture 2015;

Jahns et al. 2014), this article provides a timely analysis of seafood consumer segments with the goal of identifying groups of seafood consumers based on their response to information and how these groups may differ. We identify two distinct segments of consumers in our sample that differ by seafood purchase behavior, seafood lifestyle, and trust in seafood information sources. Specifically, we find that the majority of our sample, what we refer to as the "trust academics" group, is receptive to both risk- and benefit-focused information campaigns, a result not identified by Uchida, Roheim, and Johnston (2017). Our findings can inform future information campaign design and implementation that are more targeted and effective at improving the public's health and food literacy (Palumbo et al. 2019).

\subsection{Data}

The auction experiment was conducted between November 2012 and July 2013 in various locations across the state of Rhode Island. The auction employed a secondprice sealed-bid format (Uchida et al. 2014; Fox et al. 1998; Lusk et al. 2001;

Loureiro, McCluskey, and Mittelhammer 2002), in which participants bid on wild salmon, farmed salmon, and swordfish. These products were chosen based on (i) their particular profile of health risks and benefits, (ii) their frequent appearance in guidance related to seafood consumption, and (iii) their familiarity to consumers in our study area (Uchida, Roheim, and Johnston 2017).

The experiment design is detailed in Uchida, Roheim, and Johnston (2017); here we present the key components. Three products were bid on simultaneously, so that each participant submitted three bids in each round. There were six rounds in total 
with two information interventions at the end of the second and fourth round. These two interventions were designed to separate the effect of information content and information source. The first information intervention was on the health benefits/risks related to seafood consumption without revealing the source of said information; the second information revealed the source (e.g., U.S. government (FDA), seafood industry, NGO, and scientists). The experiment also included sessions without any information interventions to serve as control group. At the end of the sixth round, one round was chosen at random and the winner of the chosen round received the seafood voucher that was redeemable for the seafood products at a local supermarket. Each participant was given $\$ 70$ as an allowance. The winner took the voucher and change in cash; others took $\$ 70$ in cash. In total we completed 32 experimental auction sessions with 360 total participants.

Unfortunately, we did detect some participants acting strategically to simply pocket the $\$ 70$ cash allowance. Following Uchida, Roheim, and Johnston (2017), we define "non-engaging participants" as anyone bidding less than $\$ 0.50$ for all three products throughout the entire six rounds of the auction. This definition resulted in dropping twenty participants from the analysis, resulting in a sample size of $n=340$. Table 1.1 provides descriptive statistics for our sample and Table 1.2 gives a summary of the number of participants receiving each information treatment.

One of the key findings in Uchida, Roheim, and Johnston (2017) was that there was no impact of health benefit information on WTP regardless of the message type or publishing source; however, health risk information was effective at changing participants' WTP. This is evidence that current health information campaigns do not 
help consumers balance the benefits and risks of consuming seafood, but rather leads them to react more strongly to health risk information. We seek to understand further what drives consumer response to information campaigns.

\subsubsection{Exploring Heterogeneous Preferences for Seafood}

Given our sample consists of Rhode Island residents and is similar in terms of demographics relative to the Rhode Island population (table 1.1), we have a good starting point to explore the underlying heterogeneity within our sample of seafood consumers. The representativeness of the sample allows us to draw more meaningful inference for identification of potential target groups for future information campaigns. For this we start by dividing the data into four quantiles based on the average information premium, the difference in WTP before and after receiving an information intervention, for each product/information treatment combination. We explore differences in demographic characteristics such as age and gender, along with preferences and attitudes related to seafood products and information sources between each of the quantiles.

Table 1.3 presents an example summary of the analysis described above for those participants bidding on swordfish that received the FDA information treatment. Aside from the significant $t$-test for 'Benefits Greater than Risks for Pregnant Women and Children', there are no significant differences across the quantiles. This suggests that there may not be sizable sources of heterogeneity among participants for this particular combination of product and information types. The significant $t$-test related to pregnant women and children is interesting however, as a majority of the information sources target women who are pregnant or may become pregnant. As the 
FDA information treatment focuses specifically on the risk associated with high levels of mercury in swordfish, it seems intuitive that those that perceive the benefits to outweigh the risks to be in the higher quantile. This pattern, or lack thereof, is consistent for all product and information-type combinations.

A visual inspection of the data provides some further insight. In figure 1.1, box and whisker plots of the information premium are displayed by both information treatment and product. The first observation is that evidence of information being effective at reducing bids for products associated with negative health effects (swordfish) exists, but not at increasing bids for products associated with positive health effects (salmon). This is consistent with the findings of Uchida, Roheim, and Johnston (2017). What we add to the results of these authors is identification of the unique characteristics of the change in bid distributions shown in figure 1.1. The distributions of change in bid associated with the majority of the information-seafood product pairings have mean values not significantly different from zero and exhibit wide deviation about the mean. However, these distributions are not symmetric about their respective means, nor about zero. We interpret these varying distributional characteristics as evidence of sub-groups within each distribution, and thus heterogeneous treatment effects of information. With this in mind, we further explore these potentially heterogeneous groupings in our sample more rigorously using a finite mixture model. 


\subsection{Methodology}

In this section, we develop the empirical model to be estimated. First, we briefly review the rigors of finite mixture models (adapted from McLachlan and Peel 2000), followed by the presentation of our specific model.

In our and other similar applications, we wish to model the heterogeneity evidenced to exist in the data. A finite mixture model takes on this task by estimating probability density functions for each component (or group) found within the data. In particular, suppose we have a vector of observed value $\mathbf{y}_{1}, \ldots, \mathbf{y}_{n}$, with $\mathbf{y}_{i} \in \mathbf{Y}$.

Assuming $\mathbf{Y}$ to be a continuous random vector, we have the probability density function $f\left(\mathbf{y}_{i}\right)$, which can be written as

$$
f\left(\mathbf{y}_{i}\right)=\sum_{k=1}^{K} \pi_{k} f_{k}\left(\mathbf{y}_{i}\right)
$$

where $f_{k}\left(y_{i}\right)$ represents the probability density function of each of the $k$ components in our dependent measure. The term $\pi_{k}$ is the "mixing weight" and represents the percentage of the population belonging to group $k$. Per usual probability assumptions, $\pi_{k}$ is constrained within the interval, $[0,1]$ and must sum to unity over $k$. Thus, equation (1) represents the weighted sum of $k$ probability density functions and is thus itself a probability density function. Initially, the $k$ components are unknown and must be simultaneously inferred from the data, along with mixing weights and other parameter estimates of interest to the model.

The component densities $f_{k}\left(y_{i}\right)$ are specified as a distinct set of parameters

$\beta_{k}, \sigma_{k}^{2}$, and $\pi_{k}$. We assume the densities to be independent and identically distributed (iid) multivariate normal at the individual level within component $k$ such that 
$f_{k}\left(\mathbf{y}_{i} ; \beta_{k}, \sigma_{k}^{2}, \pi_{k}\right)=\pi_{k} \cdot f_{k}\left(\mathbf{y}_{i} ; \beta_{k}, \sigma^{2}{ }_{k}\right)$ with $f_{k}\left(\mathbf{y}_{i} ; \beta_{k}, \sigma^{2}{ }_{k}\right)=\phi\left(\mathbf{y}_{i} ; \beta_{k}, \sigma_{k}^{2}\right)$. The iid assumption is necessary for our application (McLachlan and Peel 2004). The choice to model preference heterogeneity as a mixture of multivariate normal densities is common in the literature. We leave exploration of alternate distributional assumptions to future work.

In estimating these models, it is common practice to employ the expectation maximization (EM) algorithm, which maximizes the log-likelihood of the mixture distribution in equation (1) (McLachlan and Peel 2000). ${ }^{2}$ The EM algorithm is ideal for estimating models that involve missing or unobserved data; for more details see Jedidi, et al. (1993). In the case of our model, the unobserved data is the component "label" vector with observations $\mathbf{z}_{1}, \ldots, \mathbf{z}_{n}$, which denote the component membership for each of the observations $\mathbf{y}_{1}, \ldots, \mathbf{y}_{n}$.

In our case, we have vectors $\mathbf{y}_{i}$ containing three elements such that, $\mathbf{y}_{i j t}=\left(y_{i 1 t}, y_{i 2 t}, y_{i 3 t}\right)$, where the second subscript $j=\{1,2,3\}$ indexes the individual seafood product that was bid on, and the third subscript $t=\{1,2,3,4,5,6\}$ indexes the information treatment received. Following Wakamatsu et al. (2017), we use the information premium as our dependent measure and control for product and information received. We do not explicitly control for auction round, as this is already taken into account in our dependent measure. Thus, an element of $y_{i j t}$ represents the participant $i$ 's change in bid between round 2 and round 6, i.e., information premium for product $j$ after receiving information treatment $t$.

\footnotetext{
${ }^{2}$ Implemented in the $\mathbf{R}$ package flexmix (R Core Team 2016).
} 
We estimate a model of the following form,

$$
\begin{gathered}
\text { InfoPremium }_{k i j t}=\alpha_{k}+\sum_{j \in J} \beta_{k i j} \text { Prod }_{j}+\sum_{t \in T} \beta_{k i t} \text { Info }_{t}+\sum_{j \in J} \sum_{t \in T} \beta_{k i j t} \text { Prod }_{j} \times \text { Info }_{t} \\
+U_{k}+V_{k i}+\varepsilon_{k i t t}, \varepsilon_{k i j t} \sim N\left(0, \sigma_{k}^{2}\right) .
\end{gathered}
$$

The dependent variable, InfoPremium, is defined as the difference in bids between round six (post information content and source being provided) and two (prior to any information treatment) for component $k$, individual $i$, product type $j$, and information type $t$. We control for the product type and the information treatment received, as well as their interaction. Our reference category is comprised of participants receiving no information, bidding on swordfish, accounted for in the component specific constant, $\alpha_{k}$. Terms $U_{k}$ and $V_{k i}$ are random effects at individual level, allowing correlation within component $k$ and within-individual $i$ in component $k$, respectively. This is necessary in our model as there are three observations per individual, which are likely to be correlated. The random effects also force "hard" component assignment, meaning each participant is assigned to one and only one component. The error term, $\varepsilon_{k i j t}$, is iid with mean zero and the variance of $\sigma_{k}^{2}$ for a given component $k$.

\subsection{Results}

The first task is to determine the number of components, or classes, to retain in the finite mixture model. We estimate our mixture model as specified in equation 2 . We do not include additional controls at this point, as we are interested in classifying consumers solely based on their response to information received, i.e., information premium. 
For determining the number of classes, we follow Biernacki, Celeux, and Govaert (2000) where they address the potential model selection pitfalls when using finite mixture models. Specifically, they point out that conventional criterion of largest integrated likelihood/BIC does not account for the clustering purpose of a finite mixture model, leading to potential overestimate of the correct class size. They instead propose an Integrated Classification Likelihood (ICL) to address the potential limitations of BIC; this model selection criterion is also embraced in the highly cited Bruhin, Fehr-Duda, and Epper (2010). As such, we chose to use BIC and ICL for determining the number of classes. Table 1.4 provides a summary of the class-number selection criteria for $k=1,2,3$, and 4 classes. While BIC and ICL are minimized with $\mathrm{k}=3$ classes, the improvement in model fit gained from specifying a three-class rather than a two-class model is much smaller than the relative improvement in fit from specifying a two-class rather than a one-class model. It should also be noted that only twenty-seven participants in our sample were assigned to the third class, which does not provide sufficient explanatory power for our analyses (Wakamatsu et al. 2017; Garrett, Eaton, and Zeger 2002). We conducted all subsequent analyses with the twoclass specification. Summary statistics for each class as well as the Rhode Island population are included in table 1.5.

As a means of capturing preference heterogeneity, the pre-auction survey included a number of questions related to different facets of seafood consumption: purchase behavior, seafood lifestyle, health perceptions, and information trust. Responses to these questions are used to capture the underlying constructs of our samples' prior seafood preferences using a factor analysis. 
Purchase behavior captures preference structure using the location participants reported visiting most to purchase seafood and factors considered during seafood purchase. Participants were asked to select the location they most often purchase seafood from a list of nine options by marking a box. Nine purchase considerations were measured on a five-point Likert scale (1 - "Strongly Disagree"/5- "Strongly Agree"). Seafood lifestyle is intended to capture the strength of participants' seafood preferences using a six-point consumption frequency measure for eleven food products (eight seafood products and three non-seafood), and indicators of whether participants recreationally fish, fish for food, or work in the fishing industry. We characterize health perceptions based on responses on a five-point Likert scale (1 "Strongly Disagree"/5- "Strongly Agree") to statements related to the nutrition, safety, and benefits of seafood consumption, along with perceived healthfulness of seventeen food products (twelve seafood and five non-seafood). Lastly, information trust is characterized by reported trust in fourteen seafood information sources measured on a five-point Likert scale (1 - "Strongly Distrust)/5 - "Strongly Trust”).

We use principal-component factor analysis of the response correlation matrix to reduce the number of variables within each measure to develop an informative profile of prior preferences and perceptions of our sample. We initially retained factors based on a threshold eigenvalue of one. However, we examine scree plots of the associated eigenvalues to determine the final number of factors to retain as the eigenvalue criteria often results in too many retained factors (Costello and Osborne 2005). Visual examination of the scree plot allows the researcher to identify the relative contribution of each factor to explained sample variance. The natural bend of 
the scree plot is indicative of the number of factors to retain. The scree plots for each of our proposed measures are presented in figure 1.2. Rotated VARIMAX loadings for the retained factors are presented in tables 1.6-1.9 for each of the four measures.

We characterize three factors of purchase behavior we denote as well-being conscious, specialty-store shopper, and quality conscious. The well-being conscious characterization is based on high loadings on agreement with purchasing seafood that is low fat, healthy, favored by one's culture or religion, and seller recommended. The quality conscious is based on high positive loadings on attributes of freshness, wild caught, purchasing seafood most often at a fish market, and high negative loading on purchasing seafood most often at a super market. Specialty-store shoppers are distinguished by high positive loading on purchasing seafood most often at specialty stores, e.g. Whole Foods, and a high negative loading on purchasing seafood most often at typical super markets, such as Stop and Shop in the northeast United States. This factor also loads high on preference for wild caught seafood.

Seafood lifestyle is characterized by four factors: surf consumer, turf consumer, locally engaged, and self-sufficient. The first two factors have high loadings on seafood and non-seafood consumption frequency, respectively. Factor three is characterized by consumption frequency of cod or haddock and swordfish (all locally caught species in Rhode Island and more broadly throughout New England) and an indicator of participation in recreational fishing. Factor four has high loading on recreational fishing and fish for food indicators.

Health perceptions are summarized by three factors: surf health, benefits outweigh the risks, and turf health. Surf (turf) health is characterized by high loadings 
on healthfulness rating of (non-)seafood products. Benefits outweigh the risks factor is characterized by high positive loadings on the perceived healthfulness and nutritious rating of consuming seafood relative to non-seafood, low perceived risks associated with eating seafood, and perceptions that the benefits outweigh the risks of eating seafood.

There are five information trust factors: government trust, social influence trust, interest group trust, media trust, and academic trust. These are characterized by high loadings on reported trust in information provided by each group of respective sources. For example, the interest group trust factor has high positive loadings on trust in information provided by environmental groups and consumer groups, whereas the media trust factor has high loadings on trust of information in the newspaper, Wikipedia, cooking shows and television/radio. The social influence trust factor is characterized by trust in information sources with social influence (family members, cooking shows, local fisherman and fishing industry). The government factor is indicative of trust in federal and state information sources, while the academic trust factor has high loadings on trust in information from dieticians and university published sources.

\subsubsection{Class Characterization}

We classify consumer types within each class based on their demographics and seafood consumption characteristics identified in the factor analysis above, as these are likely to influence how participants respond to information (Visschers et al. 2013; Verbeke et al. 2008). We use a multinomial logit (MNL) to investigate factors that characterize our classes similar to Wakamatsu et al. (2017). We regress class 
membership on demographics and all factors identified in the factor analysis above with class one as the base case. The model is summarized in table 1.10. The predicted factor values are standardized and have mean equal to zero and standard deviation equal to one. So, positive (negative) values imply a high (low) rating in a factor. Demographics are all dummy variables except age. We also conducted confirmatory analyses using ANOVA and Tukey honest significant difference tests of the regressors. Summaries of these analyses are available upon request.

The first notable result is demographic characteristics do not significantly influence class membership. This is consistent with previous findings (e.g. Johnston et al. 2001). Surprisingly, neither prior health perception factors nor classification as a well-being conscious consumer affect class membership. Given we classify individuals based on their response to health information, it is surprising that prior health perceptions have no significant effect on class membership. The defining characteristics of the two classes relate to purchase behavior, seafood lifestyle, and trust in information sources. Specifically, specialty store shoppers and those that trust information provided by social influences are more likely to be in class one, while locally engaged participants and those that trust academic published seafood information are more likely to be in class two.

\subsubsection{Response to information campaigns}

We now use our class-specific profiles to make inference about each class' response to the experimental information treatment. Table 1.11 summarizes ordinary least squares regressions of information premium using the main specification from equation 2 , excluding the random components. We add additional interaction terms to control for 
class membership as well as other interactions of interest. Standard errors are clustered at the individual-level to account for correlation among the bids for each seafood product. We are interested in investigating whether controlling for the identified heterogeneity in our sample uncovers different effects than those found by the methods of Uchida, Roheim, and Johnston (2017). Interestingly, we do in fact find treatment effects not previously identified.

One key difference between the effects identified in the two classes is the magnitude of the information premium, see figure 1.3 for a summary of average information premium by class. Class one results exhibit effect sizes with absolute value between one and seven dollars, while class two exhibits effect sizes between zero and approximately one dollar. The sign of the effects is similar within each class, which makes the magnitude distinction important as this is an indication of the intensity of the information effect. For example, while both classes increased bids for farmed salmon in the combined FDA/Industry treatment, class one increased their bids by $\$ 4.98$ while class two increased by $\$ 0.68$. This pattern holds for other cases where significant effects are identified in both classes.

We computed predictive margins of information premium based on the specification above and summarized them in figure 1.4 by class. The predicted margins provide more meaningful interpretation by summarizing the full effect of information in the form of participants' predicted information premium rather than a marginal change by regression coefficients. The notable result is that only class two has predicted information premia different from zero for all three products, while class 
one has predicted information premia different from zero for only swordfish. We discuss each class in turn.

Class one responded significantly to information while bidding on swordfish, the product all experimental treatments recommend avoiding. Specifically, these participants have negative predicted information premia when provided FDA/Industry, NAS, or University information sources. It is interesting that these participants were responsive to the combination of FDA/Industry sources, but not the sources individually. Both the FDA and Industry treatments tell readers to not eat swordfish altogether, rather than a suggested quantity or frequency to consume swordfish. Perhaps the combination of these sources reinforced avoidance of swordfish in this group of participants. The University information treatment similarly presents swordfish in a "Do Not Eat" column in a table format along with other species high in mercury. The NAS treatment presented information to readers in a graphical format but made it clear that swordfish was high in mercury, which may be harmful for one's health.

Class two responded in accordance with the predictions of Uchida, Roheim, and Johnston (2017) and the policy goals of USDA and HHS; bids for the salmon products increased and bids for swordfish decreased with information. Specifically, predicted information premium was different from zero for both farmed and wild salmon given the Industry information treatment. Average predicted information premium is different from zero for farmed salmon given the FDA/Industry treatment (10\% level) and for wild salmon given the University treatment. Considering the significant effect of the Industry information and insignificance of the FDA treatment 
for farmed salmon, we have evidence to suggest that the marginal significance of the effect of FDA/Industry together is driven by the information provided in the Industry source.

For swordfish, class two assigned a significantly negative information premium to FDA/Industry (10\% level), NAS, and University treatments, similar to class one. The effectiveness of University sourced information for two of three products is consistent with this group being more trusting of academic-sourced seafood information.

We see consistent effectiveness of NAS and University in promoting a negative information premium for swordfish in both consumer classes. We believe this is in part due to the graphical summary of species by Omega-3 and mercury levels. Swordfish is made to standout via a shading scheme that highlights its high mercury content, while farmed and wild salmon are left blank in terms of shading (though ranked one and two respectively in terms of Omega-3 content). As mentioned above, the University treatment summarizes species in a table format that is separated by suggested quantities of consumption. Class two is positively responsive to Industry and University treatments for products that provide positive health benefits, but negatively responsive to NAS and University for a product that is associated with health risks. In both NAS and University, the suggestion to avoid swordfish is focal; swordfish is shaded in the NAS information as an indicator of high mercury content and in University swordfish is contained in a column with the large header "Do Not Eat". 
The Industry treatment is consistent in promoting a positive information premium for both salmon products in class two, which also included a tabular summary of seafood species related to Omega-3 content. In this treatment, the benefits of omega-3s especially for pregnant and nursing women are succinctly stated. Salmon is focal in this treatment based on its ranking as one of the top three consumed species in the U.S. and by having more than double the omega-3 content $(1,238 \mathrm{mg})$ relative to the second highest, Canned White Tuna (535 mg).

Since the information treatments used in Uchida, Roheim, and Johnston's (2017) original study were targeted at women of child-bearing age, we build on the model above by including a control for gender that equals one if a participant is female. There is also evidence throughout the literature that men and women use nutrition and health-related information differently (Visschers et al. 2013). We find evidence in support of the supplementary analyses conducted by Uchida, Roheim, and Johnston (2017), as well as additional evidence of heterogenous responses to information by gender. In fact, we have evidence that the experimental information treatments are effective at both promoting beneficial and deterring harmful seafood consumption in the target population of women.

The plots in panel (a) of figure 1.5 summarize the predictive margins for females in each class, while panel (b) summarizes the predictive margins for males. These plots highlight the fact that female participants drive the significant information premia identified in the specification without demographic controls in each class. This is evidence that the information treatments are effective at 1) promoting beneficial seafood consumption in the majority of our sample and 2) shifting consumer 
preferences in the targeted population. We discuss these results more in the context of our specific class characterizations.

\subsection{Discussion}

Based on our MNL analysis, we concluded that participants in class one are more likely to be specialty store shoppers. Shopping at specialty stores is often deemed a symbol of social status (Samoggia and Castellini 2018). Our results are consistent with this in the sense that consumers in class one trust sources with varying levels of social influence, i.e. market, cooking show, family, local fisher, and industry sources.

Previous work has also noted that these types of consumers are more health conscious and socially aware of their food purchasing behavior (Fernandes and Srinivasan 2018), making them likely more aware of the benefits of salmon consumption. This is a potential explanation for the ineffectiveness of information in promoting salmon consumption for class one participants. Since we have a sample of Rhode Island residents, we are able to make further inference about the presentation of seafood information at specialty stores in the area and how this might relate to their information premia.

Along with multiple Whole Foods Market locations, there are local specialty stores that attract similar types of shoppers as Whole Foods. Reviewing information about seafood and methylmercury on Whole Foods' webpage reveals an understated suggestion to avoid swordfish and other high mercury seafood, while promoting consumption of low-mercury seafood ("Mercury in Seafood FAQ" 2019). The webpage of a local specialty store does not give information about mercury in seafood, but prominently displays information about salmon consumption and informs 
customers about the differences between wild and farmed salmon ("Fresh Salmon in RI" 2019). Taking these facts together we conjecture that these consumers did not respond positively to information about salmon due to prior preferences (and willingness to pay) for salmon fillets that already considers the benefits of salmon consumption.

In the context of swordfish, the information consumers are provided in-store does not make the risks associated with swordfish as focal as the benefits of salmon. Information on Whole Foods' website may even (perversely) promote higher swordfish consumption through promotion and availability of Marine Stewardship Council certified swordfish flesh, ("Harpoon-Caught Swordfish" 2019; Johnston and Roheim 2006; Johnston et al. 2001). Thus, being provided information that is open and suggestive about the risks of mercury and swordfish consumption during the auction filled the void left in the market information available at specialty stores. We imagine stores avoid using strong language or suggestions related to the mercury content of swordfish to avoid instilling a sense of fear about these less commonly consumed species ${ }^{3}$.

We have identified seafood information campaigns that worked at both increasing demand for seafood with positive health benefits in class two only and decreasing demand for seafood that poses health risks in both classes. The consistent conclusion is that information provided succinctly and accompanied by graphical representations, either a table or figure, were effective at changing the preferences of women in our sample. So, perhaps information campaigns should use a brief narrative

\footnotetext{
${ }^{3}$ Salmon has been one of the top three seafood products consumed in the United States since at least 2007 according to the National Fisheries Institute $(2018,2017,2015)$.
} 
accompanied by a clear graphic or tabular summary of information as a means of improving the saliency of the seafood message (Visschers, Hess, and Siegrist 2010). This is already a common practice in seafood information campaigns, for example the Monterey Bay Aquarium Seafood Watch information cards. Since women are the target population of these information, it is encouraging that we identify an information presentation that consistently promotes consumption of seafood that provides health benefits and deters consumption of seafood that poses potential health risks.

If information campaigns can be developed and created to target this important subpopulation, perhaps they would be more effective in promoting aggregate consumption of seafood. Our results, accounting for sample aggregation effects, provide evidence that is consistent with conjectures posed by Uchida, Roheim, and Johnston (2017). Specifically, we recommend incorporating aspects of the campaigns that were effective at promoting beneficial seafood consumption (Industry, NAS and University) as a foundation for future health information campaigns.

Should policymakers choose to pursue a targeted information campaign incorporating the information presentation format of the effective campaigns mentioned above, we suggest using information that is published or supported by academics. We base this on the fact that the majority of our sample is characterized by its trust in academic-sourced seafood information and significant response to information promoting seafood that provide health benefits and discouraging seafood that poses health risks. These consumers would be the most cost-effective and efficiently targeted group, particularly with information campaigns supported and 
published by academic researchers. This information would at a minimum discourage consumption of seafood that is high in methylmercury content across consumer segments. We do see potential challenges to fully implementing such a policy given the recent decrease in the public's trust in science (Pew Research Center 2016) and the ambiguous or inaccurate health-related information shared and promoted by socially influential public figures, such as a number of celebrities promoting the (unsupported) link between vaccinations and autism in children.

Even with these potential hurdles, our results provide a starting point for future work and policies that develop targeted health campaigns to convey the benefits of seafood consumption, with more focus on improving information exposure (Abroms and Maibach 2008; Hornik 2002). There is much focus on development and dispersion of health campaigns, but whether this information is implemented such that target audiences are actually exposed to the information is another question. It is a step in the right direction to refine the presentation of health information to consumers but is for not if the information never reaches its intended audience.

\subsection{Conclusion}

Using data from a seafood auction experiment conducted by Uchida, Roheim, and Johnston (2017), we gain further insight related to the heterogeneity of participants and their responses to seafood benefit/risk information. We identify two distinct groups of consumers characterized primarily by their preferred seafood shopping locations and trust in sources of seafood information. The majority of our sample trusts seafood information provided by academic researchers and/or dieticians and were receptive to sources of information that promoted beneficial seafood 
consumption as evidenced by positive and significant information premium for these product/information combinations. The remaining portion of our sample is characterized by a preference to shop for seafood at specialty grocery stores, like Whole Foods Markets. These participants were primarily receptive to information associated with the risk of swordfish consumption. The significant effects were driven primarily by females in each of our consumer segments, which is encouraging given the context of the original study conducted by Uchida, Roheim, and Johnston (2017). Even with ever-developing marketing methods, a large gap still exists in research on seafood information campaigns, and other food products in general, regarding how to effectively communicate health benefits in a way that increases demand. Based on these results, we recommend design of targeted information campaigns that provide information in succinct, graphical representations with particular focus on implementation that optimizes information exposure, a recommendation put forth by Nesheim and Yaktine (2007). Given the advantages associated with the modern marketing environment (see Iyer et al. 2005 for a theoretical discussion of this), it is imperative to have available a feasible mechanism to increase information exposure and promote healthy food consumption to enhance positive health outcomes in U.S. consumers. This is particularly important in low-income and other consumer segments with high risk of diet related health issues. Our results are encouraging with regard to identifying consumer segments responsive to benefit-focused health information and presents an opportunity for these results to play their own part in the comprehensive effort by academics and policymakers alike to improve public health. 


\section{References}

Abroms, Lorien C., and Edward W. Maibach. 2008. "The Effectiveness of Mass Communication to Change Public Behavior." Annual Review of Public Health 29 (1): 219-34. https://doi.org/10.1146/annurev.publhealth.29.020907.090824.

Biernacki, C., G. Celeux, and G. Govaert. 2000. “Assessing a Mixture Model for Clustering with the Integrated Completed Likelihood." IEEE Transactions on Pattern Analysis and Machine Intelligence 22 (7): 719-25. https://doi.org/10.1109/34.865189.

Boxall, Peter C., and Wiktor L. Adamowicz. 2002. "Understanding Heterogeneous Preferences in Random Utility Models: A Latent Class Approach." Environmental and Resource Economics 23 (4): 421-46. https://doi.org/10.1023/A:1021351721619.

Bruhin, Adrian, Helga Fehr-Duda, and Thomas Epper. 2010. "Risk and Rationality: Uncovering Heterogeneity in Probability Distortion." Econometrica 78 (4): 1375-1412. https://doi.org/10.3982/ECTA7139.

Carlucci, Domenico, Giuseppe Nocella, Biagia De Devitiis, Rosaria Viscecchia, Francesco Bimbo, and Gianluca Nardone. 2015. "Consumer Purchasing Behaviour towards Fish and Seafood Products. Patterns and Insights from a Sample of International Studies.” Appetite 84 (January): 212-27. https://doi.org/10.1016/j.appet.2014.10.008.

Costello, Anna B, and Jason W Osborne. 2005. "Best Practices in Exploratory Factor Analysis: Four Recommendations for Getting the Most From Your Analysis." Practical Assessment, Research \& Evaluation 10 (7): 9.

Dolgopolova, Irina, and Ramona Teuber. 2018. "Consumers' Willingness to Pay for Health Benefits in Food Products: A Meta-Analysis." Applied Economic Perspectives and Policy 40 (2): 333-52. https://doi.org/10.1093/aepp/ppx036.

Fernandes, Lawrence, and Dr R Srinivasan. 2018. "A Consumer Analysis of Whole Foods Market." International Journal of Latest Engineering and Management Research 03 (02): 5.

Food and Agricultural Organization of the United Nations. 2016. State of World Fisheries and Aquaculture 2016. Contributing to Food Security and Nutrition for All. Rome. http://www.fao.org/3/a-i5555e.pdf.

Fox, John A., Dermot J. Hayes, and Jason F. Shogren. 2002. “Consumer Preferences for Food Irradiation: How Favorable and Unfavorable Descriptions Affect Preferences for Irradiated Pork in Experimental Auctions." Journal of Risk and Uncertainty 24 (1): 75-95. https://doi.org/10.1023/A:1013229427237. 
Fox, John A., Jason F. Shogren, Dermot J. Hayes, and James B. Kliebenstein. 1998. "CVM-X: Calibrating Contingent Values with Experimental Auction Markets." American Journal of Agricultural Economics 80 (3): 455-65. https://doi.org/10.2307/1244548.

"Fresh Salmon in RI." 2019. Dave's Marketplace. http://www.davesmarketplace.com/pages/cfSeafood_Salmon.cfm (accessed January 3 , 2019).

Garrett, Elizabeth S., William W. Eaton, and Scott Zeger. 2002. "Methods for Evaluating the Performance of Diagnostic Tests in the Absence of a Gold Standard: A Latent Class Model Approach.” Statistics in Medicine 21 (9): 1289-1307. https://doi.org/10.1002/sim.1105.

Gellynck, Xavier, Wim Verbeke, and Bert Vermeire. 2006. "Pathways to Increase Consumer Trust in Meat as a Safe and Wholesome Food." 52nd International Congress of Meat Science and Technology (52nd ICoMST) 13-18 August 2006 Dublin, Ireland 74 (1): 161-71. https://doi.org/10.1016/j.meatsci.2006.04.013.

“Harpoon-Caught Swordfish.” 2019. Whole Foods Market. 2019. https://www.wholefoodsmarket.com/harpoon-caught-swordfish (accessed January 3,2019$)$.

Heiman, Amir, and Oded Lowengart. 2011. "The Effects of Information about Health Hazards in Food on Consumers' Choice Process." The Economics and Econometrics of Risk 162 (1): 140-47. https://doi.org/10.1016/j.jeconom.2010.07.003.

Hornik, Robert C., ed. 2002. Public Health Communication: Evidence for Behavior Change. LEA's Communication Series. Mahwah, N.J: L. Erlbaum Associates.

Huffman, Wallace E., Matthew Rousu, Jason F. Shogren, and Abebayehu Tegene. 2007. "The Effects of Prior Beliefs and Learning on Consumers' Acceptance of Genetically Modified Foods." Journal of Economic Behavior \& Organization 63 (1): 193-206. https://doi.org/10.1016/j.jebo.2005.04.019.

Jahns, Lisa, Susan Raatz, LuAnn Johnson, Sibylle Kranz, Jeffrey Silverstein, and Matthew Picklo. 2014. "Intake of Seafood in the US Varies by Age, Income, and Education Level but Not by Race-Ethnicity." Nutrients 6 (12): 6060-75. https://doi.org/10.3390/nu6126060.

Jedidi, Kamel, Venkatram Ramaswamy, and Wayne S. Desarbo. 1993. “A Maximum Likelihood Method for Latent Class Regression Involving a Censored Dependent Variable.” Psychometrika 58 (3): 375-94. https://doi.org/10.1007/BF02294647. 
Johnston, Robert J., and Cathy A. Roheim. 2006. "A Battle of Taste and Environmental Convictions for Ecolabeled Seafood: A Contingent Ranking Experiment." Journal of Agricultural and Resource Economics 31 (2): 283300.

Johnston, Robert J., Cathy R. Wessells, Holger Donath, and Frank Asche. 2001. "Measuring Consumer Preferences for Ecolabeled Seafood: An International Comparison." Journal of Agricultural and Resource Economics 26 (1): 20-39.

Loureiro, Maria L., Jill J. McCluskey, and Ron C. Mittelhammer. 2002. "Will Consumers Pay a Premium for Eco-Labeled Apples?" Journal of Consumer Affairs 36 (2): 203-19. https://doi.org/10.1111/j.1745-6606.2002.tb00430.x.

Lusk, Jayson L., and Keith H. Coble. 2005. "Risk Perceptions, Risk Preference, and Acceptance of Risky Food." American Journal of Agricultural Economics 87 (2): 393-405. https://doi.org/10.1111/j.1467-8276.2005.00730.x.

Lusk, Jayson L., M. Scott Daniel, Darrell R. Mark, and Christine L. Lusk. 2001. "Alternative Calibration and Auction Institutions for Predicting Consumer Willingness to Pay for Nongenetically Modified Corn Chips." Journal of Agricultural and Resource Economics 26 (1): 40-57.

Lusk, Jayson L., Lisa O. House, Carlotta Valli, Sara R. Jaeger, Melissa Moore, J.L. Morrow, and W. Bruce Traill. 2004. "Effect of Information about Benefits of Biotechnology on Consumer Acceptance of Genetically Modified Food: Evidence from Experimental Auctions in the United States, England, and France." European Review of Agricultural Economics 31 (2): 179-204. https://doi.org/10.1093/erae/31.2.179.

Lusk, Jayson L., and F. Bailey Norwood. 2011. "Animal Welfare Economics." Applied Economic Perspectives and Policy 33 (4): 463-83. https://doi.org/10.1093/aepp/ppr036.

Mancino, Lisa, Joanne Guthrie, Michele Ver Ploeg, and Biing-Hwan Lin. 2018. "Nutritional Quality of Foods Acquired by Americans: Findings From USDA's National Household Food Acquisition and Purchase Survey." 188. Economic Information Bulletin. Washington, D.C.: U.S. Department of Agriculture Economic Research Service. https://www.ers.usda.gov/webdocs/publications/87531/eib-188.pdf?utm.

Marette, Stéphan, Jutta Roosen, Sandrine Blanchemanche, and Philippe Verger. 2008. "The Choice of Fish Species: An Experiment Measuring the Impact of Risk and Benefit Information." Journal of Agricultural and Resource Economics 33 (1): $1-18$. 
McFadden, Daniel. 1986. "The Choice Theory Approach to Market Research." Marketing Science 5 (4): 275-97.

McLachlan, Geoffrey J., and David Peel. 2000. Finite Mixture Models. Wiley Series in Probability and Statistics. Applied Probability and Statistics Section. New York: Wiley.

“Mercury in Seafood FAQ.” 2019. Whole Foods Market. 2019. https://www.wholefoodsmarket.com/about-our-products/foodsafety/methylmercury-seafood (accessed January 3, 2019).

National Fisheries Institute. 2015. "Top Ten Seafood." About Seafood (blog). November 17, 2015. https://www.aboutseafood.com/resource/top-ten-seafood3/ (accessed December 19, 2018).

— 2017. "Top 10 List Highlights Seafood Consumption Progress." About Seafood (blog). November 2017. https://www.aboutseafood.com/press_release/top-10-list-highlights-seafoodconsumption-progress/ (accessed December 19, 2018).

—. 2018. "Top 10 List Shows Significant Increase in Seafood Consumption." About Seafood (blog). December 13, 2018. https://www.aboutseafood.com/press_release/top-10-list-shows-significantincrease-in-seafood-consumption/ (accessed December 19, 2018).

Nesheim, Malden C., and Ann L. Yaktine, eds. 2007. Seafood Choices: Balancing Benefits and Risks. Washington, D.C: National Academies Press.

Onozaka, Yuko, Håvard Hansen, and Arne Sørvig. 2014. "Consumer Product Perceptions and Salmon Consumption Frequency: The Role of Heterogeneity Based on Food Lifestyle Segments." Marine Resource Economics 29 (4): 35174. https://doi.org/10.1086/678928.

Palumbo, Rocco, Paola Adinolfi, Carmela Annarumma, Giuseppina Catinello, Marco Tonelli, Ersilia Troiano, Stefania Vezzosi, and Rosalba Manna. 2019. "Unravelling the Food Literacy Puzzle: Evidence from Italy." Food Policy, January. https://doi.org/10.1016/j.foodpol.2018.12.004.

Abroms, Lorien C., and Edward W. Maibach. 2008. "The Effectiveness of Mass Communication to Change Public Behavior." Annual Review of Public Health 29 (1): 219-34. https://doi.org/10.1146/annurev.publhealth.29.020907.090824.

Hornik, Robert C., ed. 2002. Public Health Communication: Evidence for Behavior Change. LEA's Communication Series. Mahwah, N.J: L. Erlbaum Associates. 
Pew Research Center. 2016. "The New Food Fights: U.S. Public Divides Over Food Science." http://www.pewinternet.org/2016/12/01/the-new-food-fights/ (accessed January 1, 2017).

Rousu, Matthew C., and Jason F. Shogren. 2006. "Valuing Conflicting Public Information About a New Technology: The Case of Irradiated Foods." Journal of Agricultural and Resource Economics 31 (3): 642-52.

Samoggia, Antonella, and Alessandra Castellini. 2018. "Health-Orientation and SocioDemographic Characteristics as Determinants of Fish Consumption." Journal of International Food \& Agribusiness Marketing 30 (3): 211-26. https://doi.org/10.1080/08974438.2017.1403986.

Sha, Sha, Julie Insignares Santos, Cathy A. Roheim, and Frank Asche. 2015. "Media Coverage of PCB Contamination of Farmed Salmon: The Response of U.S. Import Demand.” Aquaculture Economics \& Management 19 (3): 336-52. https://doi.org/10.1080/13657305.2015.1057878.

Shimshack, Jay P., Michael B. Ward, and Timothy K.M. Beatty. 2007. "Mercury Advisories: Information, Education, and Fish Consumption." Journal of Environmental Economics and Management 53 (2): 158-79. https://doi.org/10.1016/j.jeem.2006.10.002.

Shogren, Jason F., John A. Fox, Dermot J. Hayes, and Jutta Roosen. 1999. “'Observed Choices for Food Safety in Retail, Survey, and Auction Markets.” American Journal of Agricultural Economics 81 (5): 1192-99. https://doi.org/10.2307/1244106.

Teisl, Mario F., and Brian E. Roe. 2010. "Consumer Willingness-to-Pay to Reduce the Probability of Retail Foodborne Pathogen Contamination." Food Policy 35 (6): 521-30. https://doi.org/10.1016/j.foodpol.2010.07.003.

Tonsor, Glynn T., and Nicole J. Olynk. 2011. "Impacts of Animal Well-Being and Welfare Media on Meat Demand: Animal Well-Being and Welfare Media on Meat Demand." Journal of Agricultural Economics 62 (1): 59-72. https://doi.org/10.1111/j.1477-9552.2010.00266.x.

Uchida, Hirotsugu, Cathy A. Roheim, and Robert J. Johnston. 2017. "Balancing the Health Risks and Benefits of Seafood: How Does Available Guidance Affect Consumer Choices?" American Journal of Agricultural Economics 99 (4): 1056-77. https://doi.org/10.1093/ajae/aax025.

Uchida, Hirotsugu, Cathy A. Roheim, Hiroki Wakamatsu, and Christopher M. Anderson. 2014. "Do Japanese Consumers Care about Sustainable Fisheries? Evidence from an Auction of Ecolabelled Seafood." Australian Journal of 
Agricultural and Resource Economics 58 (2): 263-80.

https://doi.org/10.1111/1467-8489.12036.

United States Census Bureau. 2017a. "DP05: ACS Demographic and Housing Estimates." In 2016 American Community Survey 1-Year Estimates. United States Census Bureau's American Community Survey Office. http://factfinder2.census.gov (accessed June 29, 2018).

—. 2017b. "S1501: Educational Attainment." In 2016 American Community Survey 1-Year Estimates. United States Census Bureau's American Community Survey Office. http://factfinder2.census.gov (accessed June 29, 2018).

_. 2017c. "S2501: Occupancy Characteristics." In 2016 American Community Survey 1-Year Estimates. United States Census Bureau's American Community Survey Office. http://factfinder2.census.gov (accessed June 29, 2018).

U.S. Department of Health and Human Services, and U.S. Department of Agriculture. 2010. Dietary Guidelines for Americans 2010, 7th Edition. United States Government Printing Office. https://health.gov/dietaryguidelines/dga2010/dietaryguidelines2010.pdf (accessed June 29, 2018).

- 2015. Dietary Guidelines for Americans 2015-2020. 8th ed. United States Government Printing Office. http://health.gov/dietaryguidelines/2015/guidelines/ (accessed June 29, 2018).

Verbeke, Wim, Filiep Vanhonacker, Lynn J. Frewer, Isabelle Sioen, Stefaan De Henauw, and John Van Camp. 2008. "Communicating Risks and Benefits from Fish Consumption: Impact on Belgian Consumers' Perception and Intention to Eat Fish." Risk Analysis 28 (4): 951-67. https://doi.org/10.1111/j.1539-6924.2008.01075.x.

Visschers, Vivianne H.M., Christina Hartmann, Rebecca Leins-Hess, Simone Dohle, and Michael Siegrist. 2013. "A Consumer Segmentation of Nutrition Information Use and Its Relation to Food Consumption Behaviour." Food Policy 42 (October): 71-80. https://doi.org/10.1016/j.foodpol.2013.07.003.

Visschers, Vivianne HM, Rebecca Hess, and Michael Siegrist. 2010. "Health Motivation and Product Design Determine Consumers' Visual Attention to Nutrition Information on Food Products." Public Health Nutrition 13 (07): 1099-1106. https://doi.org/10.1017/S1368980009993235.

Wakamatsu, Hiroki, Christopher M. Anderson, Hirotsugu Uchida, and Cathy A. Roheim. 2017. "Pricing Ecolabeled Seafood Products with Heterogeneous 
Preferences: An Auction Experiment in Japan." Marine Resource Economics 32 (3): 277-94. https://doi.org/10.1086/692029. 
Table 1.1 Sample descriptive statistics

\begin{tabular}{lcc}
\hline Variable & Whole Sample & Rhode Island \\
\hline Age (years) & 38.23 & 40.2 \\
Female (\%) & 58.7 & 52.2 \\
Education (\%) & & \\
$\quad$ Less than High School & 1.2 & 11.4 \\
$\quad$ High school or GED & 19.5 & 27.8 \\
$\quad$ Some college, no degree & 21.2 & 18.4 \\
$\quad$ Associate's degree & 18.9 & 8.2 \\
$\quad$ Bachelor's degree & 26.0 & 20.6 \\
$\quad$ Graduate or professional degree & 12.7 & 13.5 \\
Income (\%) & & \\
$\quad$ Less than \$25,000 & 26.0 & 22.1 \\
$\quad$ \$25,000 - 49,999 & 28.9 & 21.2 \\
$\quad$ \$50,000 - 99,999 & 32.4 & 28.6 \\
$\quad$ \$100,000 - 149,999 & 10.0 & 16.4 \\
$\quad$ 150,000 or more & 1.2 & 11.7 \\
Household Size (\%) & 2.91 & 2.48 \\
Households with one or more people & 37.5 & 27.4 \\
under 18 years (\%) & & \\
Change in bid between rounds 2 and 6 (\$) & & \\
$\quad$ Wild Salmon & 0.09 & - \\
$\quad$ Farmed Salmon & 0.04 & - \\
$\quad$ Swordfish & -0.68 & - \\
$\quad$ N & 339 & \\
\hline
\end{tabular}

Notes: Education for Rhode Island population reported for those aged 25 years of age or older. Percent female is for those aged 18 years of ag or older in all columns. Summary of state-level statistics obtained from the most recent American Community Survey estimates (United States Census Bureau 2017a, 2017b, 2017c). 
Table 1.2 Summary of experimental information treatments

\begin{tabular}{lcccc}
\hline $\begin{array}{l}\text { Information } \\
\text { treatment }\end{array}$ & Frequency & Type & Salmon & Swordfish \\
\hline FDA & 56 & Risk & No & Yes \\
Industry & 57 & Benefit & Yes & No \\
FDA/Industry & 59 & Balanced & Yes & Yes \\
& 52 & Balanced(R) & $\begin{array}{c}\text { Fild and } \\
\text { Fnived }\end{array}$ & Yes \\
& & & Wild and & \\
NAS & 64 & Balanced(B) & Farmed & Yes \\
No Information & 52 & - & - & - \\
\hline Total & 340 & & & \\
\hline
\end{tabular}

Notes: Adapted from Uchida et al (2017). Balanced (B) denotes a balanced treatment with a slight focus on benefits, Balanced $(\mathrm{R})$ denotes a balanced treatment with slight focus on risks. 
Table 1.3 Summary of information premium by quantile

\begin{tabular}{|c|c|c|c|c|}
\hline Item & Bottom 5\% & $5 \%-50 \%$ & $50 \%-95 \%$ & Top 5\% \\
\hline & \multicolumn{4}{|c|}{$95 \% \mathrm{CI}=[-0.78,0.29]$} \\
\hline Change in bid between rounds 2 and 6 & $\begin{array}{c}\mu=- \\
2.20 * * *\end{array}$ & \multicolumn{2}{|c|}{$\mu=-0.24$} & $\begin{array}{l}\mu= \\
2.06\end{array}$ \\
\hline Age & 40.7 & 42.4 & 33.3 & 41.4 \\
\hline Gender & 0.72 & 0.43 & 0.53 & 0.57 \\
\hline Prefer Wild to Farmed ${ }^{\text {a }}$ & 3.79 & 3.20 & 3.00 & 3.38 \\
\hline Benefits Greater than Risks ${ }^{a}$ & 3.82 & 4.57 & 4.0 & 3.86 \\
\hline $\begin{array}{l}\text { Benefits Greater than Risks for Pregnant } \\
\text { Women and Children }{ }^{\text {a }}\end{array}$ & $3.19 * *$ & 3.25 & 2.27 & 4.08 \\
\hline Observations & $\mathrm{n}=18$ & $\mathrm{n}=7$ & $\mathrm{n}=17$ & $\mathrm{n}=14$ \\
\hline
\end{tabular}

and 6 for the rounds participants were bidding on swordfish after receiving the FDA information treatment. Both

the confidence interval and mean change in bid are reported above. All reported values are means of the

corresponding item within the particular quantile. $* *$ and $* * *$ Denotes statistical significance at the $5 \%$ and $1 \%$

level, respectively, of t-test for equality of means between Top and Bottom 5\%.

${ }^{\text {a }}$ Measured on 5-point Likert scale 
Table 1.4 Model Selection Summary

\begin{tabular}{cccccc}
\hline Number of Components & Iterations & Converged & log Likelihood & BIC & ICL \\
\hline 1 & 2 & TRUE & -2702 & 5535 & 5535 \\
$\mathbf{2}$ & $\mathbf{2 1}$ & TRUE & $\mathbf{- 2 1 6 4}$ & $\mathbf{4 5 9 9}$ & $\mathbf{4 6 2 2}$ \\
3 & 51 & TRUE & -2017 & 4444 & 4492 \\
4 & 69 & TRUE & -1978 & 4503 & 4556 \\
\hline
\end{tabular}

Note: Preferred model is in boldface type. 
Table 1.5 Sample descriptive statistics by class

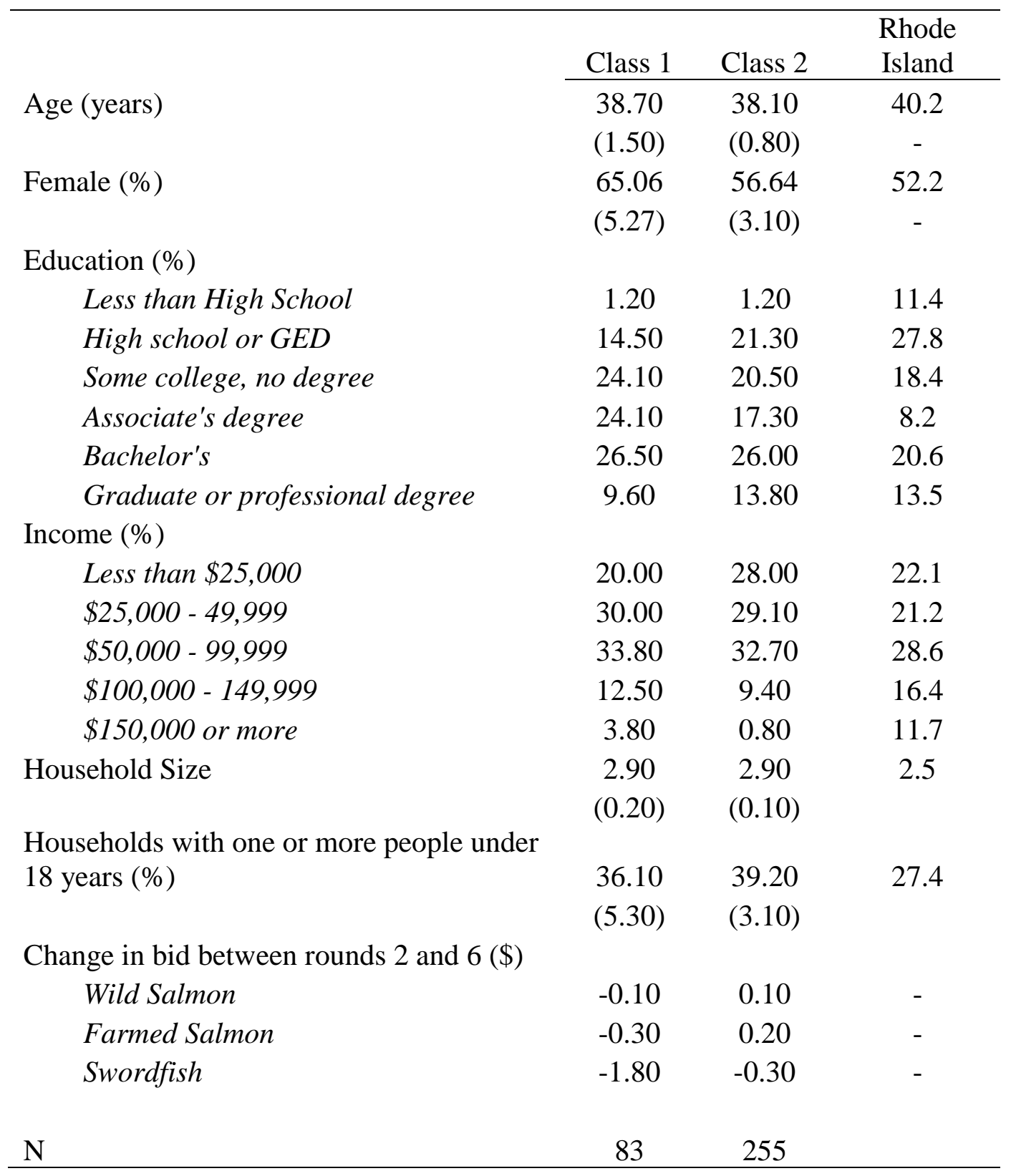


Table 1.6 Rotated factor loadings - seafood purchase behavior

\begin{tabular}{lccc}
\hline Variable & $\begin{array}{c}\text { Factor 1 } \\
\text { Well-being } \\
\text { conscious }\end{array}$ & $\begin{array}{c}\text { Factor } 2 \\
\text { Quality } \\
\text { conscious }\end{array}$ & $\begin{array}{c}\text { Factor } 3 \\
\text { Specialty } \\
\text { store shopper }\end{array}$ \\
\hline Primary seafood purchase location & & & \\
$\quad$ Super Market & 0.0053 & -0.3192 & $\mathbf{- 0 . 8 1 1 7}$ \\
Specialty grocery store & 0.0679 & -0.2209 & $\mathbf{0 . 8 5 0 6}$ \\
Warehouse retailers & -0.1582 & -0.1048 & 0.1827 \\
Fish Markets & -0.0503 & $\mathbf{0 . 6 4 4 6}$ & 0.0028 \\
Direct from fisherman & 0.2388 & 0.212 & -0.1065 \\
Farmers' markets & 0.1179 & -0.0629 & -0.0003 \\
Online shopping or direct order & 0.0165 & -0.3122 & 0.1194 \\
Catch seafood & 0.0133 & $\mathbf{0 . 6 6 3 8}$ & 0.0249 \\
"I tend to buy seafood products that..." & & & \\
I like the taste of best & -0.0106 & $\mathbf{0 . 4 6 6 7}$ & 0.0765 \\
Are from the U.S. & 0.2619 & $\mathbf{0 . 4 4 6 7}$ & 0.2009 \\
Are wild caught & 0.3464 & 0.3843 & $\mathbf{0 . 4 4 8 3}$ \\
Have low fat content & $\mathbf{0 . 7 4 6}$ & 0.0779 & 0.0658 \\
Are healthy for me & $\mathbf{0 . 7 1 2 7}$ & -0.0064 & 0.0022 \\
Are favored by my culture or religion & $\mathbf{0 . 6 0 4 8}$ & -0.0457 & 0.0446 \\
Are recommended by the fish seller & $\mathbf{0 . 4 8 7 1}$ & -0.0883 & 0.1928 \\
\hline
\end{tabular}

Note: Factor loadings greater than 0.4 in bold 
Table 1.7 Rotated factor loadings - seafood lifestyle

\begin{tabular}{lcccc}
\hline Variable & $\begin{array}{c}\text { Factor 1 } \\
\text { Surf }\end{array}$ & $\begin{array}{c}\text { Factor 2 } \\
\text { Turf }\end{array}$ & $\begin{array}{c}\text { Factor 3 } \\
\text { Locally engaged }\end{array}$ & $\begin{array}{c}\text { Factor 4 } \\
\text { Self-sufficient }\end{array}$ \\
\hline $\begin{array}{l}\text { Frequency of } \\
\text { consumption }\end{array}$ & & & & \\
$\quad$ Salmon & $\mathbf{0 . 5 6 3 3}$ & 0.2173 & 0.1401 & -0.073 \\
$\quad$ Swordfish & 0.0492 & 0.0738 & $\mathbf{0 . 8 4 1 6}$ & -0.078 \\
Tuna & $\mathbf{0 . 5 4 5}$ & -0.138 & 0.1282 & -0.1936 \\
Tilapia & $\mathbf{0 . 7 3 6 4}$ & 0.1268 & -0.0902 & 0.0496 \\
Catfish & $\mathbf{0 . 5 7 5 8}$ & -0.018 & 0.1792 & 0.1644 \\
$\quad$ Shrimp & $\mathbf{0 . 5 0 5 5}$ & -0.138 & 0.3262 & 0.1214 \\
Cod or haddock & 0.2023 & -0.064 & $\mathbf{0 . 5 7 2 9}$ & -0.0609 \\
$\quad$ Other seafood & 0.3955 & -0.203 & 0.3481 & 0.2927 \\
Chicken & -0.079 & $\mathbf{0 . 7 1 6 8}$ & 0.0817 & 0.2204 \\
Beef & 0.1057 & $\mathbf{0 . 8 1 9 2}$ & 0.0389 & -0.009 \\
Pork & 0.0052 & $\mathbf{0 . 7 6 8}$ & -0.1067 & -0.1824 \\
Recreational fisher & -0.139 & -0.168 & $\mathbf{0 . 4 5 5 5}$ & $\mathbf{0 . 5 0 9 1}$ \\
Fishes for food & 0.0891 & 0.0231 & -0.1319 & $\mathbf{0 . 8 2 0 3}$ \\
Fishing industry worker & -0.21 & 0.1279 & 0.1206 & 0.3091 \\
\hline
\end{tabular}

Note: Factor loadings greater than 0.4 in bold 
Table 1.8 Rotated factor loadings - seafood health perceptions

\begin{tabular}{|c|c|c|c|}
\hline Variable & $\begin{array}{c}\text { Factor1 } \\
\text { Seafood health } \\
\end{array}$ & $\begin{array}{c}\text { Factor2 } \\
\begin{array}{c}\text { Benefits outweigh } \\
\text { the risks }\end{array}\end{array}$ & $\begin{array}{c}\text { Factor3 } \\
\text { Turf health }\end{array}$ \\
\hline \multicolumn{4}{|l|}{ Health perceptions } \\
\hline Seafood is nutritious & 0.079 & 0.5045 & 0.1606 \\
\hline Seafood is safe to eat & 0.0281 & 0.667 & 0.0751 \\
\hline $\begin{array}{l}\text { The health benefits from eating seafood are } \\
\text { greater than the health risks for most people }\end{array}$ & 0.1933 & 0.5805 & -0.2303 \\
\hline $\begin{array}{l}\text { The health benefits of eating seafood are } \\
\text { greater than the health risks for pregnant } \\
\text { woman and children }\end{array}$ & -0.0467 & 0.3267 & -0.1083 \\
\hline $\begin{array}{l}\text { Wild seafood is better for my health than } \\
\text { farmed seafood }\end{array}$ & -0.1898 & 0.5815 & 0.2184 \\
\hline The health risks of eating seafood are small & 0.0564 & 0.5648 & -0.018 \\
\hline Seafood is healthier to eat than beef & 0.2004 & 0.6458 & -0.3182 \\
\hline Seafood is healthier to eat than poultry & 0.1445 & 0.6273 & -0.1946 \\
\hline \multicolumn{4}{|l|}{ Health rating } \\
\hline Farmed Salmon & 0.6225 & -0.0162 & 0.0021 \\
\hline Wild Salmon & 0.1675 & 0.5961 & 0.2468 \\
\hline Swordfish & 0.505 & 0.1285 & 0.1727 \\
\hline Tuna (fresh) & 0.1792 & 0.2869 & 0.2541 \\
\hline Bluefish & 0.6862 & 0.1651 & -0.0123 \\
\hline Cod / Haddock & 0.4056 & 0.1789 & 0.2204 \\
\hline Herring & 0.5824 & 0.077 & 0.0695 \\
\hline Canned tuna & 0.1945 & 0.2131 & 0.3397 \\
\hline
\end{tabular}


Table 1.8 (continued) Rotated factor loadings - seafood health perceptions

\begin{tabular}{lccc} 
Wild Oysters & $\mathbf{0 . 6 1 6 5}$ & 0.2424 & 0.1548 \\
Farmed Oysters & $\mathbf{0 . 7 6 1 4}$ & -0.0286 & 0.1044 \\
Farmed Shrimp & $\mathbf{0 . 7 1 3 2}$ & 0.0528 & 0.0107 \\
Wild Shrimp & $\mathbf{0 . 4 7 8 2}$ & 0.388 & 0.1532 \\
Ground Beef (90\% lean or more) & 0.0096 & -0.0784 & $\mathbf{0 . 7 7 1 2}$ \\
Chicken (white meat) & 0.2675 & 0.0672 & $\mathbf{0 . 5 3 4 4}$ \\
Eggs & 0.119 & 0.0752 & $\mathbf{0 . 6 1 4}$ \\
Pork Chops & 0.0993 & -0.0146 & $\mathbf{0 . 5 9 1 3}$ \\
Beef Steak (Sirloin) & 0.07 & -0.0542 & $\mathbf{0 . 7 2 9 3}$ \\
\hline
\end{tabular}


Table 1.9 Rotated factor loadings - seafood information trust

\begin{tabular}{lccccc}
\hline & Factor 1 & $\begin{array}{c}\text { Factor } 2 \\
\text { Social } \\
\text { Variable }\end{array}$ & $\begin{array}{c}\text { Factor } 3 \\
\text { Interest } \\
\text { Group }\end{array}$ & Factor 4 & Factor 5 \\
\hline Newspapers, magazines, books & 0.1452 & 0.0196 & -0.0198 & $\mathbf{0 . 7 1 2}$ & 0.1934 \\
Wikipedia or similar websites & 0.1377 & 0.0433 & 0.057 & $\mathbf{0 . 7 3 6 2}$ & -0.0096 \\
$\begin{array}{l}\text { Dieticians, nutritionists, } \\
\text { physicians }\end{array}$ & 0.1858 & 0.1405 & -0.0679 & 0.0773 & $\mathbf{0 . 8 5 7 2}$ \\
Federal government & $\mathbf{0 . 9 3 1 2}$ & 0.0379 & 0.1076 & 0.0751 & 0.1065 \\
State government & $\mathbf{0 . 9 2 1 9}$ & 0.0488 & 0.135 & 0.0976 & 0.0887 \\
Supermarkets or seafood & & & & & \\
markets & $\mathbf{0 . 4 7 5 1}$ & $\mathbf{0 . 5 8 3}$ & 0.0033 & 0.1408 & 0.0869 \\
Family and friends & -0.1796 & $\mathbf{0 . 5 9 9 4}$ & 0.035 & 0.1297 & 0.2163 \\
Cooking shows & -0.0234 & $\mathbf{0 . 4 6 2 3}$ & 0.1616 & $\mathbf{0 . 5 1 3 4}$ & 0.1877 \\
Television or radio news & 0.1686 & 0.0831 & $\mathbf{0 . 4 3 8 2}$ & $\mathbf{0 . 5 7 8 7}$ & 0.048 \\
University scientists & 0.0684 & -0.0881 & $\mathbf{0 . 5 0 7}$ & 0.1065 & $\mathbf{0 . 6 6 7 2}$ \\
Environmental groups & 0.1132 & 0.0982 & $\mathbf{0 . 8 4 3 2}$ & 0.042 & 0.0898 \\
Consumer groups & 0.2251 & 0.2176 & $\mathbf{0 . 7 6 8 2}$ & 0.089 & -0.0447 \\
Local fishermen & -0.0619 & $\mathbf{0 . 7 0 6 5}$ & 0.2432 & -0.0194 & 0.0602 \\
The seafood industry & $\mathbf{0 . 4 1 2}$ & $\mathbf{0 . 6 8 1 8}$ & 0.1684 & 0.0456 & -0.0546 \\
\hline
\end{tabular}

Note: Factor loadings greater than 0.4 in bold 
Table 1.10 Multinomial logit summary

\begin{tabular}{|c|c|}
\hline VARIABLES & $\begin{array}{c}\text { Trust Academics } \\
\text { (Specialty Store base) } \\
\end{array}$ \\
\hline Age (years) & $\begin{array}{c}0.0156 \\
(0.0176)\end{array}$ \\
\hline Female ( $=1$ if female) & $\begin{array}{l}-0.194 \\
(0.423)\end{array}$ \\
\hline College ( $=1$ if earned at least associate's degree) & $\begin{array}{l}-0.184 \\
(0.440)\end{array}$ \\
\hline $\begin{array}{l}\text { Income greater than } \$ 50,000(=1 \text { if pre-tax } \\
\text { household income is greater than } \$ 50,000)\end{array}$ & $\begin{array}{l}-0.606 \\
(0.447)\end{array}$ \\
\hline $\begin{array}{l}\text { Child ( }=1 \text { if at least one member of household } \\
\text { under } 18 \text { years of age) }\end{array}$ & $\begin{array}{c}0.359 \\
(0.416)\end{array}$ \\
\hline \multicolumn{2}{|l|}{ Purchase behavior factors } \\
\hline Well-being conscious & $\begin{array}{l}-0.114 \\
(0.197)\end{array}$ \\
\hline Quality conscious & $\begin{array}{l}-0.326 \\
(0.205)\end{array}$ \\
\hline Specialty store & $\begin{array}{l}-0.516 * * \\
(0.210)\end{array}$ \\
\hline \multicolumn{2}{|l|}{ Seafood lifestyle factors } \\
\hline Surf & $\begin{array}{l}-0.0186 \\
(0.229)\end{array}$ \\
\hline Turf & $\begin{array}{l}-0.0477 \\
(0.207)\end{array}$ \\
\hline Locally engaged & $\begin{array}{l}0.795 * * * \\
(0.234)\end{array}$ \\
\hline Self-sufficient & $\begin{array}{c}0.113 \\
(0.234)\end{array}$ \\
\hline \multicolumn{2}{|l|}{ Health perception factors } \\
\hline Surf health & $\begin{array}{l}-0.0840 \\
(0.211)\end{array}$ \\
\hline Benefits outweigh the risks & $\begin{array}{l}-0.232 \\
(0.236)\end{array}$ \\
\hline Turf health & $\begin{array}{l}-0.0937 \\
(0.226)\end{array}$ \\
\hline
\end{tabular}


Government

0.251

$(0.251)$

Social influence

$-0.529 * *$

(0.249)

Interest group

0.201

$(0.225)$

Media

$-0.247$

(0.198)

Academic

$0.385^{*}$

$(0.218)$

1.039

$(0.778)$

Chi-square (d.f.)

$29.34(20)$

Pseudo R-squared

0.155

Note: Robust standard errors in parentheses. *** $\mathrm{p}<0.01, * * \mathrm{p}<0.05, * \mathrm{p}<0.1$ 
Table 1.11 Effect of information on information premium by class

\begin{tabular}{|c|c|c|}
\hline VARIABLES & $(1)$ & $(2)$ \\
\hline Farmed & $\begin{array}{l}-2.498 \\
(1.976)\end{array}$ & $\begin{array}{c}1.003 \\
(2.135)\end{array}$ \\
\hline Wild & $\begin{array}{l}-1.148 \\
(1.517)\end{array}$ & $\begin{array}{c}1.003 \\
(1.766)\end{array}$ \\
\hline FDA & $\begin{array}{l}-1.400 \\
(2.994)\end{array}$ & $\begin{array}{c}7.681 * * * \\
(2.766)\end{array}$ \\
\hline Industry & $\begin{array}{l}-1.566 \\
(3.209)\end{array}$ & $\begin{array}{c}6.387 * * \\
(2.608)\end{array}$ \\
\hline FDA/Industry & $\begin{array}{l}-3.826 \\
(2.974)\end{array}$ & $\begin{array}{c}0.587 \\
(2.951)\end{array}$ \\
\hline NAS & $\begin{array}{l}-3.635 \\
(3.083)\end{array}$ & $\begin{array}{c}4.789 \\
(2.999)\end{array}$ \\
\hline University & $\begin{array}{l}-4.092 \\
(3.045)\end{array}$ & $\begin{array}{c}1.977 \\
(3.673)\end{array}$ \\
\hline Farmed x FDA & $\begin{array}{l}3.725^{*} \\
(2.142)\end{array}$ & $\begin{array}{l}-0.621 \\
(2.476)\end{array}$ \\
\hline Farmed x Industry & $\begin{array}{c}1.533 \\
(2.214)\end{array}$ & $\begin{array}{c}1.362 \\
(2.326)\end{array}$ \\
\hline Farmed x FDA/Industry & $\begin{array}{c}4.894 * * \\
(2.382)\end{array}$ & $\begin{array}{l}5.249^{*} \\
(2.727)\end{array}$ \\
\hline Farmed x NAS & $\begin{array}{c}6.903 * * * \\
(2.274)\end{array}$ & $\begin{array}{c}2.312 \\
(2.618)\end{array}$ \\
\hline Farmed x University & $\begin{array}{l}5.047^{* * *} \\
(2.174)\end{array}$ & $\begin{array}{c}2.445 \\
(2.524)\end{array}$ \\
\hline Wild x FDA & $\begin{array}{c}4.820 \\
(3.229)\end{array}$ & $\begin{array}{c}5.223 \\
(6.418)\end{array}$ \\
\hline Wild x Industry & $\begin{array}{c}2.658 \\
(2.566)\end{array}$ & $\begin{array}{l}-0.131 \\
(1.885)\end{array}$ \\
\hline Wild x FDA/Industry & $\begin{array}{c}3.480 \\
(2.120)\end{array}$ & $\begin{array}{c}2.499 \\
(2.785)\end{array}$ \\
\hline Wild x NAS & $\begin{array}{l}3.257^{*} \\
(1.798)\end{array}$ & $\begin{array}{c}0.104 \\
(2.361)\end{array}$ \\
\hline Wild x University & $\begin{array}{c}2.591 \\
(1.926)\end{array}$ & $\begin{array}{l}-1.193 \\
(3.029)\end{array}$ \\
\hline \multicolumn{3}{|l|}{ Class Interactions } \\
\hline Trust Academics $(=1)$ & $\begin{array}{l}-0.828 \\
(2.754)\end{array}$ & $\begin{array}{c}6.593 * * * \\
(2.230)\end{array}$ \\
\hline
\end{tabular}


Table 1.11 (continued) Effect of information on information premium by class

$\begin{array}{lcc}\text { Farmed x Trust Academics } & 2.381 & -1.217 \\ \text { Wild x Trust Academics } & (1.984) & (2.157) \\ & 1.072 & -1.341 \\ \text { FDA x Trust Academics } & (1.528) & (1.790) \\ & 1.272 & -8.059^{* * *} \\ \text { Industry x Trust Academics } & (3.002) & (2.787) \\ & 1.226 & -6.804 * * \\ \text { FDA/Industry x Trust Academics } & (3.222) & (2.640) \\ & 3.553 & -1.384 \\ \text { NAS x Trust Academics } & (2.982) & (2.979) \\ & 3.049 & -5.648^{*} \\ \text { University x Trust Academics } & (3.091) & (3.019) \\ & 3.668 & -2.455 \\ \text { Farmed x FDA x Trust Academics } & (3.057) & (3.694) \\ \text { Farmed x Industry x Trust Academics } & -3.411 & 1.067 \\ & (2.155) & (2.510) \\ \text { Farmed x FDA/Industry x Trust Academics } & -0.708 & -0.731 \\ & (2.232) & (2.362) \\ \text { Farmed x NAS x Trust Academics } & -4.214 * & -4.191 \\ & (2.394) & (2.755) \\ \text { Farmed x University x Trust Academics } & -6.056^{* * *} & -1.341 \\ & (2.292) & (2.647) \\ \text { Wild x FDA x Trust Academics } & -4.132^{*} & -2.007 \\ & (2.199) & (2.573) \\ \text { Wild x Industry x Trust Academics } & -4.580 & -4.448 \\ & (3.238) & (6.431) \\ \text { Wild x FDA/Industry x Trust Academics } & -1.647 & 1.203 \\ \text { Wild x NAS x Trust Academics } & (2.588) & (1.936) \\ \text { Wild x University x Trust Academics } & -2.916 & -1.598 \\ \text { Female Interactions } & (2.134) & (2.809) \\ & -2.763 & 0.727 \\ & (1.817) & (2.393) \\ & -1.630 & 1.985 \\ & (1.950) & (3.063) \\ & & \\ & & 10.19 * * * \\ & & (3.899) \\ & -5.002 \\ & (3.292)\end{array}$


Table 1.11 (continued) Effect of information on information premium by class

Wild x Female

FDA x Female

Industry x Female

FDA/Industry x Female

NAS x Female

University x Female

Farmed x FDA x Female

Farmed x Industry x Female

Farmed x FDA/Industry x Female

Farmed x NAS x Female

Farmed x University x Female

Wild x FDA x Female

Wild x Industry x Female

Wild x FDA/Industry x Female

Wild x NAS x Female

Wild x University x Female

Trust Academics x Female

Farmed x Trust Academics x Female

Wild x Trust Academics x Female
$-3.073$

(2.642)

$-13.76 * * *$

(4.461)

$-11.28 * *$

(4.683)

$-6.382$

(4.536)

$-12.42 * * *$

(4.790)

$-8.460 *$

(4.999)

$6.552 *$

(3.675)

0.562

(3.605)

$-0.397$

(3.995)

$6.884^{*}$

(3.962)

3.541

(3.753)

$-1.609$

(6.721)

3.923

(3.906)

1.435

(3.907)

4.803

(3.301)

5.727

(3.764)

$-10.59 * * *$

(3.915)

5.137

(3.313)

3.440

(2.669) 
Table 1.11 (continued) Effect of information on information premium by class

FDA x Trust Academics x Female

Industry x Trust Academics x Female

FDA/Industry x Trust Academics x Female

NAS x Trust Academics x Female

University x Trust Academics x Female

Farmed x FDA x Trust Academics x Female

Farmed x Industry x Trust Academics x Female

Farmed x FDA/Industry x Trust Academics x Female

Farmed x NAS x Trust Academics x Female

Farmed x University x Trust Academics x Female

Wild x FDA x Trust Academics x Female

Wild x Industry x Trust Academics x Female

Wild x FDA/Industry x Trust Academics x Female

Wild x NAS x Trust Academics x Female

Wild x University x Trust Academics x Female

Constant

Observations

Adjusted R-squared
$14.10 * * *$

$11.29 * *$

(4.721)

7.239

(4.562)

$12.79 * * *$

(4.814)

$8.431^{*}$

(5.029)

$-6.746^{*}$

(3.710)

$-0.154$

(3.650)

$-0.278$

(4.025)

$-7.074 *$

(4.008)

$-2.609$

(3.810)

0.787

(6.740)

$-3.915$

(3.963)

$-1.946$

(3.937)

$-5.324$

(3.344)

$-5.294$

(3.813)

0.799

$-6.337 * * *$

(2.750)

(2.210)

1,017

1,017

0.071

Note: Robust standard errors clustered at the individual-level $(\mathrm{n}=338)$ are reported in parentheses. $* * * \mathrm{p}<0.01, * * \mathrm{p}<0.05, * \mathrm{p}<0.1$ 
Figure 1.1 Summary of information premium by product and information treatment

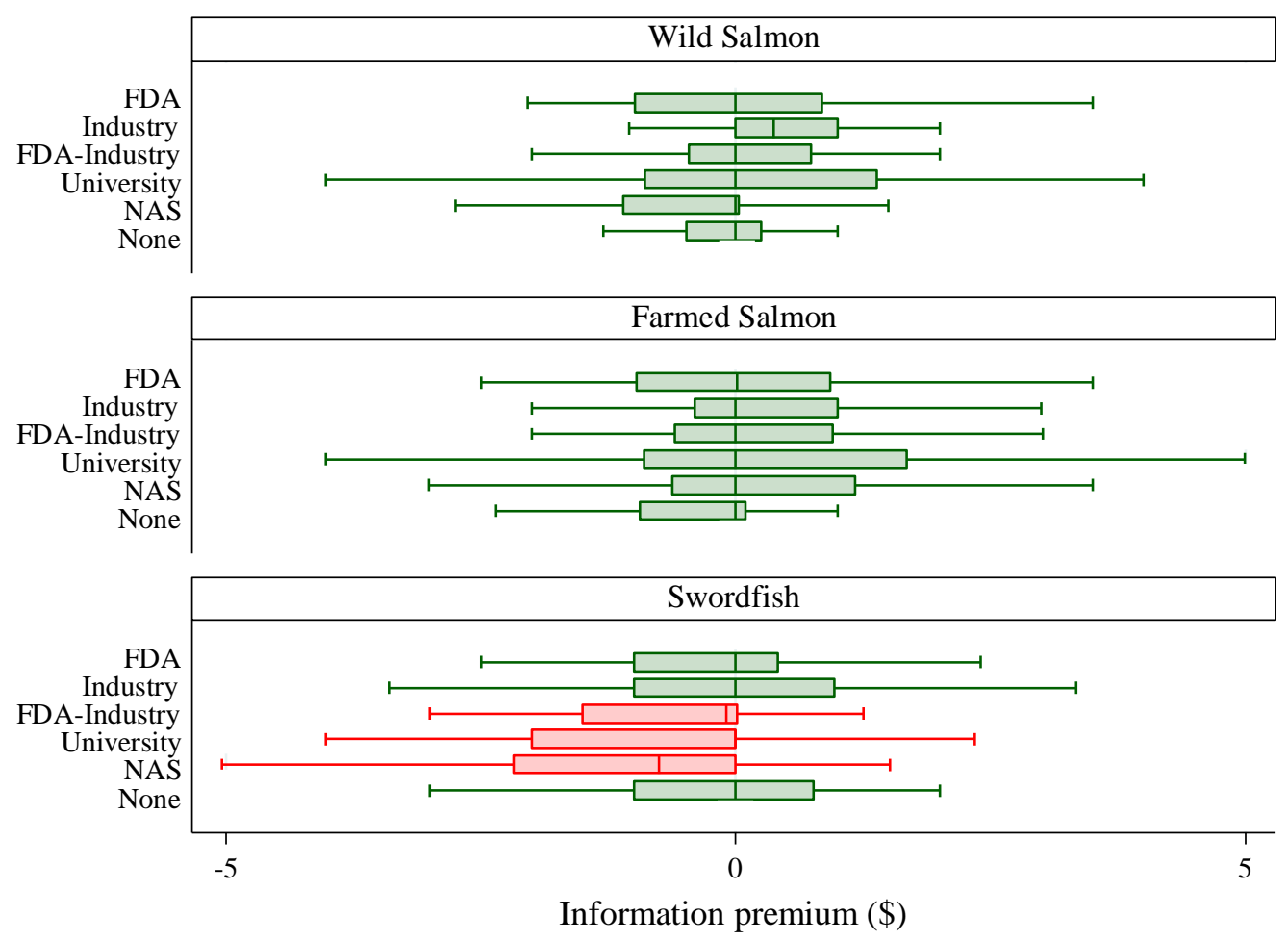

Note: Boxes in red have mean change in bid significantly different from zero at the $95 \%$ level. 
Figure 1.2 Scree plots for prior seafood consumption profile factors
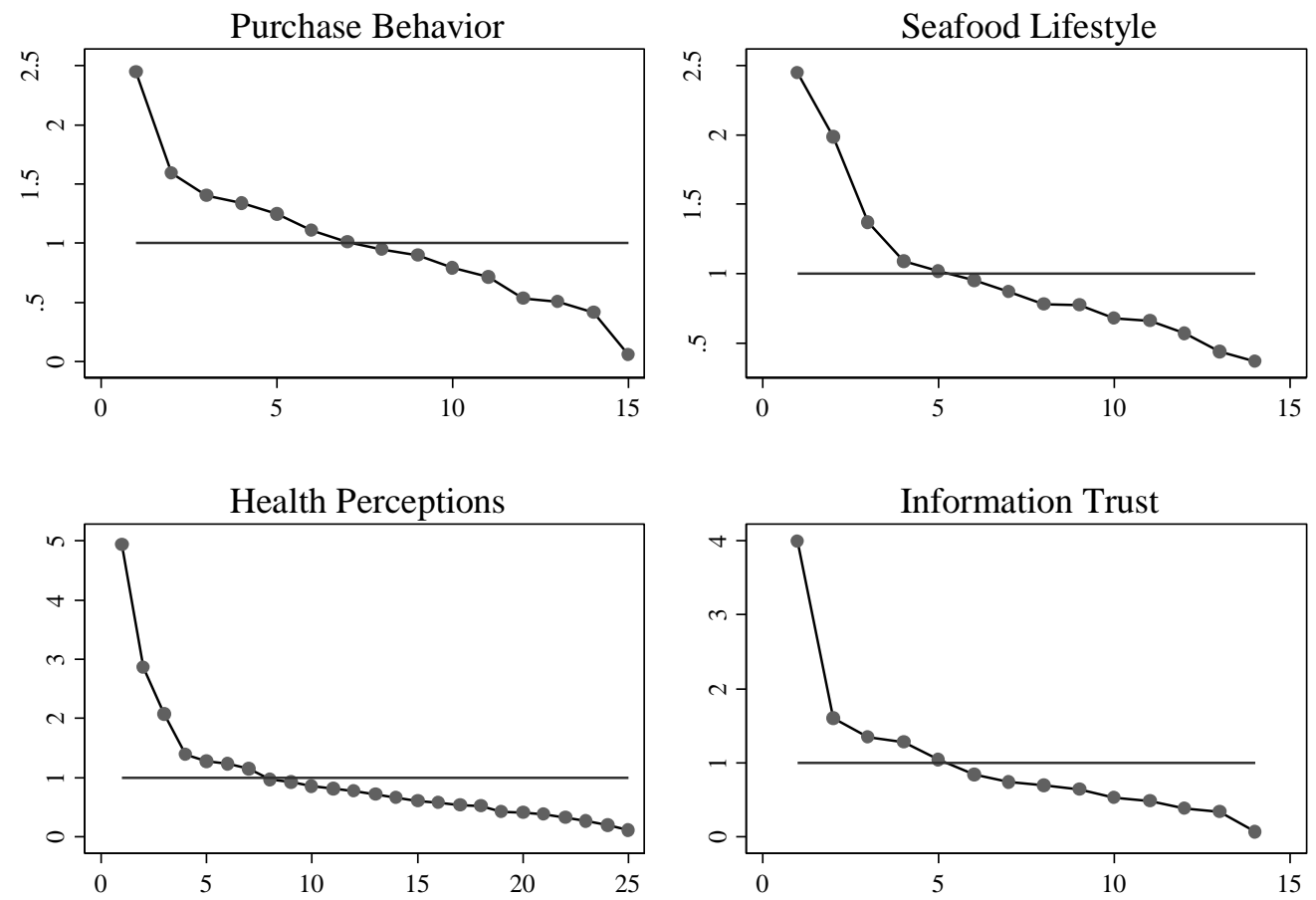

Note: The $\mathrm{x}$-and $\mathrm{y}$-axis denote number of factors and eigenvalues, respectively. The horizontal line indicates the typical cut-off used to determine the number of retained factors. 
Figure 1.3 Quantile plot of information premium by class

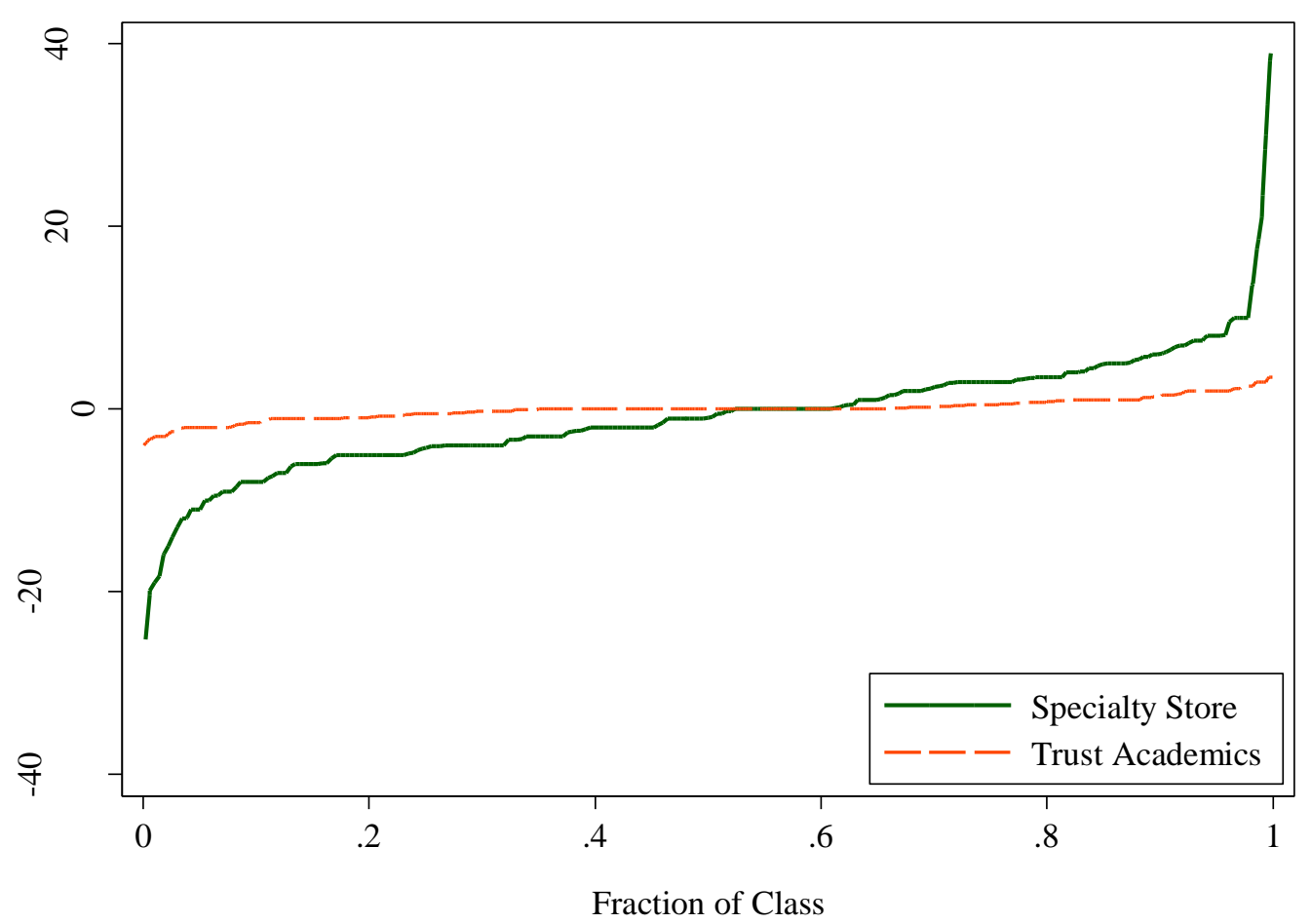


Figure 1.4 Margins plot by class for information-product combination
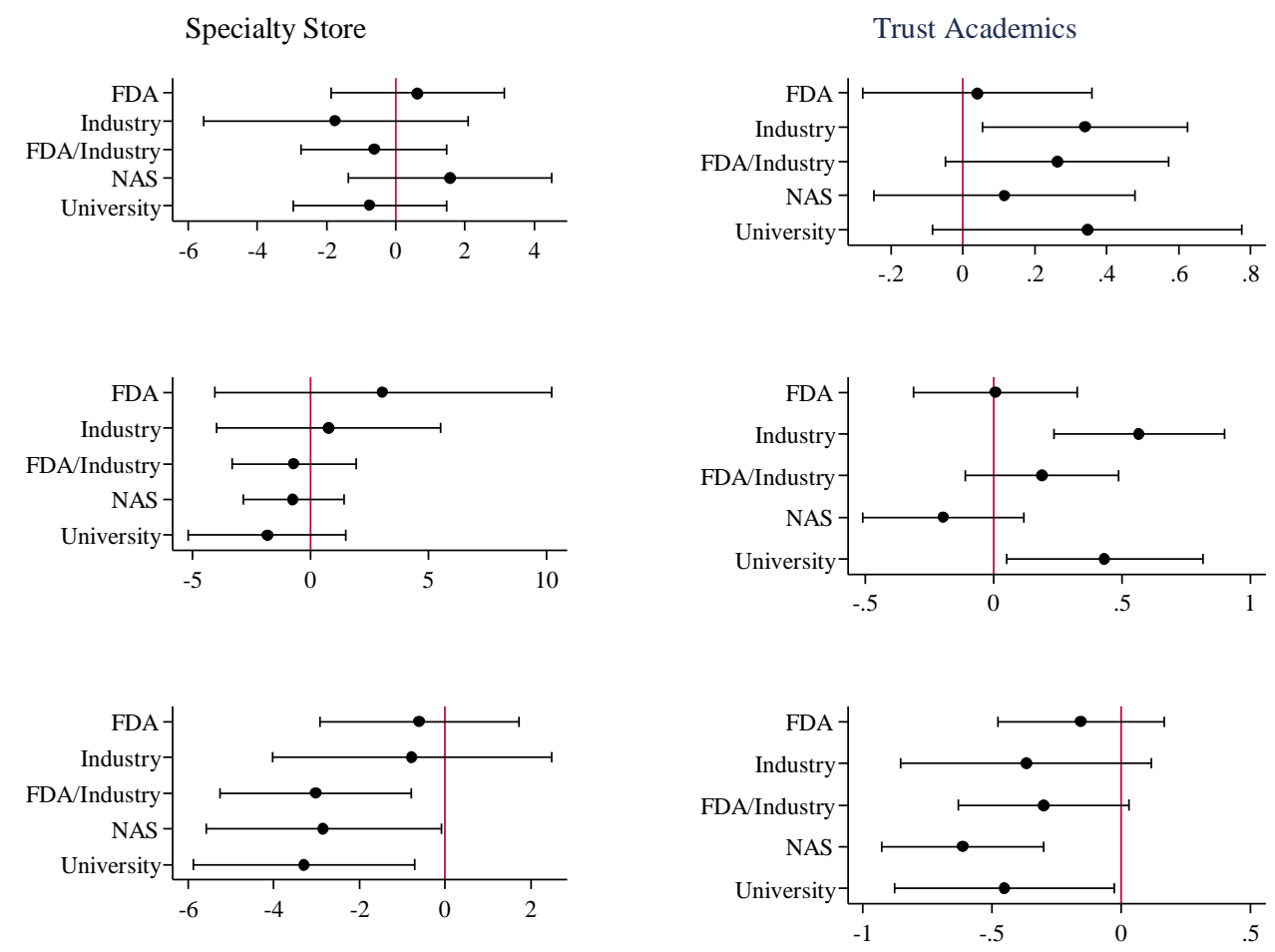

Note: Error bars are $95 \%$ confidence intervals about the mean predictive margin. 
Figure 1.5 Margins plot by class, by gender
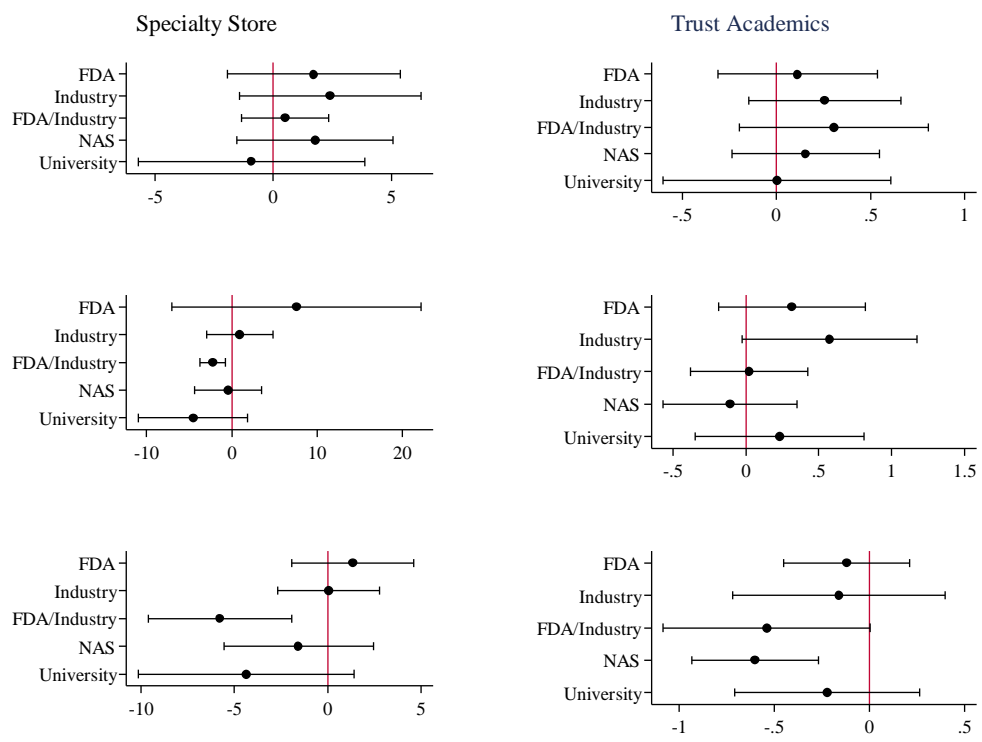

(a) Male
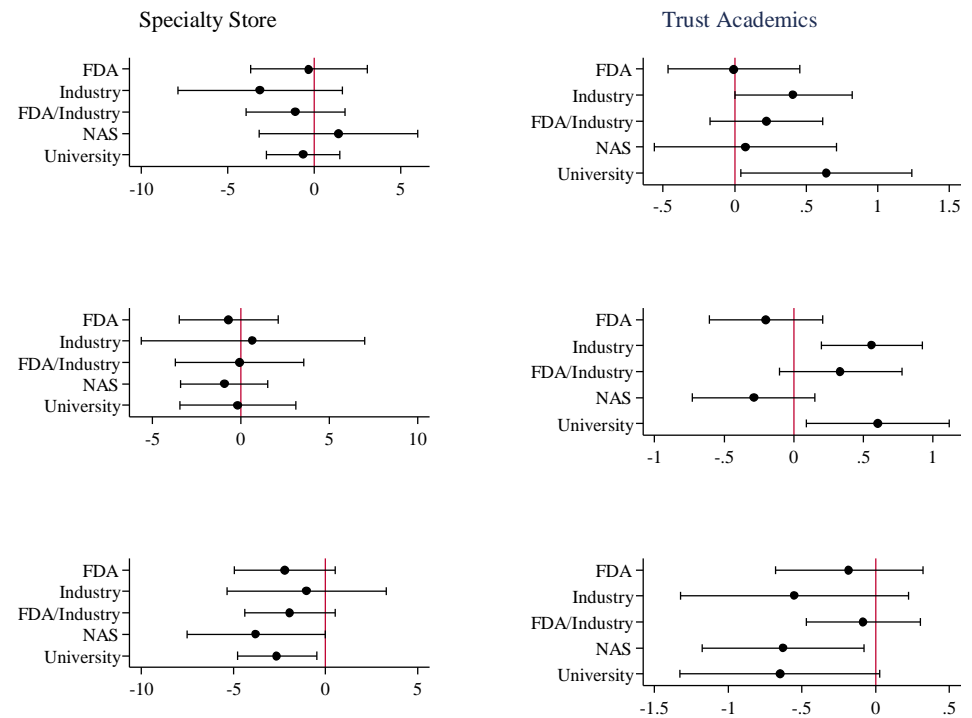

(b) Female

Note: Error bars are 95\% confidence intervals about the mean predictive margin. 


\title{
NATIONAL BIOENGINEERED FOOD DISCLOSURE STANDARD AND THE POLARIZING EFFECT OF MARKET INFORMATION ON DEMAND FOR GENETICALLY MODIFIED SEAFOOD
}

(To be submitted to Food Policy)

By

\author{
Michael J. Weir ${ }^{\mathrm{a}}$, Hirotsugu Uchida ${ }^{\mathrm{a}}$, and Maya Vadiveloo ${ }^{\mathrm{b}}$ \\ ${ }^{a}$ Department of Environmental and Natural Resource Economics, University of Rhode \\ Island, Kingston, RI \\ ${ }^{\mathrm{b}}$ Department of Nutrition and Food Sciences, University of Rhode \\ Island, Kingston, RI
}

Abstract

Recently, the aquaculture industry has expanded to meet growing global seafood demand through increased investment and technological innovations; one of which being the development of genetically modified (GM) fish. Under the recently signed National Bioengineered Food Disclosure Standard, foods containing any of the commercially available GM foods will require mandatory disclosure. Considering these developments, we investigate consumer preferences for GM seafood using an online choice experiment to determine willingness to pay for Atlantic Salmon fillets with labels denoting the presence or absence of GM technology. We find participants are willing to pay a premium for fillets that are labeled as Verified Non-GM, Organic, or Fed-GM, and require a discount for fillets labeled GM. Our results confirm previous conjectures that information about biotechnology has a polarizing effect on demand. We highlight the marketing challenges faced by producers of GM seafood and opportunities for improved science communication about novel food technologies. 


\subsection{Introduction}

Annual global per capita seafood consumption has more than doubled since the 1960s to over $20 \mathrm{~kg}$, making up over 16 percent of global animal protein intake and more than 6 percent of all protein consumed (FAO 2016). However, global harvest of wild fish has remained almost constant since the 1990s. Meanwhile, the aquaculture industry expanded rapidly to fill the gap and meet global seafood demand (FAO 2016), and this trend is expected to continue in the foreseeable future. This will encourage and attract more investment and technological innovations in aquaculture sector; particularly the development of genetically-modified (GM) fish that grows faster, meatier, disease tolerant, etc. Looking at the experience of the agriculture industry in adoption of GM technologies, it is only a matter of time before the U.S. consumers and seafood supply chain are faced with decisions involving GM seafood. The question is whether the market will accept GM seafood, and will it advance the contribution of aquaculture in meeting the world seafood demand.

In an attempt to explore the possibilities of using GM technologies in aquaculture, the Canadian government approved legislation in 1989 that allowed production of GM Atlantic Salmon in research facilities. This would spark a group of researchers to form what is today AquaBounty Technologies, Inc. located in Massachusetts and Prince Edward Island. These researchers developed a GM Atlantic Salmon, marketed as AquAdvantage Salmon ${ }^{\circledR}$, which grows to market weight twice as quickly as conventionally farmed salmon. AquAdvantage Salmon ${ }^{\odot}$ has been sold in Argentina, Brazil and Canada and approved for sale in the U.S. in 2015. However, the controversy surrounding AquAdvantage Salmon ${ }^{\circledR}$ among aquaculture and fishery 
stakeholders (Smith et al. 2010) has halted it reaching the market until a clear labeling standard is put in place.

On July 29, 2016 the National Bioengineered Food Disclosure Standard (NBFDS) was signed into law (Agricultural Marketing Act of 1946, 7 U.S.C. $\$ \S 291$ 296 2016). The first iteration of the standard was available for public comment on May 3, 2018. As it currently stands, foods containing any of the commercially available GM foods and their derivatives will be subject to disclosure, while small food manufacturers, restaurants, animals fed with GM products, and foods certified under the National Organic Program are exempt (Agricultural Marketing Act of 1946, 7 U.S.C. $§ \S 291-296$ 2016). Disclosure is proposed to be carried out via written text, a symbol similar to the USDA Organic symbol, or electronically using QR codes, for example. The NBFDS was finalized in December 2018 and is set to be fully implemented on January 1, 2020 (Boudreau 2018).

Given this definition, there are a variety of seafood products that will be subject to disclosure. Processed seafood where Non-GM fish is combined with GM plant-based ingredients, e.g. surimi, is one example. Surimi is often used as imitation crab meat and made from minced white fish fillets such as pollock and ingredients made from sugar, vegetable oils, corn starch, and soy-based protein. Over $90 \%$ of the plant -based ingredients in surimi that are produced in the U.S. come from GM plant varieties and would require disclosure under the NBFDS (International Service for the Acquisition of Agri-biotech Applications 2018; USDA ERS 2017). Another example is farmed fish, like Atlantic salmon, that are fed fish meal containing GM plant-based ingredients (Naylor et al. 2009). 
For companies in the seafood industry, and food producers in general, the final labeling standard is projected to have significant and negative economic impacts (Bovay and Alston 2018). In anticipation of these impacts, some companies are taking proactive steps before implementation of the NBFDS. For example, Washington-based seafood supplier Trans-Ocean Products, Inc. obtained a Non-GM certification for its Simply Surimi brand by Non-GMO Project, one of the leading programs of this kind in an effort to combat any confusion among consumers once the final standard is set (Kearns 2017). While not all seafood companies will go as far as Trans-Ocean Products, one can reasonably expect that seafood suppliers will be making business decisions, if not already, in response to the new GM labeling standard.

In this paper, we investigate consumer preferences using a discrete choice experiment where participants make choices between fresh Atlantic Salmon fillets with labels denoting the presence or absence of GM technology and test the impact of additional market information on demand for labeled products. We find participants are willing to pay a significantly higher premium for Verified Non-GM salmon fillets than Organic fillets. Interestingly and in opposition to previous findings, participants are willing to pay a premium for fillets from a Fed-GM salmon. We associate this result with the definition provided within the discrete choice experiment (DCE) for this attribute. Regarding the provision of additional market information alongside GM labels, we confirm previous findings that information about biotechnology in food production processes has a relatively uniform, polarizing effect on consumer demand. 


\subsection{Background}

Since the first availability of GM foods in the U.S. nearly twenty-five years ago, much academic work has been dedicated to understanding consumer perceptions and acceptance of GM technology in food products to investigate future adoption possibilities and uncover gaps in public understanding. On average, economics literature has shown evidence that consumers are generally averse to GM food products (Lusk, McFadden, and Wilson 2018; Hess et al. 2016; Dannenberg 2009; Lusk et al. 2005), though aversion is mediated by information about tangible benefits to consumers, such as increased nutrient content (Lusk, McFadden, and Rickard 2015;

Lusk et al. 2004; Colson, Huffman, and Rousu 2011; Grunert et al. 2001) and positive reasons for the use of GM technology like environmental benefits or improved food security (Lusk et al. 2004; Hossain et al. 2003; Gaskell, Allum, and Stares 2003; Grunert et al. 2001).

Much of the skepticism about the use of GM technology is attributed to unknown environmental and health consequences of production and consumption of GM products. The most prevalent issues in discussions being unanticipated allergic responses, spread of pest resistance or herbicide tolerance to wild plants, and inadvertent harm to wildlife (Curtis, McCluskey, and Wahl 2004). Aside from the tangible risks often associated with GM products, other studies have shown moral acceptability to be a significant predictor for the encouragement of biotechnology applications (Amin et al. 2014; Gaskell et al. 2004).

Other authors argue that it is not simply a lack of knowledge about the consequences of GM technology, but also the demand to know, i.e. demand for information, that drives the "dread of Genetically Modified (GM) food" (Costa-Font 
and Mossialos 2005). While this seems credible, some authors have found evidence of a "red flag effect" induced by labeling, in which consumers are more averse to GM foods that require a label (Lusk and Rozan 2008). However, recent findings by Kolodinsky and Lusk (2018) support the information demand argument by identifying a 19\% decrease in opposition to GM foods in Vermont following the passing of its mandatory GM labeling law, which has since been preempted by the NBFDS. While this is promising leading up to the final NBDFS, it is clear there are mixed findings in the literature.

While there is a large body of work dedicated to consumer preferences for GM foods, the majority of previous studies focus on products from the agriculture sector (e.g. apples and beefsteak) with very few focused on seafood (Rickertsen, Gustavsen, and Nayga Jr. 2017; Chern 2006; Chern et al. 2002; Kaneko and Chern 2005; Grunert et al. 2001; Kuznesof and Ritson 1996). When the NBFDS takes effect, consumers will be faced with the choice of (knowingly) buying GM seafood for the first time in history, whether it is a GM species (salmon) or processed product containing GM ingredients (canned salmon). U.S. consumers purchase a variety of foods that derive from GM agricultural products, either in whole form or through derivative ingredients like sugars, soy bean oil, or corn syrup. However, the time when GM foods were introduced to the market is very different from today's market environment; consumers are more aware and relatively concerned about GM food (Lusk, McFadden, and Wilson 2018). Thus, further work is needed to understand consumer attitudes and reaction to the soon to be transparent GM seafood market in the context of the NBFDS. 
The seafood industry is no stranger of GM technology. One of the primary criticisms against the aquaculture industry is feed inefficiency of carnivorous species where, for example, two tons of fish are required for feed to produce one ton of salmon. The fish used as feed are generally wild harvest species, which adds to the criticisms of feed inefficiency given the dim state of world fisheries (Food and Agricultural Organization of the United Nations 2016). The industry's solution was to increase the use of fish feed containing soybean derivatives as protein substitutes, which are primarily GM strains (Food and Agriculture Organization of the United Nations 2016; Naylor et al. 2009; Tacon and Metian 2008). Another use of plant-based ingredients in seafood is processed seafood products like surimi, as mentioned above, and products like smoked oysters or smoked salmon which are often canned and stored with soybean or cottonseed oil and likely derived from GM strains given the extensive use of GM crops in U.S. agriculture.

GM foods have never required a label disclosing production technologies or methods since their introduction, nor has GM seafood been on consumers' radars aside from news about AquAdvantage Salmon ${ }^{\odot}$. Given the uncertainty among consumers, scientists, and other stakeholders regarding potential long-term impacts of GM technology, GM food labels will act as a quality label for consumers. Generally, the introduction of quality labels can improve social welfare for the majority of consumers, though there are potentially large subpopulations that may be impacted negatively by the introduction of such labels (Bonroy and Constantatos 2014). However, there is a large gap in understanding the potentially unique effects of the NBFDS on consumer seafood demand. This is problematic for companies interested in 
strategizing their marketing campaigns to combat the impacts from the GM labeling

law. Gaining further understanding of the consequences, both intended and

unintended, of the forthcoming NBFDS on consumer demand has important

implications regarding the extent the seafood industry should invest in the use of GM technology and for the future of production technology labels in the seafood market, which has never been associated with the use of genetic modification until recent years.

\subsection{Data}

\subsubsection{Sample Characteristics}

We recruited 1,041 online survey participants via Amazon Mechanical Turk (denoted “Mturk”). Mturk workers with greater than zero approved tasks, task approval rating greater than $97 \%$, and located in the United States saw the survey announcement for a “20-minute Academic Study". The full announcement described the study as follows:

We are currently recruiting participants to complete an academic survey about seafood consumption. To participate, you must have at least a $97 \%$ approval rate, live in the United States, be at least 18 years old, and meet our screening standards. Given you meet the screening standards, you will receive $\$ 2.00$ for completing this survey which takes about 20 minutes.

Participants were asked to answer a screener questionnaire to confirm eligibility prior to gaining access to the full the survey. Eligible participants were 1) aged 18 years or older, 2) lived in the United States, 3) consumed seafood regularly, and 4) consumed salmon. We paid participants $\$ 2.00$ upon completion of the survey.

Using an online approach allows us to more closely mimic the familiar market settings in which the seller posts the product price and consumers choose whether to purchase (Alfnes et al. 2006), in contrast to in-person experiments like a second-price 
sealed bid auction. Most importantly, this survey methodology allows us to efficiently collect quality data from multiple geographic regions to allow for broad inference about consumer attitudes toward GM seafood and implications for the seafood market under the NBFDS.

Our final sample consists of a diverse group of respondents from every state in the United States aside from Delaware, table 2.1 provides sample summary statistics. Compared to the most recent American Community Survey (United States Census Bureau 2017a, 2017b, 2017c), our sample differs from the general population of the United States primarily in gender distribution (40.1\% female compared to $50.8 \%$ in the ACS) and educational attainment (60\% with Bachelor's degree or higher compared to $31.2 \%$ in the ACS). The fact that our Mturk sample is more representative than most college student samples, internet survey panels, or in-person convenience samples is not a surprise as this has been observed many times in other studies using Mturk as a survey platform. While this sample is not a generally representative sample of the United States population given previously identified nuances of the Mturk worker population (Goodman and Paolacci 2017), we are confident in saying our sample is sufficiently representative of U.S. seafood consumers given our screening criteria.

\subsubsection{DCE and Survey Design}

We designed a DCE to simulate seafood purchase scenarios for fresh farmed Atlantic Salmon fillets and canned farmed Atlantic Salmon with different labels denoting presence or absence of genetic modification, country of origin, and price. The survey instrument also asked respondents questions about their food consumption habits, 
general attitudes toward food and technology, and specific attitudes toward GM foods.

Table 2.2 summarizes the levels of each product attribute used in our DCE which were chosen based on previous literature and current market conditions. Participants were randomly assigned to one of four information treatment groups related to GM technology in food production: positive, negative, balanced, control. The positive (negative) information groups received information generally supportive (disapproving) of GM technology. The balanced treatment is a combination of both the positive and negative information treatments. The control group received no further information.

We used a full factorial design with each respondent answering a total of six salmon fillet choices. Due to the large number of total choices $(4 \times 5 \times 3=60$ total combinations for salmon) we blocked our choice sets to reduce the cognitive burden on our participants. The design was created in STATA version 13 with the userwritten program dcreate, which implements an algorithm to maximize D-efficiency of a given experimental design ${ }^{4}$ (StataCorp 2013; Hole 2015). Each respondent was randomly assigned to one choice set block. Each choice question had two choice alternatives plus a no purchase option. The order of each question in a given block was randomized for each participant. Figure 2.1 is an example fillet choice set.

\subsection{Methodology}

\subsubsection{Conceptual Framework}

\footnotetext{
${ }^{4}$ Assuming naïve priors and including an alternative specific constant for the opt-out alternative, our design has a D-error of 0.237 assuming only a main effects model. Assuming an interaction effect between the GM label and country of origin our design has a D-error of 0.484 .
} 
We use a random utility framework for analysis of our choice experiment data. Thus, we assume individual $i$ makes choices between $J$ alternatives under $T$ choice situations by considering all alternatives offered in a choice situation and chooses the alternative with the highest utility. The indirect utility associated with alternative $j$ for individual $i$ in choice situation $t$ is characterized by

$$
U_{i j t}=V_{i j t}+\varepsilon_{i j t}
$$

where $V_{i j t}=\boldsymbol{\beta}_{i}{ }^{\prime} \mathbf{x}_{i j t}$ is the deterministic portion of utility with individual parameter vector $\boldsymbol{\beta}_{i}$ assumed to be drawn from a population distribution, $g(\boldsymbol{\beta} \mid \boldsymbol{\theta})$ where $\boldsymbol{\theta}$ is the population parameter for the distribution, and the error term, $\varepsilon_{i j t}$, is independent and identically distributed extreme value type- 1 . Since our data have a panel structure in that each participant answered six choice questions for each product, we need to account for correlation between choices. As discussed in (Train 2009), the probability individual $i$ chooses choice sequence $s_{i}=\left\{s_{i 1}, s_{i 2}, \ldots, s_{T}\right\}$ given choice profiles $x_{i}=\left\{x_{i 1}, x_{i 2}, \ldots, x_{T}\right\}$ is written as the integral,

$$
\operatorname{Pr}\left(s_{i} \mid x_{i}, \boldsymbol{\theta}\right)=\int_{\boldsymbol{\beta}} \operatorname{Pr}\left(s_{i} \mid x_{i}, \boldsymbol{\beta}_{i}\right) g(\boldsymbol{\beta} \mid \boldsymbol{\theta}) d \boldsymbol{\beta}
$$

which must be evaluated numerically using maximum-likelihood methods. We simulate log-likelihood using 200 Halton draws in NLOGIT version 5.0 (Greene 2012), which has been shown to be sufficiently large for this type of estimation procedure (Campbell, Hutchinson, and Scarpa 2007). Individual-level regression coefficients for willingness-to-pay derivation are derived from sampling populationlevel parameter distributions conditional on observed choice patterns using the method proposed by Revelt and Train (2000). 


\subsubsection{Empirical specification}

We control for alternative specific attributes (price, country of origin, and GM label) for each model of product choice. Price is specified as a continuous variable while the other alternative specific attributes are specified as dummy variables with the United States and No Label being the reference category. Participants were provided an information treatment related to GM technology, we interact dummy variables that denote treatment group with GM label dummy variables to investigate whether information influences choices for different levels of GM technology. The no information group is the reference category. We also include an alternative specific constant which to account for the no purchase option.

All coefficients are assumed to be normally distributed to account for unobserved individual heterogeneity, the primary advantage of the mixed logit model (Hensher and Greene 2003). We specify the random parameters associated with each choice attribute to be correlated to account for systematic, but unobserved, effects of common attributes across the choice alternatives (loc. cit.). While previous works have assumed log-normal or triangular distributions for price coefficients to guarantee a negative coefficient, and thus theoretically consistent, we wished to avoid imposing such a restriction and opted for use of a normal distribution. Even without imposing this restriction, the price parameter of our preferred model is negative giving us confidence that our sample considered price in a theoretically consistent manner. We did estimate models assuming price coefficients to be distributed triangular and lognormal, all of which had qualitatively similar results to the model presented herein. 


\subsection{Results}

\subsubsection{Food Purchase Preferences}

Prior to seeing any choice scenarios, participants were asked a suite of questions related to food purchase behavior and preferences/perceptions of GM food/technology. The majority of our sample (69\%) "Often" or "Always" read food labels when purchasing a new product. Between $50-60 \%$ of our sample believe it is either "Very Important" or "Extremely Important" to label each of Organic, Non-GM, Contains GM ingredients, GM-fed, and GM food products (table 2.3). This aligns with the general sentiment of consumer "right to know" and use of information regarding food production methods identified in various academic work as well as independent polls. For example, a Pew Research Center poll (2016) found that $89 \%$ of respondents $(n=1,480)$ believe the general public should play at least a minor role in making policy decisions related to GM foods, while $40 \%$ of respondents believe the news media does not take the health risks of GM foods seriously enough. We also asked participants to rank four food labels in terms of likelihood of purchasing a product with each label (table 2.4).

Unsurprisingly, participants ranked Organic as most likely to be purchased, followed by Certified Non-GMO, Contains GM ingredients, and Produced with Genetic Engineering. We did allow participants to rank multiple labels equally to indicate indifference. There is a clear association made between Organic and Certified Non-GMO labels as well as Contains GM Ingredients and Produced with Genetic Engineering labels as evidenced by their relative average ranks by our sample. 
Participants were also asked if they preferred to eat GM or Non-GM food allowing for an "I don't know" or "I don't care" selection. Less than three-percent of respondents selected "I don't care" in response to the question which is indicative that most of our sample has some preference for consumption of GM foods. Over half of the sample (56\%) prefer to eat Non-GM foods. Interestingly, sixteen percent of our sample claim to prefer eating GM food. We did not ask any follow up to this question. A quarter of our sample is unsure about consumption preferences between GM and Non-GM food (table 2.5).

Lastly, participants rated their seafood purchase habits on a five-point Likert scale to indicate level of agreement with statements about seafood. As expected, based on prior literature, participants have a general preference for seafood that is wildcaught, domestic, low-priced, freshest, and healthy for them (table 2.6).

\subsubsection{Mixed Logit Results}

Mixed logit results are summarized in table 2.7. As mentioned above, we observe a significant, negative price effect which is consistent with economic theory. Overall, the GM labels have the expected sign based on previous works. Participants are more likely to choose organic and verified Non-GM salmon fillets compared to a salmon with no GM production label. Participants are also more likely to choose a verified Non-GM fillet over a non-labeled fillet compared to the choice between an organic fillet and a non-labeled fillet, which is interesting as the organic label denotes a product that meets a stricter standard, which includes a Non-GM verification. As expected, participants are less likely to choose a GM salmon fillet though are more likely to choose a GM-fed fillet, in opposition to the literature. This is a new finding 
which we conjecture is related to the attribute definitions provided to participants, as we highlighted the use of GM-derived fish feed to reduce pressure on wild-caught fish species. Participants are more likely to choose salmon fillets originating from either Norway or Chile, which could be due to the fact that few Atlantic Salmon fillets with U.S. origin are available on the market, due to endangered wild populations and farming operations only in the state of Maine.

All main effects were strengthened by information treatments, regardless of treatment received. The positive information about GM food technology did not curb aversion to GM food products, which is not surprising given the difficulties in shifting negative associations with food production processes due avoidance of information that contradicts one's existing beliefs (Steenkamp 1990). The reduction in demand for GM products and increased demand for the other labeled products in the DCE caused by the negative information treatment is further evidence that is consistent with previous findings suggesting cognitive dissonance and confirmatory biases play a significant role in food-related decisions (Messer, Costanigro, and Kaiser 2017). We find evidence that providing positive information along with negative information about GM food technology, while still reducing demand for GM products overall, could help mitigate the effect of negative information alone. These results, however, provide further evidence that decisions about GM foods continue to be subject to the effects of negativity bias.

\subsubsection{Willingness to pay for product attributes}

We estimate the distribution of willingness to pay for each attribute using 5,000 replications of the Krinsky-Robb method (Krinsky and Robb 1986). This method has 
been recommended in the literature as it allows for asymmetric confidence intervals about the mean WTP. For more detailed discussion of this procedure see Hensher, Rose, and Greene (2015). Table 2.8 provides a summary of WTP for product attributes. The reference case for each WTP is a salmon fillet originating from the U.S. with no GM food label and no additional market information. As discussed above, our sample exhibited higher demand for Norwegian and Chilean produced salmon relative to U.S. produced salmon and are willing to pay more $\$ 1.75$ and $\$ 1.29$ more for each origin, respectively. Participants had a positive WTP for both organic (\$.15) and Verified Non-GM (\$2.04) labeled fillets which is consistent with previous findings. WTP for a GM-fed fillet is $\$ .94$ which is a surprising result and could be an interesting marketing opportunity for producers. As expected, participants are willing to pay less for GM labeled salmon fillets (\$1.04). Each of the main attributes have 95\% confidence intervals that do not contain zero.

We now turn to the WTP for the GM attributes in the presence of additional market information. These values are the total WTP for information and GM attribute, formulated as $W T P_{\text {LABELXINFO }}=\left(\beta_{\text {LABEL }}+\beta_{\text {LABELXINFO }}\right) /-\beta_{\text {PRICE }}$ and estimated using the same methodology described above. Each information treatment magnified WTP for each GM label absent additional information. Only WTP for Verified Non-GM and GM labels are statistically different from zero in the presence of information. The magnitude of WTP for these two attributes is lowest in the presence of positive information and highest in the presence of negative information. The magnitude difference in WTP is nine- and ten-percent higher for Verified Non-GM relative to GM in the presence of positive and balanced information, respectively, while this 
difference is nearly thirty-percent in the presence of negative information. These results are indicative of the polarizing effect of information in the context of biotechnology.

\subsection{Discussion/Conclusion}

In the pre-DCE survey, participants ranked foods with an organic label as more likely to be purchased than foods with a Verified Non-GM label, while exhibiting an association between both labels. In the mixed logit results, we identify stronger preference for Verified Non-GM fillets than organic fillets. This contradicts the rankings participants reported prior to the DCE. While we did provide a definition of organic that denoted the absence of GM technology in production, perhaps the stronger preference for Non-GM is explained by the fact that this label is more transparent. Since the label denotes that the fillets were Verified Non-GM participants could more easily use this information to refine their preferences associated with GM food production technology. Though the organic label implies the product is also Non$\mathrm{GM}$, if a consumer is most concerned about the use of GM technology, they are required to recall that the organic label has this associated implication. This may require additional inference on the part of the consumer, resulting in potential confusion and/or misinterpretation of the labels making them ineffective at aligning consumers' purchases with their preferences (Messer, Costanigro, and Kaiser 2017).

As noted above, participants were willing to pay a premium for GM-fed fillets regardless of information treatment, which has not been previously identified in literature investigating consumer preferences for GM-fed animals. For example, Lusk, Roosen, and Fox (2003) found participants were willing to pay a premium to avoid 
GM-fed beef, while Kaneko and Chern (2005) found similar results for GM-fed salmon. As an explanation, we consider the definition used for GM-fed that was provided to participants during the DCE. The definition read as follows:

Fed with GM Soy - To avoid using wild-caught fish to feed farmed salmon, some salmon farmers use fish feed containing a soy-based protein alternative. Approximately $95 \%$ of all soy grown in the US is GM. The salmon itself is NOT GM. ${ }^{5}$

Previous research has found that consumers are more accepting of biotechnology uses associated with a tangible benefit, such as increased nutrition or environmental benefits (Dannenberg 2009; Lusk et al. 2005). Though we cannot explicitly test for this effect, we conjecture that the definition provided for the GM-fed label acted as product-specific benefit information, which in turn resulted in willingness to pay a premium for GM-fed salmon. Under the NBFDS, products derived from animals consuming GM feed are currently not mandated to require a label. Our results may be informative to producers for product differentiation strategies or tactics to counter-act negative press associated with production processes.

\subsubsection{Ineffective information}

We find that information is ineffective at shifting consumer demand for foods that use biotechnology in production processes. We find instead that information, regardless of its support of biotechnology, has a relatively uniform effect on consumer demand. Specifically, information has a polarizing effect, strengthening participants' demand for fillets with each of the production process labels no matter which information

\footnotetext{
${ }^{5} \mathrm{We}$ are confident in the content validity of this definition based on the discussion in a variety of sources (Food and Agriculture Organization of the United Nations 2016; Naylor et al. 2009; Tacon and Metian 2008) as well as feedback from focus group participants prior to survey deployment.
} 
treatment they received. Previous works have found similar findings in regard to the effect of information on consumer preferences for GM food products (e.g. Frewer, Howard, and Shepherd 1998; Peters 1998). The only exception is demand for fillets with a GM-fed label given the balanced information treatment. Participants in this experimental condition exhibited no significant change in demand for this product attribute.

Considering the positive information condition, we conjecture information was ineffective at increasing demand for GM fillets due to participants' preference for Non-GM foods identified in responses to the food purchase and preference questions leading up to the DCE. As discussed above, participants were asked if they preferred to eat GM or Non-GM to which $56 \%$ of participants reported a preference for NonGM foods. Thus, the majority of our sample has a preference for Non-GM food products, while $28 \%$ reported that they either do not know or do not care about a preference for GM relative to Non-GM. Given this preference profile of our sample, our results corroborate the previously identified ineffectiveness of benefit information to shift consumer preferences toward support of biotechnology in the presence of prior opposition (Scholderer and Frewer 2003). Though the effects of information are not statistically different from one another, we do find evidence that positive information leads to less extreme polarization in demand for these product attributes.

\subsubsection{More effective science communication}

Scholderer and Frewer (2003) say communication strategies related to biotechnology have focused on "engaging consumers in the debate about innovation processes rather than attempting to align their views with those held by expert communities." While 
labels can promote consumer information search and education, search results usually lead consumers to mass media sources which have a known tendency to focus on reporting negative aspects of a topic. This is an issue in terms of aligning consumer perceptions with scientific evidence, as scientific results are produced at a much slower pace than media sensations (Messer et al. 2017).

We find participants in our DCE are 1) willing to pay more for Fed-GM salmon given a Fed-GM label/ definition combination, and 2) willing to pay a premium above the definition/label combination when provided general benefit information about GM technology. Based on these results, we second the recommendation put forth by Messer et al. (2017) regarding the provision of secondary information along with the labels at the point of purchase to help mitigate the potentially negative effect of the forthcoming NBFDS. Specifically, we propose providing product-specific benefit information alongside general benefit information about biotechnology in conjunction with the labels. These results provide further support for recommendations posed recently in the marketing literature to promote GM foods as "a man-made object created with intent" (Hingston and Noseworthy 2018). Qin and Brown (2006) posited similar recommendations after conducting focus groups centered on the topic of GM salmon saying that communication about GM applications "should contain basic and specific, including process- and productrelated, information to... help consumers reach informed opinions" (pg. 262). The NBFDS was finalized in December 2018 with full implementation to occur by 2020. Taking our results together with previous findings we see food retailers as an outlet to provide general/balanced information about genetic modification and 
product-/process-specific information to complement the informative role of the NBFDS. Maintaining transparency and openness throughout this informing process can be constructive in fulfilling consumers demand for information about genetic modification, while helping mitigate the effects of potential or pre-existing stigmas. 
References

Agricultural Marketing Act of 1946, 7 U.S.C. $\S \S 291-296.2016$. https://www.congress.gov/bill/114th-congress/senatebill/764/text?resultIndex=1.

Alfnes, Frode, Atle G. Guttormsen, Gro Steine, and Kari Kolstad. 2006. 'Consumers' Willingness to Pay for the Color of Salmon: A Choice Experiment with Real Economic Incentives." American Journal of Agricultural Economics 88 (4): 1050-61. https://doi.org/10.1111/j.1467-8276.2006.00915.x.

Amin, Latifah, Md. Abul Kalam Azad, Mohd Hanafy Gausmian, and Faizah Zulkifli. 2014. "Determinants of Public Attitudes to Genetically Modified Salmon." PLOS ONE 9 (1): e86174. https://doi.org/10.1371/journal.pone.0086174.

Bonroy, Olivier, and Christos Constantatos. 2014. "On the Economics of Labels: How Their Introduction Affects the Functioning of Markets and the Welfare of All Participants." American Journal of Agricultural Economics 97 (1): 239-59.

Boudreau, Catherine. 2018. "USDA Eyes Dec. 1 for Final GMO Labeling Rule.” POLITICO Pro (blog). https://subscriber.politicopro.com/agriculture/whiteboard/2018/09/usda-eyesdec-1-for-final-gmo-labeling-rule-1904831 (accessed November 16, 2018).

Bovay, John, and Julian M. Alston. 2018. "GMO Food Labels in the United States: Economic Implications of the New Law." Special Issue on The Economics and Politics GM Food Labeling 78 (July): 14-25. https://doi.org/10.1016/j.foodpol.2018.02.013.

Campbell, Danny, George Hutchinson, and R. Scarpa. 2007. "Using Mixed Logit Models to Derive Individual-Specific WTP Estimates for Landscape Improvements under Agri-Environmental Schemes: Evidence from the Rural Environmental Protection Scheme in Ireland.” In Choice Experiments Informing European Environmental Policy.

Chern, Wen S. 2006. "Genetically Modified Organisms (GMOs) and Sustainability in Agriculture." In International Association of Agricultural Economists Conference, August 12-18, 2006. Gold Coast, Queensland, Australia.

Chern, Wen S, Kyrre Rickertsen, Nobuhiro Tsuboi, and Tsu-Tan Fu. 2002. "Consumer Acceptance and Willingness to Pay for Genetically Modified Vegetable Oil and Salmon: A Multiple-Country Assessment." AgBioForum 5: 105-12.

Colson, Gregory J., Wallace E. Huffman, and Matthew C. Rousu. 2011. "Improving the Nutrient Content of Food through Genetic Modification: Evidence from Experimental Auctions on Consumer Acceptance." Journal of Agricultural and Resource Economics 36 (2): 343-64. 
Costa-Font, Joan, and Elias Mossialos. 2005. "Is Dread of Genetically Modified Food Associated with the Consumers' Demand for Information?" Applied Economics Letters 12 (14): 859-63. https://doi.org/10.1080/13504850500365830.

Curtis, Kynda R., Jill J. McCluskey, and Thomas I. Wahl. 2004. "Consumer Acceptance of Genetically Modified Food Products in the Developing World." AgBioForum 7 (1 \& 2): 70-75.

Dannenberg, Astrid. 2009. "The Dispersion and Development of Consumer Preferences for Genetically Modified Food - A Meta-Analysis.” Ecological Economics 68 (8): 2182-92. https://doi.org/10.1016/j.ecolecon.2009.03.008.

Food and Agricultural Organization of the United Nations. 2016. State of World Fisheries and Aquaculture 2016. Contributing to Food Security and Nutrition for All. Rome. http://www.fao.org/3/a-i5555e.pdf (accessed October 10, 2017).

Food and Agriculture Organization of the United Nations. 2016. "Aquaculture Feed and Fertilizer Resources Information System." Atlantic Salmon - Feed Production. http://www.fao.org/fishery/affris/species-profiles/atlanticsalmon/feedproduction/en/(accessed October 10, 2017).

Frewer, Lynn J., Chaya Howard, and Richard Shepherd. 1998. "The Influence of Initial Attitudes on Responses to Communication about Genetic Engineering in Food Production." Agriculture and Human Values 15 (1): 15-30. https://doi.org/10.1023/A:1007465730039.

Gaskell, G, N Allum, and S Stares. 2003. Europeans and Biotechnology in 2002: Eurobarometer 58.0. Brussels: European Commission.

Gaskell, George, Nick Allum, Wolfgang Wagner, Nicole Kronberger, Helge Torgersen, Juergen Hampel, and Julie Bardes. 2004. "GM Foods and the Misperception of Risk Perception.” Risk Analysis 24 (1): 185-94. https://doi.org/10.1111/j.0272-4332.2004.00421.x.

Goodman, Joseph K., and Gabriele Paolacci. 2017. "Crowdsourcing Consumer Research.” Journal of Consumer Research 44 (1): 196-210. https://doi.org/10.1093/jcr/ucx047.

Greene, William H. 2012. NLOGIT Version 5.0 Reference Guide. Plainview, NY: Econometric Software, Inc.

Grunert, Klaus G, Liisa Lähteenmäki, Niels Asger Nielsen, Jacob B Poulsen, Oydis Ueland, and Annika Åström. 2001. "Consumer Perceptions of Food Products Involving Genetic Modification-Results from a Qualitative Study in Four 
Nordic Countries." Food Quality and Preference 12 (8): 527-42.

https://doi.org/10.1016/S0950-3293(01)00049-0.

Hensher, David A., and William H. Greene. 2003. "The Mixed Logit Model: The State of Practice." Transportation 30 (2): 133-76. https://doi.org/10.1023/A:1022558715350.

Hensher, David A., John M. Rose, and William H. Greene. 2015. Applied Choice Analysis. Second edition. Cambridge, United Kingdom: Cambridge University Press.

Hess, Sebastian, Carl Johan Lagerkvist, William Redekop, and Ashkan Pakseresht. 2016. "Consumers' Evaluation of Biotechnologically Modified Food Products: New Evidence from a Meta-Survey." European Review of Agricultural Economics 43 (5): 703-36. https://doi.org/10.1093/erae/jbw011.

Hingston, Sean T., and Theodore J. Noseworthy. 2018. "Why Consumers Don't See the Benefits of Genetically Modified Foods, and What Marketers Can Do About It." Journal of Marketing 82 (5): 125-40. https://doi.org/10.1509/jm.17.0100.

Hole, Arne Risa. 2015. DCREATE: Stata Module to Create Efficient Designs for Discrete Choice Experiments (version Statistical Software Components S458059). Boston College Department of Economics. https://ideas.repec.org/c/boc/bocode/s458059.html.

Hossain, Ferdaus, Benjamin Onyango, Brian Schilling, William Hallman, and Adesoji Adelaja. 2003. "Product Attributes, Consumer Benefits and Public Approval of Genetically Modified Foods." International Journal of Consumer Studies 27 (5): 353-65. https://doi.org/10.1046/j.1470-6431.2003.00303.x.

International Service for the Acquisition of Agri-biotech Applications. 2018. "Knowledge Center." International Service for the Acquisition of Agri-Biotech Applications. http://www.isaaa.org/kc/default.asp (accessed December 5, 2018).

Kaneko, Naoya, and Wen S. Chern. 2005. "Willingness to Pay for Genetically Modified Oil, Cornflakes, and Salmon: Evidence from a U.S. Telephone Survey." Journal of Agricultural and Applied Economics 37 (3): 701-19. https://doi.org/10.1017/S1074070800027188.

Kearns, Madelyn. 2017. "US Surimi Supplier Certified as Non-GMO, Announces Weight Watchers Campaign.” Seafood Source, December 14, 2017. https://www.seafoodsource.com/news/foodservice-retail/us-surimi-supplierscores-non-gmo-vetting-announces-weight-watchers-campaign. 
Kolodinsky, Jane, and Jayson L. Lusk. 2018. "Mandatory Labels Can Improve Attitudes toward Genetically Engineered Food." Science Advances 4 (6). https://doi.org/10.1126/sciadv.aaq1413.

Krinsky, Itzhak, and A. Leslie Robb. 1986. "On Approximating the Statistical Properties of Elasticities." The Review of Economics and Statistics 68 (4): 715-19. https://doi.org/10.2307/1924536.

Kuznesof, Sharron, and Christopher Ritson. 1996. "Consumer Acceptability of Genetically Modified Foods with Special Reference to Farmed Salmon." British Food Journal 98 (4/5): 39-47. https://doi.org/10.1108/00070709610119874.

Lusk, Jayson L., Lisa O. House, Carlotta Valli, Sara R. Jaeger, Melissa Moore, J.L. Morrow, and W. Bruce Traill. 2004. "Effect of Information about Benefits of Biotechnology on Consumer Acceptance of Genetically Modified Food: Evidence from Experimental Auctions in the United States, England, and France." European Review of Agricultural Economics 31 (2): 179-204. https://doi.org/10.1093/erae/31.2.179.

Lusk, Jayson L., Mustafa Jamal, Lauren Kurlander, Maud Roucan, and Lesley Taulman. 2005. "A Meta-Analysis of Genetically Modified Food Valuation Studies." Journal of Agricultural and Resource Economics 30 (1): 28-44.

Lusk, Jayson L., Brandon R. McFadden, and Bradley J. Rickard. 2015. "Which Biotech Foods Are Most Acceptable to the Public?" Biotechnology Journal 10 (1): 13-16. https://doi.org/10.1002/biot.201400561.

Lusk, Jayson L., Brandon R. McFadden, and Norbert Wilson. 2018. "Do Consumers Care How a Genetically Engineered Food Was Created or Who Created It?" Food Policy 78: 81-90. https://doi.org/10.1016/j.foodpol.2018.02.007.

Lusk, Jayson L., Jutta Roosen, and John A. Fox. 2003. "Demand for Beef from Cattle Administered Growth Hormones or Fed Genetically Modified Corn: A Comparison of Consumers in France, Germany, the United Kingdom, and the United States." American Journal of Agricultural Economics 85 (1): 16-29. https://doi.org/10.1111/1467-8276.00100.

Lusk, Jayson L., and Anne Rozan. 2008. "Public Policy and Endogenous Beliefs: The Case of Genetically Modified Food." Journal of Agricultural and Resource Economics 33 (2): 270-89.

Messer, Kent D., Marco Costanigro, and Harry M. Kaiser. 2017. "Labeling Food Processes: The Good, the Bad and the Ugly." Applied Economic Perspectives and Policy 39 (3): 407-27. https://doi.org/10.1093/aepp/ppx028. 
Naylor, Rosamond L., Ronald W. Hardy, Dominique P. Bureau, Alice Chiu, Matthew Elliott, Anthony P. Farrell, Ian Forster, et al. 2009. "Feeding Aquaculture in an Era of Finite Resources." Proceedings of the National Academy of Sciences, August, pnas.0905235106. https://doi.org/10.1073/pnas.0905235106.

Peters, Hans Peter. 1998. "Is the Negative More Relevant than the Positive? Cognitive Responses to TV Programs and Newspaper Articles on Genetic Engineering." In 5th International Conference on Public Communication of Science and Technology (PCST), Berlin, 17-19.

Pew Research Center. 2016. "The New Food Fights: U.S. Public Divides Over Food Science.” http://www.pewinternet.org/2016/12/01/the-new-food-fights/ (accessed January 1, 2017).

Qin, Wei, and J. Lynne Brown. 2006. “Consumer Opinions about Genetically Engineered Salmon and Information Effect on Opinions: A Qualitative Approach." Science Communication 28 (2): 243-72. https://doi.org/10.1177/1075547006294770.

Revelt, David, and Kenneth E. Train. 2000. "Customer-Specific Taste Parameters and Mixed Logit: Households' Choice of Electric Supplier.” Working Paper, University of California, Berkeley.

Rickertsen, Kyrre, Geir W. Gustavsen, and Rodolfo M. Nayga Jr. 2017. “Consumer Willingness to Pay for Genetically Modified Vegetable Oil and Salmon in the United States and Norway." AgBioForum 20 (2): 94-104.

Scholderer, Joachim, and Lynn J. Frewer. 2003. "The Biotechnology Communication Paradox: Experimental Evidence and the Need for a New Strategy." Journal of Consumer Policy 26 (2): 125-57. https://doi.org/10.1023/A:1023695519981.

Smith, Martin D., Frank Asche, Atle G. Guttormsen, and Jonathan B. Wiener. 2010. "Genetically Modified Salmon and Full Impact Assessment." Science 330 (6007): 1052. https://doi.org/10.1126/science.1197769.

StataCorp. 2013. Stata Statistical Software: Release 13. College Station, TX: StataCorp LC.

Steenkamp, Jan-Benedict E.M. 1990. "Conceptual Model of the Quality Perception Process.” Journal of Business Research 21 (4): 309-33. https://doi.org/10.1016/0148-2963(90)90019-A.

Tacon, Albert G.J., and Marc Metian. 2008. "Global Overview on the Use of Fish Meal and Fish Oil in Industrially Compounded Aquafeeds: Trends and Future Prospects." Aquaculture 285 (1): 146-58. https://doi.org/10.1016/j.aquaculture.2008.08.015. 
Train, Kenneth. 2009. Discrete Choice Methods with Simulation. 2nd ed. Cambridge ; New York: Cambridge University Press.

United States Census Bureau. 2017a. "DP05: ACS Demographic and Housing Estimates." In 2016 American Community Survey 1-Year Estimates. United States Census Bureau's American Community Survey Office. http://factfinder2.census.gov(accessed June 29, 2018).

_ 2017b. "S1501: Educational Attainment." In 2016 American Community Survey 1-Year Estimates. United States Census Bureau's American Community Survey Office. http://factfinder2.census.gov (accessed June 29, 2018).

_.2017c. "S2501: Occupancy Characteristics." In 2016 American Community Survey 1-Year Estimates. United States Census Bureau's American Community Survey Office. http://factfinder2.census.gov (accessed June 29, 2018).

USDA ERS. 2017. "Adoption of Genetically Engineered Crops in the U.S." https://www.ers.usda.gov/data-products/adoption-of-genetically-engineeredcrops-in-the-us/ (accessed July 12, 2017). 
Table 2.1 Sample summary statistics

\begin{tabular}{|c|c|c|c|}
\hline & Mean & SD & 2016 ACS \\
\hline Age & 35.9 & 11.0 & 37.7 \\
\hline Female (\%) & 40.1 & 49.0 & 51.60 \\
\hline \multicolumn{4}{|l|}{ Income $(\%)$} \\
\hline Less than $\$ 49,999$ & 48.5 & 50.0 & 45.4 \\
\hline$\$ 50,000-99,999$ & 37.1 & 48.3 & 30.0 \\
\hline$\$ 100,000-149,999$ & 5.8 & 23.5 & 13.5 \\
\hline Greater than $\$ 150,000$ & 2.7 & 16.2 & 11.1 \\
\hline \multicolumn{4}{|l|}{ Education $(\%)$} \\
\hline Less than high school & 0.4 & 6.3 & 12.5 \\
\hline High School degree & 9.4 & 29.2 & 27.2 \\
\hline Some college or Associate's & 29.0 & 45.4 & 29.0 \\
\hline Bachelor's degree & 42.5 & 49.5 & 19.3 \\
\hline Graduate or professional degree & 57.5 & 49.5 & 11.9 \\
\hline \multicolumn{4}{|l|}{ Household size $(\%)$} \\
\hline 1 & 19.5 & 39.7 & 27.7 \\
\hline 2 & 26.7 & 44.2 & 33.7 \\
\hline 3 & 24.2 & 42.9 & 15.7 \\
\hline 4 & 18.8 & 39.1 & 13.1 \\
\hline 5 & 6.8 & 25.2 & 6.0 \\
\hline 6 & 3.0 & 17.1 & 2.3 \\
\hline 7 or more & 0.9 & 9.5 & 1.5 \\
\hline \multicolumn{4}{|l|}{ Race $(\%)$} \\
\hline White & 74.7 & 43.5 & 73.3 \\
\hline Black or African American & 13.5 & 34.2 & 12.6 \\
\hline Hispanic or Latino & 7.0 & 25.5 & 17.3 \\
\hline Native American or Alaska Native & 1.8 & 13.5 & 0.8 \\
\hline Asian & 4.3 & 20.2 & 5.2 \\
\hline Native Hawaiian or Pacific Islander & 0.4 & 6.2 & 0.2 \\
\hline Other & 0.9 & 9.3 & 4.8 \\
\hline Observations & 1043 & & \\
\hline
\end{tabular}

Note: 2016 ACS column reports mean values from the 2016 American Community Survey, except age which is reported as a median. ACS summary of household size includes both family and nonfamily households. 
Table 2.2 DCE attributes and levels

\begin{tabular}{ll}
\multicolumn{2}{c}{ Atlantic Salmon Fillets } \\
\hline Price & 6.49 \\
& 9.99 \\
& 13.49 \\
& 16.99 \\
GM Label & No Label \\
& Organic \\
& Verified Non-GM \\
& GM-Fed \\
& GM \\
& \\
Origin & U.S. \\
& Norway \\
& Chile \\
\hline
\end{tabular}


Table 2.3 Importance of labeling

\begin{tabular}{lccccc}
\hline $\begin{array}{l}\text { How important is it to } \\
\text { label the following food } \\
\text { categories? }\end{array}$ & & & & & \\
Organic & Not at all & Slightly & Moderately & Very & Extremely \\
\cline { 2 - 6 } Non-GM & 9.54 & 13.15 & 20.25 & 32.23 & 24.83 \\
Contains GM Ingredients & 13.27 & 14.73 & 21.27 & 26.15 & 24.59 \\
GM-Fed & 15.77 & 16.07 & 18.5 & 24.15 & 25.51 \\
GM & 17.43 & 15.97 & 19.08 & 23.76 & 23.76 \\
\hline
\end{tabular}

Note: Reported as percentage of respondents selecting given response. 
Table 2.4 Label ranking summary

\begin{tabular}{llcc}
\hline & & Average & \\
Rank & Label Text & Rank & SD \\
\hline 1 & Organic & 1.61 & 0.89 \\
2 & Certified Non-GMO & 1.91 & 0.87 \\
3 & Contains GM Ingredients & 3.00 & 0.82 \\
4 & Produced with Genetic Engineering & 3.24 & 0.97 \\
\hline
\end{tabular}


Table 2.5 Preference for GM/Non-GM food

\begin{tabular}{lccc}
\hline & Frequency & Percent & Cumulative Percent \\
\cline { 2 - 4 } Prefer to eat GM & 166 & 16.15 & 16.15 \\
Prefer to eat Non-GM & 576 & 56.03 & 72.18 \\
I don't care & 28 & 2.72 & 74.9 \\
I don't know & 258 & 25.1 & 100 \\
\hline Total & 1028 & 100 & \\
\hline
\end{tabular}


Table 2.6 Seafood preferences

\begin{tabular}{|c|c|c|c|c|c|c|}
\hline I buy seafood that is... & $\begin{array}{l}\text { Strongly } \\
\text { Disagree }\end{array}$ & Disagree & $\begin{array}{c}\text { Neither Agree } \\
\text { nor Disagree }\end{array}$ & Agree & $\begin{array}{c}\text { Strongly } \\
\text { Agree }\end{array}$ & $\mathrm{N}$ \\
\hline Low priced & 7.02 & 20.98 & 18.54 & 41.27 & 12.2 & 1025 \\
\hline Most fresh & 1.17 & 4.1 & 12.88 & 34.44 & 47.41 & 1025 \\
\hline From USA & 3.33 & 10.87 & 29.68 & 31.93 & 24.19 & 1025 \\
\hline Caught in the wild & 3.41 & 10.54 & 25.07 & 35.9 & 25.07 & 1021 \\
\hline Healthy for me & 1.27 & 4.99 & 15.26 & 41.19 & 37.28 & 1022 \\
\hline Recommended by fish seller & 5.95 & 12.59 & 31.8 & 33.07 & 16.59 & 1025 \\
\hline
\end{tabular}


Table 2.7 Mixed logit results

\begin{tabular}{|c|c|c|}
\hline Fillet Choice & Coefficient & Standard Error \\
\hline \multicolumn{3}{|c|}{ Random parameters in utility functions } \\
\hline No Purchase & $-7.53 * * *$ & 0.54 \\
\hline Price & $-0.29 * * *$ & 0.03 \\
\hline Organic & $0.04 * * *$ & 0.01 \\
\hline Verified Non-GM & $0.66 * * *$ & 0.13 \\
\hline GM-fed & $0.33 * *$ & 0.17 \\
\hline GM & $-0.38 * * *$ & 0.14 \\
\hline Norway & $0.46 * * *$ & 0.15 \\
\hline Chile & $0.38 * * *$ & 0.12 \\
\hline \multicolumn{3}{|c|}{ Positive Information x GM Label } \\
\hline Organic & $0.41 *$ & 0.24 \\
\hline Verified Non-GM & $1.44 * * *$ & 0.26 \\
\hline GM-fed & $0.73 * * *$ & 0.24 \\
\hline GM & $-1.58 * * *$ & 0.33 \\
\hline \multicolumn{3}{|c|}{ Negative Information x GM Label } \\
\hline Organic & $0.5 * *$ & 0.20 \\
\hline Verified Non-GM & $2.71 * * *$ & 0.57 \\
\hline GM-fed & $0.63 * *$ & 0.27 \\
\hline GM & $-1.84 * * *$ & 0.36 \\
\hline \multicolumn{3}{|c|}{ Balanced Information x GM Label } \\
\hline Organic & $0.89 * * *$ & 0.23 \\
\hline Verified Non-GM & $1.74 * * *$ & 0.42 \\
\hline GM-fed & -0.35 & 0.28 \\
\hline GM & $-1.61 * * *$ & 0.32 \\
\hline \multicolumn{3}{|c|}{ Standard deviations of random parameters } \\
\hline No Purchase & $9.12 * * *$ & 0.80 \\
\hline Price & $0.5 * * *$ & 0.03 \\
\hline Organic & $0.05 * * *$ & 0.02 \\
\hline Verified Non-GM & $1.3 * * *$ & 0.23 \\
\hline GM-fed & $1.14 * * *$ & 0.28 \\
\hline GM & $1.06 * * *$ & 0.36 \\
\hline Norway & $1.17 * * *$ & 0.42 \\
\hline Chile & $1.2 * * *$ & 0.20 \\
\hline \multicolumn{3}{|c|}{ Positive Information x GM Label } \\
\hline Organic & $1.51 * *$ & 0.71 \\
\hline Verified Non-GM & $1.58 * * *$ & 0.33 \\
\hline GM-fed & $3.23 * * *$ & 0.55 \\
\hline GM & $3.19 * *$ & 1.26 \\
\hline
\end{tabular}


Table 2.7 (continued) Mixed logit results

Negative Information x GM Label

Organic

$2.1 * * *$

0.36

Verified Non-GM

$5.09 * * *$

0.76

GM-fed

$2.78 * * *$

0.56

GM

$3.32 * * *$

0.45

Balanced Information x GM Label

Organic

$2.74 * * *$

0.37

Verified Non-GM

$4.52 * * *$

0.59

GM-fed

$2.86 * * *$

0.44

GM

$3.86 * * *$

0.75

Log-likelihood

$-4747.6373$

Chi squared [ 184 d.f.]

3797.93401

McFadden Pseudo R-squared

0.2857048

Observations

6050

Note: $* * *, * *, *$ denote significance at $1 \%, 5 \%, 10 \%$ level. Results based on 200 Halton draws. All parameters are assumed to be normally distributed and correlated. 
Table 2.8 Willingness to pay summary

\begin{tabular}{|c|c|c|c|}
\hline & Mean & $\begin{array}{c}\text { 95\% Confidence } \\
\text { Interval }\end{array}$ & $\begin{array}{c}\% \text { Premium } \\
\text { (Discount) }\end{array}$ \\
\hline \multicolumn{4}{|l|}{ Attribute } \\
\hline Organic & 0.15 & {$[0.07,0.23]$} & 1.28 \\
\hline Verified Non-GM & 2.04 & {$[1.71,2.39]$} & 17.38 \\
\hline Fed GM & 0.94 & {$[0.63,1.26]$} & 8.01 \\
\hline GM & -1.04 & {$[-1.29,-0.78]$} & -8.86 \\
\hline Norway & 1.75 & {$[1.42,2.09]$} & 14.91 \\
\hline Chile & 1.29 & {$[1.06,1.52]$} & 10.99 \\
\hline \multicolumn{4}{|c|}{ WTP with Positive Information } \\
\hline Organic & 0.69 & {$[-4.8,6.11]$} & 5.88 \\
\hline Verified Non-GM & 6.89 & {$[1.52,12.30]$} & 58.69 \\
\hline Fed GM & 2.94 & {$[-2.41,8.27]$} & 25.04 \\
\hline GM & -6.32 & {$[-11.62,-0.96]$} & -53.83 \\
\hline \multicolumn{4}{|c|}{ WTP with Negative Information } \\
\hline Organic & 1.74 & {$[-3.51,7.10]$} & 14.82 \\
\hline Verified Non-GM & 10.70 & {$[5.25,16.17]$} & 91.14 \\
\hline Fed GM & 2.81 & {$[-2.67,8.27]$} & 23.94 \\
\hline GM & -8.27 & {$[-13.77,-3.02]$} & -70.44 \\
\hline \multicolumn{4}{|c|}{ WTP with Balanced Information } \\
\hline Organic & 3.15 & {$[-2.05,8.64]$} & 26.83 \\
\hline Verified Non-GM & 7.99 & {$[2.56,13.50]$} & 68.06 \\
\hline Fed GM & -0.97 & {$[-6.46,4.45]$} & -8.26 \\
\hline GM & -7.25 & {$[-12.58,-2.03]$} & -61.75 \\
\hline
\end{tabular}

Note: 95\% Confidence intervals created using 5,000 replications of the Krinsky -Robb procedure.

Bolded values indicate significant at the $5 \%$ level. 
Figure 2.1 Example choice menu

Please select your most preferred option.

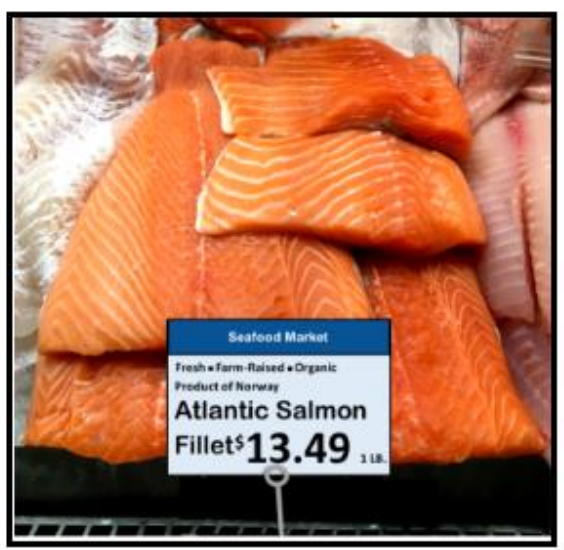

Atlantic Salmon Fillet

Fresh, Farm-Raised, Organic

Product of Norway

$\$ 13.491 \mathrm{LB}$

(

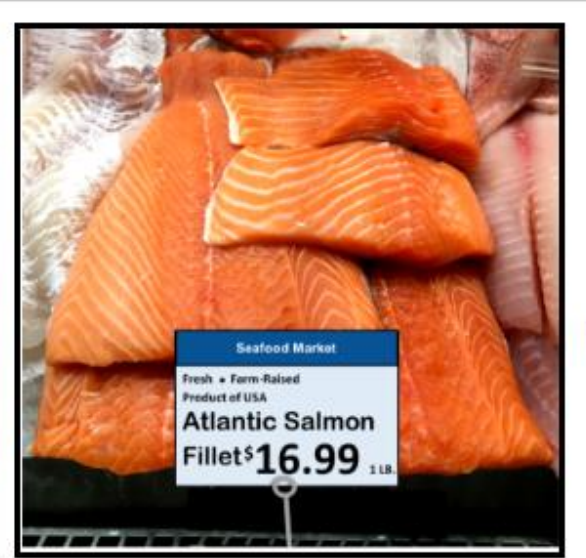

Atlantic Salmon Fillet Fresh, Farm-Raised

Product of USA

$\$ 16.991 \mathrm{LB}$.
If these were my only

options, I would not

purchase salmon

fillets. 
INCORPORATING INDIVIDUAL-LEVEL BEHAVIORAL MEASURES TO

PREDICT CONSUMER PURCHASES IN THE GENETICALLY MODIFIED

SEAFOOD MARKET: AN APPLICATION OF LASSO PENALIZED

REGRESSION

(To be submitted to Sustainability)

By

\author{
Michael J. Weir ${ }^{\text {a }}$ and Thomas W. Sproul ${ }^{\text {a }}$ \\ ${ }^{a}$ Department of Environmental and Natural Resource Economics, University of Rhode \\ Island, Kingston, RI
}

\begin{abstract}
We expand the relatively new body of literature related to prediction policy problems by applying a least absolute shrinkage and selection operator (LASSO) as means of model selection to evaluate the potential effects of the National Bioengineered Food Disclosure Standard. The primary goal of the paper is to develop a predictive model of consumer choice by incorporating overlooked behavioral measures into our choice model. We also provide a methodological contribution by applying a random sampling routine to select a more parsimonious sub-model of the regularized model. Our findings show that 1) health and environmental risk perceptions, confidence and concern about potential health and environmental risks, subjective knowledge, and ambiguity aversion in the domain of GM foods are significant predictors of salmon fillet choice and 2) LASSO-regularized models can be made even more sparse without compromising out of sample fit or prediction accuracy.
\end{abstract}




\subsection{Introduction}

Prediction problems are prevalent and important in policy evaluation studies. New advances in machine learning are increasingly being adapted by economists to investigate these problems (Mullainathan and Spiess 2017; Kleinberg et al. 2015). Machine learning methods excel at addressing these types of problems due to their ability to discover complex data structures that are not specified or known a priori. This is in stark contrast to many applied economic applications focused on parameter estimation and causal inference. Recent applications of machine learning in policy prediction problems include environmental monitoring (Hino, Benami, and Brooks 2018), judicial behavior (Kleinberg et al. 2017), changes in household diet (Hut and Oster 2018; Emily Oster Forthcoming), poverty quantification (Blumenstock 2016; Jean et al. 2016; Blumenstock, Cadamuro, and On 2015), tax policy evaluation (Andini et al. 2018), restaurant hygiene inspections (Kang et al. 2013), and highway procurement auctions (Jung 2019).

We expand this literature by applying LASSO (least absolute shrinkage and selection operator) penalized regression to identify behavioral factors that predict consumer choice in the context of seafood purchases. Specifically, we investigate the potential impact of the forthcoming National Bioengineered Food Disclosure Standard (NBFDS) on demand for Atlantic Salmon. On July 29, 2016 the NBFDS was signed

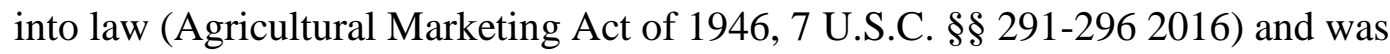
finalized in December 2018. The Standard is set to be fully implemented on January 1, 2020 (Boudreau 2018). As it currently stands, foods containing any of the commercially available GM foods and their derivatives will be subject to disclosure, while small food manufacturers, restaurants, animals fed with GM products, and foods 
certified under the National Organic Program are exempt (Agricultural Marketing Act of 1946, 7 U.S.C. $\S \S 291-296$ 2016). Disclosure will be carried out via written text, a symbol similar to the USDA Organic symbol, or electronically using QR codes. A recent ruling by the Food and Drug administration motivated by the final NBFDS approval, the import ban on GM salmon eggs has been lifted (Blank 2019). This means that production of GM salmon in the United States is likely to begin in the near future with products reaching seafood counters by 2021 (Blank 2018).

Labels presented under current institutions, including the forthcoming NBFDS, act as a signal of quality and safety for consumers (Lusk and Rozan 2008). Generally, the information provided in a food label is expected to be a positive course of action by providing more information than was previously available. However, labels can be ineffective if the information is misperceived (Bonroy and Constantatos 2014). For example, consumers may over-estimate risks related to the labeled product, perceiving the label as a type of warning, resulting in the (unintended) effect of decreased consumption (Marette and Roosen 2011; Lusk and Rozan 2008; Liu, Huang, and Brown 1998). This ineffectiveness can be related to inferential processing on the part of the consumer. From a public policy standpoint, this is undesirable because label interpretation is reliant upon consumers' subjective beliefs (Messer, Costanigro, and Kaiser 2017; Steenkamp 1990).

Studies have shown that risk perceptions, preferences, and other intangible aspects are becomingly increasingly important in consumer food choice (Lusk and Coble 2005; Petrolia 2016; Messer, Costanigro, and Kaiser 2017), but no work has addressed which subjective/behavioral measures are most important. Considering the 
controversy associated with the NBFDS itself and the use of GM technology in food production in general, behavioral measures are likely to have significant influence on the effectiveness of the NBFDS and ultimately consumer choice. Considering the importance of behavioral measures and the forthcoming NBFDS, we have a unique opportunity to explore this policy prediction problem using machine learning techniques. The goal of our study is two-fold.

First, we seek to develop a predictive model of consumer choice by incorporating often-overlooked behavioral measures into our choice model (Lusk and Coble 2005). Inclusion of these data and other "non-conventional" measures is important given the potentially significant effects they can have on predictive accuracy of choice models (Loewenstein 2000). Developing an accurate predictive model that incorporates this data is particularly important in evaluating the potentially unintended consequences of policy interventions such as the NBFDS.

Second, we contribute to the methodology of using machine learning algorithms in policy prediction problems. Using a random sampling routine, we compare prediction performance of the (LASSO-) regularized model with that of a more parsimonious model, what we refer to as the "Intersection" model. If economists are interested in developing predictive models to promote as decision support tools, then balancing model complexity with predictive performance is a critical consideration. Overly complex predictive models may require large amounts of (potentially unavailable) data or may be difficult to implement. If this is the case, then these tools become a barrier to decisions in stark contrast to the goal that motivates their development. 
Our results show that behavioral measures do indeed play an important role in predicting consumer choice. Specifically, we find that risk perception, confidence in risk perceptions and concern about the risks associated with GM technology are the prominent behavioral factors in the health domain. Risk perception, confidence in risk perceptions, and concern are also important behavioral factors in the environmental domain. Both context specific subjective knowledge and ambiguity aversion have a significant influence on consumer choice of salmon fillets. In terms of methodological contributions, we find that models selected by the LASSO can be made still more parsimonious using our intersection approach without compromising out of sample fit or out of sample prediction accuracy.

\subsubsection{Background}

When shopping for food, labels act as signals to consumers (Lusk and Rozan 2008).

GM food labels will act as a signal of quality and safety for consumers deciding on what to purchase. This aligns with groups that advocate for consumer "right to know" about what goes into their food. Generally, information provided via a food label is expected to be a positive course of action, as labels are meant to correct for the lack of information previously available to consumers. In the case of GM foods, labels are desired to as an attempt correct the information asymmetry regarding food production processes of many food products available on the market. Advocates of the NBFDS cite unknown environmental and health consequences of production and consumption of GM products as justification for distinction of GM foods from conventional products as a means of facilitating informed consumer choice. The most prevalent issues in the discussion are unanticipated allergic responses, spread of pest resistance 
or herbicide tolerance to wild plants, and inadvertent harm to wildlife (Curtis, McCluskey, and Wahl 2004). Aside from the tangible risks often associated with GM products, other studies have shown moral acceptability to be a significant predictor for the encouragement of biotechnology applications (Amin et al. 2014; Gaskell et al. 2004)

Bonroy and Constantatos (2014) note that labels can be less effective at fixing the lack of information issue given consumer misperceptions of the information provided by the label. One form of misperception can be an over- or under- estimation of risks or benefits related to a product attribute (Marette and Roosen 2011). This type of misperception is related to what Lusk and Rozan (2008) call the "red flag effect" and is attributed to (undesired) inferential processing on the part of the consumer (Messer, Costanigro, and Kaiser 2017; Steenkamp 1990). If one considers the varying attitudes and opinions as an alternate form of "advertising" for GM foods, it becomes clear that this ambiguous advertising may influence consumer evaluation of GM product safety and quality, and ultimately the magnitude of the "red flag" effect (Hoch and Ha 1986).

As is the case with GM foods, lack of information related to a specific decision or choice may lead to ambiguity in the consumer's evaluation of the probability of an outcome, such as health or environmental impacts of GM food consumption. This transformation of information ambiguity to probability ambiguity can influence individual decision-making (Snow 2010). Even in the context of food-borne pathogens, few consumers know the odds of becoming ill from it and many consumers have ill-formed beliefs about their chances of actually becoming ill from a food-borne 
pathogen (Kivi and Shogren 2010). Further, when individuals seek out information in an attempt to gain more information on a topic, there is seldom consensus among interest groups or between lay people and the scientific community, particularly regarding GM foods as mentioned above (Viscusi, Magat, and Huber 1999).

It is common in situations of uncertain origin or outcome that lay peoples' risk perceptions will differ from expert provided technical risk estimates (Kaptan, Fischer, and Frewer 2018; Hansen et al. 2003). We know from the works discussed above that this difference in perception hinders the effectiveness of expert provided information meant to alleviate the information asymmetry (Frewer et al. 1997). We conjecture that the contrasting states of knowledge among interest groups and ultimately the information available to consumers, plays a significant role in driving consumer aversion to genetically modified food products. Given the lack of consensus on the consequences of genetic modification, we argue that this may reinforce consumer aversion to GM technology in food, and thus ambiguity aversion drives preferences for GM food and demand for a labeling regime such as NBFDS.

It is a natural extension to discuss risk perceptions along with ambiguity preferences in the evaluating the effectiveness of the NBFDS as these measures are often overlooked in explaining consumer demand for food products (Lusk and Coble 2005). However, assessing risk perceptions' effect on consumer choice can be difficult as comprehensive measurement of risk perception is not trivial.

Risk perception as a concept is multidimensional, meaning that a single question on a survey may not capture all the nuances of individual risk perception (van der Linden 2017; Meagher 2018; Hansen et al. 2003; Slovic 1999). A large body of 
work exists in the risk communication field focused on measuring risk perceptions in the context of climate change. Van der Linden (2017) discusses the fact that while the public might perceive some long-term changes in long-term climate conditions, psychological factors are often much more influential in determining public perception of climate change risk. We utilize a framework proposed in van der Linden (2017) to measure and interpret our results. This framework breaks down risk perception into a hierarchy of components which allows us to identify the relative importance of each component of risk perception in explaining consumer demand for GM salmon under the NBFDS.

\subsection{Data}

\subsubsection{Sample Characteristics}

We recruited 1,041 survey participants via Amazon Mechanical Turk (denoted "Mturk"). Mturk workers with greater than zero approved tasks, task approval rating greater than $97 \%$, and located in the United States saw the survey announcement for a "20-minute Academic Study". Our final sample consists of a diverse group of respondents from every state in the United States aside from Delaware, Table 3.1 provides sample summary statistics. Compared to the most recent American Community Survey (United States Census Bureau 2017a, 2017b, 2017c), our sample differs from the general population of the United States primarily in gender distribution (40.1\% female compared to $50.8 \%$ in the ACS) and educational attainment (60\% with Bachelor's degree or higher compared to $31.2 \%$ in the ACS), consistent with previous summaries of the Mturk population (Goodman and Paolacci 2017). We consider our sample to be sufficiently representative of U.S. seafood 
consumers given our screening criteria, acknowledging these previously identified nuances of the Mturk population.

We have further confidence in considering our sample to be sufficiently representative of the U.S. seafood consumers based on their prior preferences and attitudes related to GM food technology. Between $50-60 \%$ of our sample believe it is either "Very Important" or "Extremely Important" to label each of Organic, Non-GM, Contains GM ingredients, GM-fed, and GM food products (Table 3.3). This is representative of the general sentiment of consumer "right to know" movements and use of information regarding food production methods identified in various academic work as well as independent polls. For example, a Pew Research Center poll (2016) found that $89 \%$ of respondents $(n=1,480)$ believe the general public should play at least a minor role in making policy decisions related to GM foods, while $40 \%$ of respondents believe the news media does not take the health risks of GM foods seriously enough.

As an alternate means of capturing prior preferences related to production process labeling, participants were asked to rank four food labels based on likelihood of purchasing a product displaying each label: Organic, Certified Non-GMO, Contains GM Ingredients, and Produced with Genetic Engineering. As we expected based on the prior preferences summarized above, participants ranked Organic as most likely to be purchased, followed by Certified Non-GMO, Contains GM ingredients, and Produced with Genetic Engineering. We did allow participants to rank multiple labels equally to indicate indifference. The rankings are indicative of an association between 
Organic and Certified Non-GMO labels and Contains GM Ingredients and Produced with Genetic Engineering labels as evidenced by their relative average rankings. As we are studying GM food labels in the context of seafood, we also had participants rate their seafood purchase habits on a five-point Likert scale to indicate level of agreement with statements about seafood. As expected, based on prior literature, participants have a general preference for seafood that is wild-caught, domestic, lowpriced, freshest, and healthy for them.

\subsubsection{DCE and Survey Design}

We designed a discrete choice experiment (DCE) to simulate seafood purchase scenarios for fresh, farmed Atlantic Salmon fillets and canned, farmed Atlantic Salmon with different labels denoting presence or absence of genetic modification, country of origin, and price. The survey instrument also asked respondents questions about their food consumption habits, general attitudes toward food and technology, and specific attitudes toward GM foods. Table 3.2 summarizes the levels of each product attribute used in our DCE, which were chosen based on previous literature and current market conditions. Participants were randomly assigned to one of four information treatment groups that differed in support of GM technology in food production. The positive (negative) information groups received information generally supportive (disapproving) of GM technology. The balanced treatment is a combination of both the positive and negative information treatments. The control group received no further information.

We used a full factorial design with each respondent answering a total of six salmon fillet choices. Due to the large number of total choices $(4 \times 5 \times 3=60$ total 
combinations for salmon) we blocked our choice sets to reduce the cognitive burden on our participants. The design was created in STATA version 13 with the userwritten program dcreate ${ }^{6}$ (StataCorp 2013; Hole 2015). Each respondent was randomly assigned to one choice set block. Each choice question had two choice alternatives plus a no purchase option. The order of each question in a given block was randomized for each participant. Figure 3.1 is an example fillet choice set.

\subsubsection{Behavioral measures}

Prior to seeing the choice scenarios, participants answered questions regarding their knowledge level and risk perceptions related to GM technology. We refer to this series of questions as "behavioral measures" (including our ambiguity aversion measure discussed below). The questions specifically addressed participants'1) knowledge level about the facts and issues associated with GM technology, 2) risk perception of GM foods relative to foods produced without GM, 3) confidence in risk perception, and 4) concern-level about potentially negative impacts of GM foods. Specifically, the risk perception series of questions was presented as follows:

1) How much do you agree with the following statement?

GM foods pose a greater (health/environmental) risk than foods produced without GM technology.

2) How confident are you in your answer to the previous question?

3) How concerned are you about GM foods leading to negative [health, environmental] impacts?

\footnotetext{
${ }^{6}$ Assuming naïve priors and including an alternative specific constant for the opt-out alternative, our design has a D-error of 0.237 assuming only a main effects model. Assuming an interaction effect between the GM label and country of origin our design has a D-error of 0.484 .
} 
This series was asked separately for the health and environmental domains. The risk perception series and self-reported knowledge level were measured on a five-point Likert scale.

We elicited this specific series of behavioral measures to capture the relationship between these variables in a similar manner as van der Linden (2017). In their work, van der Linden developed a "hierarchy of concern" (HoC) model to conceptualize public perception of climate change similar to Maslow's "hierarchy of needs" framework for human motivation. The HoC establishes a transitive relationship between likelihood of an event, perceived seriousness, general concern, and personal worry. For reasoning similar to the climate change case, an individual may think that effects of consuming and/or producing genetically modified foods are likely to occur, but that does not imply that they perceive the issue to be serious. The relationship between each level of the hierarchy is comparable to the example above. The transitivity axiom is not a necessary condition for this framework to remain a useful tool for conceptualizing risk perceptions of genetic modification, climate change, or other issues. Figure 3.2 presents a pictorial representation of the hierarchy measured for our study.

The highest level in the HoC is personal worry. This level distinguishes concern at a societal versus a personal level. This distinction can be important as individuals often exhibit optimism bias in which they overestimate the likelihood of positive life events and underestimate the likelihood of negative events. The resulting bias translates into overestimates of risk perceptions if measures only rely on single question to capture concern level. Since we are not interested in analyzing the specific 
level of public concern about the risks of GM technology, we opted to only use a single-question measure of concern and personal worry levels. We purposely used a concern measure that could be subjectively interpreted as a means of capturing an overall level of concern about the risks of GM technology rather than only societal- or personal-level concern.

We are also interested in establishing the relationship food purchases have with subjective knowledge and ambiguity aversion. The relationship between subjective knowledge and ambiguity aversion was proposed and tested in Fox and Tversky's (1995) comparative ignorance hypothesis. The authors' work concludes that as subjective knowledge (how knowledgeable you feel about a topic) increases, so too does ambiguity aversion. A related explanation lies in Heath and Tversky’s (1991) competence hypothesis. Costa-Font (2013) formally tests the link between these variables in the context of three food scares, which included GM food technology. One important result is the confirmation of subjective knowledge having a positive and significant effect on ambiguity aversion in line with the results of Fox and Tversky (1995) and Heath and Tversky (1991).

\subsubsection{Ambiguity aversion elicitation}

Along with the behavioral measures outlined above, we elicited participants' aversion to ambiguity. We developed a domain-specific ambiguity aversion elicitation mechanism as there is evidence that effects of behavioral measures could depend on how measures are elicited (Petrolia 2016). Specifically, participants iterated through a series of choice menus that asked them to make a choice between a salmon fillet with

a known chance of being GM and a fillet with an unknown chance of being GM. This 
method was developed as an adaption of that used by Dimmock, Kouwenberg, Mitchell, and Peijnenburg (2015). Figure 3.3 presents an example "lottery" menu. We are aware of only one other work that that framed an ambiguity measure in the context of a specific food product or category (Costa-Font 2013). The measure used by CostaFont relied on a single question that was asked participants to choose a country to live in (Country A or Country B) based on known or vague information about deaths associated with bovine spongiform encephalopathy. This was adapted from a measure used by Viscusi (1997).

We truncated the tails of the distribution for elicitation purposes based on discussions with colleagues that have used this elicitation method in similar applications. Thus, our measure falls in the range $[.15, .85]$ rather than $[0,1.0]$. The menus were designed in the loss frame based on current negative perceptions of GM technology. Participants are ambiguity averse if $\alpha$, the individual level ambiguity aversion parameter, is greater than 0.5 . Based on this definition, $26.65 \%$ of our sample is considered ambiguity averse. Figure 3.4 presents the distribution of $\alpha$ in our sample.

\subsection{Methodology}

\subsubsection{Mixed Logit}

Since every choice elicitation includes a no-purchase option in addition to the two fillets, we consider multinomial logit models to estimate choice. A random-parameters logit framework relaxes the independence assumption necessary in a traditional multinomial logit. This framework allows us to appropriately account for the panel structure of our data, in which choice errors may not be independent within 
individuals. The model accounts for the panel structure by including a random intercept term for each participant and participant-choice set combination. All other covariates are specified as fixed effects (i.e., non-random effects, not to be confused with dummy variables used in fixed effects regression). Our empirical specification includes a total of 192 covariates that include an alternative specific constant (ASC) for the no-purchase alternative, choice set attributes (price, country of origin, and GM label; described in Table 3.2), and interactions of the behavioral measures with all choice set attributes.

\subsubsection{LASSO Penalized Regression}

We use the LASSO L1-regularization to select the most important behavioral measures for predicting participant choices (Hastie, Tibshirani, and Friedman 2009). Since these measures are correlated, the selection of a sparse model is based on the explicit assumption that there is a subset of our measures that is more important in predicting choice behavior. We follow Huseynov, Kassas, Segovia, and Palma (2018) to reformulate the LASSO in a logit framework.

All independent measures are standardized prior to estimating a maximum binomial likelihood to fit the LASSO to our training data. Specifying an individual's non-selection probability as $p\left(x_{i t}\right)=\operatorname{Pr}\left(y_{i t}=0 \mid X_{i t}\right)$, we maximize the following loglikelihood:

$$
\max _{\beta}\left[\frac{1}{N} \sum_{i=1}^{N}\left\{I\left(y_{i t}=0\right) \log p\left(x_{i t}\right)+I\left(y_{i t}=1\right) \log \left(1-p\left(x_{i t}\right)\right)\right\}-\lambda\|\beta\|_{\ell_{1}}\right] .
$$

We ran 100 iterations of a modified two-fold cross-validation LASSO routine to confirm the stability of the optimal tuning parameter. Each iteration used a randomly 
selected 50-50 split (permutation) of the full data into training and test data sets. This split for cross validation routines has been shown to be optimal for a broad class of loss functions independent of the data distribution, and particularly in the case of classification via logistic regression (Afendras and Markatou 2015, working paper). For each replication, the LASSO was fit on the training data and out-of-sample loglikelihood (OOSLL) was calculated using the test data. We fit 22 values of lambda ranging in penalty strength. This range is slightly smaller relative to other applications and defaults of popular software packages that typically evaluate 30-100 values of the tuning parameter, see for example Friedman, Hastie and Tibshirani (2010). We decided to focus our attention on this range of candidate tuning parameters based on preliminary analysis conducted using this data set. For each iteration and value of the tuning parameter, we recorded 1) variable selection, 2) in-sample Bayesian Information Criteria (BIC), and 3) OOSLL. The OOSLL values we report are calculated using the regularized model, in which the regression betas represent maximum a posteriori estimates given a Laplacian prior (Tibshirani 1996).

We used the results from the routine described above to select the optimal tuning parameter, $\lambda^{*}$, based on average OOSLL and mean prediction accuracy across the replications. Once we determined the optimal tuning parameter, $\lambda^{*}$, we re-ran the LASSO on our full data set with that penalty term to generate the list of covariates with non-zero coefficient estimates. This set of covariates was used to estimate a naïve post-LASSO model fit, discussed below, to conduct inference on the effect of these covariates on seafood purchase decisions. We account for the use of this naïve postLASSO inference method using bootstrapped standard errors based on 100 bootstrap 
replications. Below, we discuss the variables selected by this procedure in order to identify the important behavioral measures for consumer purchasing of GM seafood.

In addition to the above, we use the results of our resampling routine to specify a more parsimonious model than that of the cross-validated LASSO. Specifically, we are interested in evaluating the performance of LASSO in balancing bias and variance by considering how well it balances parsimony and complexity. We evaluate this balance by using the results of our replication analysis to specify an "intersection" model, specified by taking the intersection of covariates with non-zero betas after regularization across all 100 iterations.

\subsection{Results}

All models were fit implementing the R package glmmLasso (Groll 2017; R Core Team 2018). We utilized Elastic Cloud Computing instances on Amazon Web Services to alleviate computing constraints. Based on the results of our replication analysis, the optimal tuning parameter is $\lambda^{*}=100$. Figure 3.5 plots the average OOSLL for each value of the tuning parameter we tested. Figure 3.6 plots average prediction accuracy at each value of the tuning parameter tested in our resampling analysis.

The fitted model includes 155 covariates after LASSO regularization using $\lambda^{*}$, denoted Lasso* in the text and figures to follow. The Intersection model includes only 98 covariates, as the remaining 57 covariates appeared only in some of the models generated by our resampling scheme, but not all. This list of 98 covariates is a perfect subset of the 155 covariates retained in the Lasso* model. Table 3.3 summarizes the 
included covariates for direct effects and provides counts of behavioral measure interactions included in each approach.

Prior to presenting our findings, a discussion about inference in regularized regression is necessary. In an application such as ours where regularized regression is used for variable selection, we are using the data to sparse a full set of covariates into a sub-model that was not known or specified a priori. The problem arises due to the fact that when fitting the sub-model for the purposes of inference, we are looking at the data twice: once to determine the sub-set of covariates and once to test hypotheses (Zhao, Shojaie, and Witten 2017, working paper). There are a variety of methods proposed to deal with this selection bias like sample-splitting (Cox 1975), simultaneous inference (Berk et al. 2013), exact post-selection inference methods (Lee et al. 2016; Tibshirani et al. 2016), as well as double-selection methods (Belloni, Chernozhukov, and Hansen 2013). All of these methods account for the regularization procedure to compute adjusted p-values, conditional on the particular sub-model being selected. Under certain conditions, the naïve post-LASSO inference approach that simply refits the sparse model on the full data set not accounting for regularization can provide valid p-values and confidence intervals (Zhao, Shojaie, and Witten 2017, working paper).

All the selective inference approaches mentioned above have been developed and validated in the context of models that assume only fixed (non-stochastic) parameter estimates. We are unaware of developments in the selective inference literature that address the case of selective inference issues in mixed models, as is the case for our work. It would be ideal to compute adjusted p-values and confidence 
intervals conditional on the regularization routine. However, given the lack of available methods for computing adjusted p-values and confidence intervals in the case of regularized mixed models, we are limited in the way we handle selective inference in our case. Thus, we report bootstrapped standard errors for each coefficient in our final models to account for potential issues associated with selection bias that is inherent in using a feature selection tool like LASSO. Bootstrapping standard errors, under the assumption that our empirical model is correct, allows us to quantify the uncertainty associated with our parameter estimates.

While we rely on a naïve post-LASSO approach outlined in the literature, we are confident in the validity of the inference given our relatively large sample size in relation to the number of considered covariates. In addition, we are not concerned with issues of endogeneity of our treatment conditions (GM labels) based on the fact that choice question blocks were randomly assigned to participants. This is the primary issue considered by Belloni, Chernozhukov, and Hansen (2013). We did evaluate the correlation between our controls and choice question assignment and found no evidence of statistically significant correlations. Any significant correlation observed would be spurious given the random assignment of choice question blocks.

\subsubsection{Model fit}

In terms of comparing overall model fit between the approaches, Figures 3.5 and 3.6 summarize the average OOSLL and average out of sample predication accuracy for each value of the tuning parameter. Prediction accuracy was determined by comparing predicted alternative choice and actual alternative choice for each participant-choice set pair. Predicted alternative choice was determined using the highest predicted 
choice probability among alternatives from each iteration of the resampling procedure and at each level of the penalty term. The prediction accuracy is the percent of correct predictions at each step in the resampling routine.

The data points associated with the optimal model and the Intersection model are marked by a diamond and X, respectively, in both Figures 3.5 and 3.6. The takeaway from these figures is that determining a sub-model covariate list by replicating the regularization procedure does not compromise out of sample fit and, in fact, can improve both out of sample model fit and out of sample prediction accuracy. Difference of means tests were conducted using the results of our resampling scheme as data. Both OOSLL and out of sample prediction accuracy were significantly improved between the two approaches $(p<0.001)$. Though the extra prediction accuracy gained from $55.8 \%$ to $56.5 \%$ may not be economically significant, this is a sizeable gain in prediction accuracy in comparison to the null model. Accounting for the fact that $13.7 \%$ of choices in our data were no-purchase decisions, there is a $43.15 \%$ chance one of the purchase alternatives would be selected by random chance. The fact that we are able to accurately predict approximately $56 \%$ of choices in our data set while simultaneously considering both the purchase and no-purchase alternatives is a substantial improvement over the null model.

\subsubsection{Behavioral Measures}

As shown in Table 3.3, the regularized model fit on the full data set retained all of the direct effect attribute levels aside from the GM label attribute. The Intersection model followed the same pattern while also excluding the Chile label attribute. All behavioral measures were retained in some form in both modeling approaches which is an early 
indication of their importance in explaining consumer choice in the context of GM seafood. Tables 3.4 and 3.5 present the covariates with coefficient estimates significant at the 99\% level based on bootstrapped standard errors for the Lasso* and Intersection model, respectively. This subset of covariates is materially the same whether or not we consider bootstrap standard errors. All covariates were standardized prior to model fitting. As such, we can directly interpret the magnitude of each coefficient as a measure of relative signal strength. We acknowledge that focusing only on covariates with $99 \%$ significance is an arbitrary decision. However, due to the large number of implicit hypothesis tests ( 155 for the Lasso* model and 98 for the Intersection model) inherent in our analysis we only dedicate time to this subset. The interested reader is encouraged to contact the authors for further additional summary figures.

The first notable result in both modeling approaches is the significant and negative coefficient on fillet price, which is evidence our participants made rational choices among the choice alternatives (yay economics!). In terms of the other direct effect variables, we find results consistent with previous findings. Participants prefer salmon fillets that are Verified Non-GM while they dislike Fed-GM fillets. We also find that participants dislike imported salmon fillets relative to domestic based on the negative coefficients on the Norway and Chile attribute indicators. We now consider the significant behavioral interactions in the Lasso* and Intersection models by category.

\section{Health domain}


We first focus on the Lasso* model. In the health domain, concern about the health risks associated with GM technology is present in two of the four significant interactions. As concern level increases, Fed-GM labeled fillets become less attractive to consumers. A related observation is that concern level makes the no-purchase option more attractive. This would imply that consumers would rather not buy salmon fillets at all as their concern about the health risks of GM technology increased. Similarly, confidence in health risk perception makes the no-purchase option more attractive. Confidence in health risk perception level also increases the likelihood of purchasing Organic salmon for those in the positive information treatment. This is somewhat unexpected as the information provides benefits of using GM technology in food production. However, we believe the confidence in risk perception is the driving force behind this effect. This is indicative of substitution away from GM salmon given strong prior confidence in health risk perceptions.

The prominent story for the health domain interactions in the Intersection model is their relationship with the no-purchase option. All of increased risk perception, confidence and concern about the health risks of GM make the nopurchase option more attractive. Concern about health risks decreases the likelihood of purchasing both Fed-GM and GM fillets, consistent with our sample's prior preferences.

\section{Environment domain}

In the environment domain, risk perception decreases the likelihood of purchasing a Fed-GM or GM fillet given the balanced information treatment. The fact that balanced information could not override the effects of prior risk perceptions provides further 
support for the negativity bias related to food technology identified in previous works (Mizerski 1982; Kahneman, Knetsch, and Thaler 1991). The result that the interaction of confidence in environmental risk perception makes Organic fillets less attractive for those in the balanced information treatment could be driven by those that are confident GM foods do not pose environmental risks. The justification for this interpretation is the fact that we are able to separate risk perception from confidence in the risk perception under the framework of the HoC. Specifically, higher confidence in risk perception does not necessarily imply a graver risk assessment.

Turning to the Intersection model, we see that increased confidence in environmental risk assessment of GM foods makes the no purchase alternative less attractive in contrast to the same interaction in the health domain. This effect is also present in the Lasso* model. This may be evidence that health risks are more salient on a personal-level, while environmental risks are more salient on a societal-level providing an exhibition of optimism bias as described by van der Linden (2017). We also see that the interaction of confidence in environmental risk perception makes Organic fillets less attractive for those in the balanced information treatment as in the full Lasso* specification. Lastly, concern about environmental risks makes Fed GM fillets more attractive. We believe this could be related to the definition used for the Fed-GM attribute which mentioned that salmon farmers use plant-based protein alternatives to reduce pressure on wild-caught species used for fish feed.

\section{Subjective knowledge}

There are two interactions with subjective knowledge included in the Lasso* model. We find a significant and positive effect of subjective knowledge on purchase 
likelihood of Fed-GM fillets, while subjective knowledge decreases the likelihood of selecting the no-purchase alternative. This second effect is also present in the Intersection model. As subjective knowledge about GM technology in food production increases, so does likelihood of purchasing products in this category. Similarly, if consumers feel knowledgeable about GM technology in food, they perceive no or minimal information asymmetry about these food products and feel more confident making decisions that involve them. We consider these results consistent with the motivation behind "consumer right to know" campaigns.

\section{Ambiguity Aversion}

Domain specific ambiguity aversion significantly increases the likelihood of purchasing Fed-GM salmon. If you are more competent or consider yourself more competent about GM technology in food, then you are more ambiguity averse in the domain of GM food. Thus, you prefer "betting" on purchases you are familiar with or feel knowledgeable about. If you know a product is not GM with certainty, then all bets are off. This ties directly back to the subjective knowledge measures, as we know from the literature that these measures increase together, specifically in this domain (Costa-Font 2013). An alternate phrasing of the results uses the definition of an ambiguity-averse individual. As individual ambiguity aversion increases, so does the probability of losses they are willing to accept to avoid making a decision with an ambiguous outcome. So, ambiguity aversion in the GM domain implies that an individual would rather buy a fillet with a known high probability of being GM than a fillet with an unknown probability of being GM. 


\subsection{Discussion and Conclusion}

We find that behavioral measures do play an important role in predicting consumer choice of seafood products. Specifically, we find that health and environmental risk perceptions, confidence and concern about potential health risks, confidence and concern about environmental risks, subjective knowledge, and ambiguity aversion have a significant influence on consumer choice of salmon fillets. In the context of van der Linden's Hierarchy of Concern framework, we see that risk perception, confidence, and concern about the risks associated with GM technology are the prominent behavioral factors in both the health and environment domain. Both context specific subjective knowledge and ambiguity aversion promote consumption of FedGM labeled salmon fillets, which is consistent with the competence hypothesis (Heath and Tversky 1991) and comparative ignorance hypothesis (Fox and Tversky 1995).

Our results show that familiarity with GM technology is an important component of demand for GM seafood, as well as the ultimate efficacy of the NBFDS at addressing the information asymmetry issue in the market for GM seafood. Further, we provide evidence that familiarity with the use of GM technology in food can promote consumption of these products. On the other side of this, however, is the fact that concern and confidence about the potential health and environmental risks associated with GM technology can push consumers out of the salmon market all together. These results indicate that while labels under the NBFDS can effectively promote informed consumer choice, the labels might unintentionally reduce overall salmon consumption, which is problematic given the already low levels of seafood consumption in the United States. This is particularly relevant given the recent lift of 
the import ban on AquaAdvantage salmon eggs and large-scale production of the product.

In light of these findings, it is all the more pressing that future work focuses on using empirical techniques, like machine learning, to better understand how behavioral measures might lead to perverse outcomes of the NBFDS. We see strong opportunity to utilize available data sets such as those associated with the Eurbarometer and/or Pew Research Center surveys as a means of feasibly investigating this issue. Some additional considerations to explore as behavioral predictors might include measures of cultural cognition and social norms as they relate to scientific communication and public policy (Kahan, Jenkins-Smith, and Braman 2011). These analyses will continue to build evidence in support of incorporating "non-conventional" data in models to improve predictive performance (Huseynov et al. 2018).

In terms of modeling approaches, we have shown that behavioral factors must be considered in a decision aid should the goal be to predict consumer choice and evaluate potential policy implications. Our results provide evidence that models determined by LASSO regularization can be further reduced in dimension without harming out of sample fit or out of sample prediction (see Table 3.3 and Figures 3.5 and 3.6). In fact, this further reduction in dimension results in improved out of sample model fit and prediction accuracy. If machine learning techniques are to be used to develop decision support tools for policy makers, then careful consideration should go into the development of these decision aids. If prediction is the aim, the Intersection approach investigated within this work could be a more reasonable tool for policy makers to use in decision making given it is a more parsimonious sub-model of the 
full set of covariates relative to the Lasso* model. We also deem this approach more reasonable given its inherently reduced data requirement.

Regardless of the approach adopted, these models can only be as effective as the data available to decision makers. The European Union (EU) conducts the annual Eurobarometer to assess public opinion on various topics ranging from trust in national government to consumer habits regarding fishery and aquaculture products. A triennial special topic survey focuses on public perception of biotechnology in the EU and a variety of studies have used the publicly available data set to infer public perception of GM foods (Gaskell et al. 2004; Gaskell, Hohl, and Gerber 2017). In the United States, the Pew Research Center conducts similar public surveys and provides data sets for public use.

We propose that these data sources be more thoroughly utilized by policy makers to address the policy prediction problem associated with food process labels. Using these data with a model selection approach like LASSO can help to tease out important behavioral considerations that, as we have shown, are important in consumer decision making in the seafood market and can aid in targeting policy initiatives or strategizing business plans more effectively. 


\section{References}

Afendras, Georgios, and Marianthi Markatou. 2015. "Optimality of Training/Test Size and Resampling Effectiveness of Cross-Validation Estimators of the Generalization Error.” ArXiv:1511.02980 [Math, Stat], November. http://arxiv.org/abs/1511.02980.

Amin, Latifah, Md. Abul Kalam Azad, Mohd Hanafy Gausmian, and Faizah Zulkifli. 2014. "Determinants of Public Attitudes to Genetically Modified Salmon." PLOS ONE 9 (1): e86174. https://doi.org/10.1371/journal.pone.0086174.

Andini, Monica, Emanuele Ciani, Guido de Blasio, Alessio D'Ignazio, and Viola Salvestrini. 2018. "Targeting with Machine Learning: An Application to a Tax Rebate Program in Italy.” Journal of Economic Behavior \& Organization 156 (December): 86-102. https://doi.org/10.1016/j.jebo.2018.09.010.

Belloni, A., D. Chen, V. Chernozhukov, and C. Hansen. 2012. "Sparse Models and Methods for Optimal Instruments With an Application to Eminent Domain." Econometrica 80 (6): 2369-2429. https://doi.org/10.3982/ECTA9626.

Belloni, Alexandre, Victor Chernozhukov, and Christian Hansen. 2013. "Inference on Treatment Effects after Selection among High-Dimensional Controls $\uparrow . "$ The Review of Economic Studies 81 (2): 608-50. https://doi.org/10.1093/restud/rdt044.

- 2014. "High-Dimensional Methods and Inference on Structural and Treatment Effects." Journal of Economic Perspectives 28 (2): 29-50. https://doi.org/10.1257/jep.28.2.29.

Berk, Richard, Lawrence Brown, Andreas Buja, Kai Zhang, and Linda Zhao. 2013. "Valid Post-Selection Inference." The Annals of Statistics 41 (2): 802-37. https://doi.org/10.1214/12-AOS1077.

Blank, Christine. 2018. "GE Salmon Advancing in the US with FDA's Blessing." Seafood Source. May 1, 2018. https://www.seafoodsource.com/news/aquaculture/ge-salmon-advancing-inthe-us-with-fda-blessing. (accessed May 1, 2018).

- 2019. "FDA Lifts Import Alert on GE Salmon, Clears Way for AquaBounty." Seafood Source. March 8, 2019. https://www.seafoodsource.com/news/supplytrade/fda-lifts-import-alert-on-ge-salmon-clears-way-for-aquabounty. (accessed March 8, 2019).

Blumenstock, Joshua. 2016. "Fighting Poverty with Data.” Science 353 (6301): 753. https://doi.org/10.1126/science.aah5217. 
Blumenstock, Joshua, Gabriel Cadamuro, and Robert On. 2015. "Predicting Poverty and Wealth from Mobile Phone Metadata.” Science 350 (6264): 1073. https://doi.org/10.1126/science.aac4420.

Bouchouicha, Ranoua, Peter Martinsson, Haileselassie Medhin, and Ferdinand M. Vieider. 2017. "Stake Effects on Ambiguity Attitudes for Gains and Losses." Theory and Decision 83 (1): 19-35. https://doi.org/10.1007/s11238-016-95855.

Boudreau, Catherine. 2018. "USDA Eyes Dec. 1 for Final GMO Labeling Rule." POLITICO Pro (blog). September 14, 2018. https://www.politicopro.com/ (accessed November 16, 2018)

Cox, D. R. 1975. “A Note on Data-Splitting for the Evaluation of Significance Levels." Biometrika 62 (2): 441-44. https://doi.org/10.2307/2335385.

Curtis, Kynda R., Jill J. McCluskey, and Thomas I. Wahl. 2004. "Consumer Acceptance of Genetically Modified Food Products in the Developing World." AgBioForum 7 (1 \& 2): 70-75.

Dimmock, Stephen G., Roy Kouwenberg, Olivia S. Mitchell, and Kim Peijnenburg. 2015. "Estimating Ambiguity Preferences and Perceptions in Multiple Prior Models: Evidence from the Field." Journal of Risk and Uncertainty 51 (3): 219-44. https://doi.org/10.1007/s11166-015-9227-2.

Emily Oster. Forthcoming. "Diabetes and Diet: Purchasing Behavior Change in Response to Health Information." American Economic Journal: Applied Economics.

Fox, Craig R., and Amos Tversky. 1995. "Ambiguity Aversion and Comparative Ignorance*." The Quarterly Journal of Economics 110 (3): 585-603. https://doi.org/10.2307/2946693.

Frewer, Lynn J., Chaya Howard, Duncan Hedderley, and Richard Shepherd. 1997. "The Elaboration Likelihood Model and Communication About Food Risks." Risk Analysis 17 (6): 759-70. https://doi.org/10.1111/j.15396924.1997.tb01281.x.

Friedman, Jerome H., Trevor Hastie, and Rob Tibshirani. 2010. "Regularization Paths for Generalized Linear Models via Coordinate Descent." Journal of Statistical Software; Vol 1, Issue 1 (2010), February. https://www.jstatsoft.org/v033/i01.

Gaskell, George, Nick Allum, Wolfgang Wagner, Nicole Kronberger, Helge Torgersen, Juergen Hampel, and Julie Bardes. 2004. "GM Foods and the Misperception of Risk Perception." Risk Analysis 24 (1): 185-94. https://doi.org/10.1111/j.0272-4332.2004.00421.x. 
Gaskell, George, Katrin Hohl, and Monica M. Gerber. 2017. "Do Closed Survey Questions Overestimate Public Perceptions of Food Risks?” Journal of Risk Research 20 (8): 1038-52. https://doi.org/10.1080/13669877.2016.1147492.

Goodman, Joseph K., and Gabriele Paolacci. 2017. "Crowdsourcing Consumer Research.” Journal of Consumer Research 44 (1): 196-210. https://doi.org/10.1093/jcr/ucx047.

Groll, Andreas. 2017. "GlmmLasso: Variable Selection for Generalized Linear Mixed Models by L1-Penalized Estimation" R package version 1.5.1. https://CRAN.R-project.org/package=glmmLasso.

Hansen, Janus, Lotte Holm, Lynn Frewer, Paul Robinson, and Peter Sandøe. 2003. "Beyond the Knowledge Deficit: Recent Research into Lay and Expert Attitudes to Food Risks." Appetite 41 (2): 111-21. https://doi.org/10.1016/S0195-6663(03)00079-5.

Hastie, Trevor, Robert Tibshirani, and J. H. Friedman. 2009. The Elements of Statistical Learning: Data Mining, Inference, and Prediction. 2nd ed. Springer Series in Statistics. New York, NY: Springer.

Heath, Chip, and Amos Tversky. 1991. "Preference and Belief: Ambiguity and Competence in Choice under Uncertainty." Journal of Risk and Uncertainty 4 (1): 5-28. https://doi.org/10.1007/BF00057884.

Hino, M., E. Benami, and N. Brooks. 2018. "Machine Learning for Environmental Monitoring." Nature Sustainability 1 (10): 583-88. https://doi.org/10.1038/s41893-018-0142-9.

Hoch, Stephen J., and Young-Won Ha. 1986. "Consumer Learning: Advertising and the Ambiguity of Product Experience." Journal of Consumer Research 13 (2): 221-33. https://doi.org/10.1086/209062.

Hole, Arne Risa. 2015. DCREATE: Stata Module to Create Efficient Designs for Discrete Choice Experiments (version Statistical Software Components S458059). Boston College Department of Economics. https://ideas.repec.org/c/boc/bocode/s458059.html.

Hut, Stefan, and Emily Oster. 2018. "Changes in Household Diet: Determinants and Predictability.” w24892. Cambridge, MA: National Bureau of Economic Research. https://doi.org/10.3386/w24892.

Jean, Neal, Marshall Burke, Michael Xie, W. Matthew Davis, David B. Lobell, and Stefano Ermon. 2016. "Combining Satellite Imagery and Machine Learning to 
Predict Poverty." Science 353 (6301): 790.

https://doi.org/10.1126/science.aaf7894.

Jung, Hojin. 2019. "Predicting Bid Prices by Using Machine Learning Methods AU Kim, Jong-Min.” Applied Economics 51 (19): 2011-18. https://doi.org/10.1080/00036846.2018.1537477.

Kahan, Dan M., Hank Jenkins-Smith, and Donald Braman. 2011. "Cultural Cognition of Scientific Consensus." Journal of Risk Research 14 (2): 147-74. https://doi.org/10.1080/13669877.2010.511246.

Kahneman, Daniel, Jack L Knetsch, and Richard H Thaler. 1991. "Anomalies: The Endowment Effect, Loss Aversion, and Status Quo Bias." Journal of Economic Perspectives 5 (1): 193-206. https://doi.org/10.1257/jep.5.1.193.

Kang, Jun Seok, Polina Kuznetsova, Michael Luca, and Yejin Choi. 2013. "Where Not to Eat? Improving Public Policy by Predicting Hygiene Inspections Using Online Reviews." Proceedings of the 2013 Conference on Empirical Methods in Natural Language Processing, 1443-48.

Kaptan, Gülbanu, Arnout R.H. Fischer, and Lynn J. Frewer. 2018. "Extrapolating Understanding of Food Risk Perceptions to Emerging Food Safety Cases." Journal of Risk Research 21 (8): 996-1018. https://doi.org/10.1080/13669877.2017.1281330.

Kivi, Paul A., and Jason F. Shogren. 2010. "Second-Order Ambiguity in Very Low Probability Risks: Food Safety Valuation." Journal of Agricultural and Resource Economics 35 (3): 443-56.

Kleinberg, Jon, Himabindu Lakkaraju, Jure Leskovec, Jens Ludwig, and Sendhil Mullainathan. 2017. "Human Decisions and Machine Predictions*." The Quarterly Journal of Economics 133 (1): 237-93. https://doi.org/10.1093/qje/qjx032.

Kleinberg, Jon, Jens Ludwig, Sendhil Mullainathan, and Ziad Obermeyer. 2015. "Prediction Policy Problems." American Economic Review 105 (5): 491-95. https://doi.org/10.1257/aer.p20151023.

Kothiyal, Amit, Vitalie Spinu, and Peter P. Wakker. 2014. "An Experimental Test of Prospect Theory for Predicting Choice under Ambiguity." Journal of Risk and Uncertainty 48 (1): 1-17.

Lee, Jason D., Dennis L. Sun, Yuekai Sun, and Jonathan E. Taylor. 2016. "Exact PostSelection Inference, with Application to the Lasso." The Annals of Statistics 44 (3): 907-27. https://doi.org/10.1214/15-AOS1371. 
Linden, Sander van der. 2017. "Determinants and Measurement of Climate Change Risk Perception, Worry, and Concern." In The Oxford Encyclopedia of Climate Change Communication, edited by M.C. Nisbet, M. Schafer, E. Markowitz, S. Ho, S. O'Neill, and J. Thaker. Vol. 1. Oxford, UK: Oxford University Press. https://doi.org/10.1093/acrefore/9780190228620.013.318.

Loewenstein, George. 2000. "Emotions in Economic Theory and Economic Behavior." The American Economic Review 90 (2): 426-32.

Lusk, Jayson L., and Keith H. Coble. 2005. "Risk Perceptions, Risk Preference, and Acceptance of Risky Food." American Journal of Agricultural Economics 87 (2): 393-405. https://doi.org/10.1111/j.1467-8276.2005.00730.x.

Lusk, Jayson L., and Anne Rozan. 2008. "Public Policy and Endogenous Beliefs: The Case of Genetically Modified Food." Journal of Agricultural and Resource Economics 33 (2): 270-89.

Marette, Stéphan, and Jutta Roosen. 2011. "Bans and Labels with Controversial Food Technologies." Edited by Jayson L. Lusk, Jason F. Shogren, and Jutta Roosen. The Oxford Handbook of the Economics of Food Consumption and Policy. https://doi.org/10.1093/oxfordhb/9780199569441.013.0020.

Messer, Kent D., Marco Costanigro, and Harry M. Kaiser. 2017. "Labeling Food Processes: The Good, the Bad and the Ugly." Applied Economic Perspectives and Policy 39 (3): 407-27. https://doi.org/10.1093/aepp/ppx028.

Mizerski, Richard W. 1982. "An Attribution Explanation of the Disproportionate Influence of Unfavorable Information.” Journal of Consumer Research 9 (3): 301. https://doi.org/10.1086/208925.

Mullainathan, Sendhil, and Jann Spiess. 2017. "Machine Learning: An Applied Econometric Approach.” Journal of Economic Perspectives 31 (2): 87-106. https://doi.org/10.1257/jep.31.2.87.

Petrolia, Daniel R. 2016. "Risk Preferences, Risk Perceptions, and Risky Food.” Food Policy 64 (October): 37-48. https://doi.org/10.1016/j.foodpol.2016.09.006.

Pew Research Center. 2016. "The New Food Fights: U.S. Public Divides Over Food Science." http://www.pewinternet.org/2016/12/01/the-new-food-fights/. (accessed January 1, 2017)

R Core Team. 2018. "R: A Language and Environment for Statistical Computing" R version 3.5.2 (December). http://www.R-project.org/.

Snow, Arthur. 2010. "Ambiguity and the Value of Information." Journal of Risk and Uncertainty 40 (2): 133-45. 
StataCorp. 2013. Stata Statistical Software: Release 13. College Station, TX: StataCorp LC.

Steenkamp, Jan-Benedict E.M. 1990. “Conceptual Model of the Quality Perception Process.” Journal of Business Research 21 (4): 309-33. https://doi.org/10.1016/0148-2963(90)90019-A.

Tibshirani, Robert. 1996. "Regression Shrinkage and Selection via the Lasso.” Journal of the Royal Statistical Society. Series B (Methodological) 58 (1): 267-88.

Tibshirani, Ryan J., Jonathan Taylor, Richard Lockhart, and Robert Tibshirani. 2016. "Exact Post-Selection Inference for Sequential Regression Procedures." Journal of the American Statistical Association 111 (514): 600-620. https://doi.org/10.1080/01621459.2015.1108848.

United States Census Bureau. 2017a. "DP05: ACS Demographic and Housing Estimates.” In 2016 American Community Survey 1-Year Estimates. United States Census Bureau's American Community Survey Office. http://factfinder2.census.gov. (accessed June 29, 2018)

. 2017b. "S1501: Educational Attainment." In 2016 American Community Survey 1-Year Estimates. United States Census Bureau's American Community Survey Office. http://factfinder2.census.gov. (accessed June 29, 2018)

—.2017c. "S2501: Occupancy Characteristics." In 2016 American Community Survey 1-Year Estimates. United States Census Bureau's American Community Survey Office. http://factfinder2.census.gov. (accessed June 29, 2018)

Viscusi, W. Kip. 1997. “Alarmist Decisions with Divergent Risk Information.” The Economic Journal 107 (445): 1657-70. https://doi.org/10.1111/j.14680297.1997.tb00073.x.

Viscusi, W. Kip, Wesley A. Magat, and Joel Huber. 1999. "Smoking Status and Public Responses to Ambiguous Scientific Risk Evidence." Southern Economic Journal 66 (2): 250-70. https://doi.org/10.2307/1061142.

Wall, Patrick G., and Junshi Chen. 2018. "Moving from Risk Communication to Food Information Communication and Consumer Engagement." Npj Science of Food 2 (1): 21. https://doi.org/10.1038/s41538-018-0031-7.

Zhao, Sen, Ali Shojaie, and Daniela Witten. 2017. "In Defense of the Indefensible: A Very Naive Approach to High-Dimensional Inference." ArXiv:1705.05543 [Math, Stat], May. http://arxiv.org/abs/1705.05543. 
Table 3.1 Sample Summary Statistics

\begin{tabular}{|c|c|c|c|}
\hline & Mean & SD & 2016 ACS \\
\hline Age & 35.9 & 11.0 & 37.7 \\
\hline Female $(\%)$ & 40.1 & 49.0 & 51.60 \\
\hline \multicolumn{4}{|l|}{ Income $(\%)$} \\
\hline Less than $\$ 49,999$ & 48.5 & 50.0 & 45.4 \\
\hline$\$ 50,000-99,999$ & 37.1 & 48.3 & 30.0 \\
\hline$\$ 100,000-149,999$ & 5.8 & 23.5 & 13.5 \\
\hline Greater than $\$ 150,000$ & 2.7 & 16.2 & 11.1 \\
\hline \multicolumn{4}{|l|}{ Education $(\%)$} \\
\hline Less than high school & 0.4 & 6.3 & 12.5 \\
\hline High School degree & 9.4 & 29.2 & 27.2 \\
\hline Some college or Associate's & 29.0 & 45.4 & 29.0 \\
\hline Bachelor's degree & 42.5 & 49.5 & 19.3 \\
\hline Graduate or professional degree & 57.5 & 49.5 & 11.9 \\
\hline \multicolumn{4}{|l|}{ Household size (\%) } \\
\hline 1 & 19.5 & 39.7 & 27.7 \\
\hline 2 & 26.7 & 44.2 & 33.7 \\
\hline 3 & 24.2 & 42.9 & 15.7 \\
\hline 4 & 18.8 & 39.1 & 13.1 \\
\hline 5 & 6.8 & 25.2 & 6.0 \\
\hline 6 & 3.0 & 17.1 & 2.3 \\
\hline 7 or more & 0.9 & 9.5 & 1.5 \\
\hline \multicolumn{4}{|l|}{ Race $(\%)$} \\
\hline White & 74.7 & 43.5 & 73.3 \\
\hline Black or African American & 13.5 & 34.2 & 12.6 \\
\hline Hispanic or Latino & 7.0 & 25.5 & 17.3 \\
\hline Native American or Alaska Native & 1.8 & 13.5 & 0.8 \\
\hline Asian & 4.3 & 20.2 & 5.2 \\
\hline Native Hawaiian or Pacific Islander & 0.4 & 6.2 & 0.2 \\
\hline Other & 0.9 & 9.3 & 4.8 \\
\hline Observations & 1043 & & \\
\hline
\end{tabular}

Note: 2016 ACS column reports mean values from the 2016 American Community Survey, except age which is reported as a median. ACS summary of household size includes both family and nonfamily households. 
Table 3.2 DCE attributes and levels

\begin{tabular}{ll}
\multicolumn{2}{c}{ Atlantic Salmon Fillets } \\
\hline Price & 6.49 \\
& 9.99 \\
& 13.49 \\
& 16.99 \\
GM Label & No Label \\
& Organic \\
& Verified Non-GM \\
& GM-Fed \\
& GM \\
& \\
& \\
Origin & U.S. \\
& Norway \\
& Chile \\
\hline
\end{tabular}


Table 3.3 Covariates selected by LASSO regularization

\section{Lasso* Intersection}

\begin{tabular}{|c|c|c|}
\hline \multicolumn{3}{|l|}{ Direct Effects } \\
\hline No Purchase (ASC) & $\mathbf{Y}$ & $\mathbf{Y}$ \\
\hline Fillet Price & $\mathbf{Y}$ & $\mathbf{Y}$ \\
\hline Organic & $\mathbf{Y}$ & $\mathbf{Y}$ \\
\hline Verified Non-GM & $\mathbf{Y}$ & $\mathbf{Y}$ \\
\hline Fed with GM Soy & $\mathbf{Y}$ & $\mathbf{Y}$ \\
\hline GM & $N$ & $N$ \\
\hline Both GM & $\mathbf{Y}$ & $\mathbf{Y}$ \\
\hline Norway & $\mathbf{Y}$ & $\mathbf{Y}$ \\
\hline Chile & $\mathbf{Y}$ & $N$ \\
\hline \multicolumn{3}{|l|}{ Information } \\
\hline Positive x Organic & $\mathbf{Y}$ & $\mathbf{Y}$ \\
\hline Positive x Verified Non-GM & $\mathbf{Y}$ & $\mathbf{Y}$ \\
\hline Positive x Fed with GM Soy & $N$ & $N$ \\
\hline Positive x GM & $\mathbf{Y}$ & $N$ \\
\hline Positive x Both GM & $\mathbf{Y}$ & $\mathbf{Y}$ \\
\hline Negative $\mathrm{x}$ Organic & $\mathbf{Y}$ & $\mathbf{Y}$ \\
\hline Negative x Verified Non-GM & $\mathbf{Y}$ & $\mathbf{Y}$ \\
\hline Negative $x$ Fed with GM Soy & $\mathbf{Y}$ & $N$ \\
\hline Negative x GM & $N$ & $N$ \\
\hline Negative $x$ Both GM & $\mathbf{Y}$ & $N$ \\
\hline Balanced x Organic & $\mathbf{Y}$ & $\mathbf{Y}$ \\
\hline Balanced x Verified Non-GM & $\mathbf{Y}$ & $\mathbf{Y}$ \\
\hline Balanced x Fed with GM Soy & $\mathbf{Y}$ & $N$ \\
\hline Balance x GM & $\mathbf{Y}$ & $N$ \\
\hline Balance $\mathrm{x}$ Both GM & $\mathbf{Y}$ & $\mathbf{Y}$ \\
\hline
\end{tabular}


Table 3.3 (continued) Covariates selected by lasso regularization

\section{Health domain interactions}

Risk perception

Confidence in risk perception

Concern about risks

Environmental domain interactions

Risk perception

Confidence in risk perception

Concern about risks

Subjective Knowledge about GM

Ambiguity aversion

$\begin{array}{ll}18 & 11 \\ 15 & 10 \\ 19 & 11\end{array}$

$19 \quad 11$

$19 \quad 11$

$15 \quad 10$

$18 \quad 10$

159

$15 \quad 11$

Average out-of-sample log-likelihood $\quad-2896.167 \quad-2883.807$

Standard error (OOSLL) $\quad 2.934 \quad 1.626$

Average OOS prediction accuracy $\quad 0.558 \quad .565$

Standard error (OOS pred. accuracy) $\quad 0.002 \quad .001$

Average McFadden's R-squared $\quad .492 \quad 0.494$

Standard error (McFadden's R-squared) $\quad .0005 \quad .0003$

Total covariates retained $\quad 155 \quad 98$

Notes: "Y" indicates a variable remained after regularization; " $N$ " indicates variable was excluded during regularization 
Table 3.4 Significant covariates ( $99 \%$ level), Lasso* fit on full sample

Fillet Choice

Direct Effects

No Purchase (ASC)

Fillet Price (\$)

Verified Non-GM

Fed with GM Soy

Norway

Chile
Bootstrap

Coefficient Standard error

$-1.89$

0.11

$-0.95$

0.04

0.47

0.18

$-0.70$

0.10

$-0.22$

0.02

$-0.32$

0.02

\section{Health domain interactions}

No Purchase (ASC) x Confidence

0.23

0.09

Positive $x$ Organic x Confidence

0.27

0.11

No Purchase (ASC) x Concern

0.49

0.08

Fed with GM Soy x Concern

$-0.43$

0.10

\section{Environment domain interactions}

Balanced x Fed with GM Soy x Risk Perception

$-0.35$

0.11

Balanced x GM x Risk Perception

$-0.34$

0.10

No Purchase (ASC) x Confidence

$-0.21$

0.08

Balanced x Organic x Confidence

0.10

\section{Subjective knowledge interactions}

No Purchase (ASC)

$-0.32$

0.07

Fed with GM Soy

0.39

0.06

\section{Ambiguity aversion interactions}

Fed with GM Soy

0.24

0.07

Notes: Reported coefficients are significant at the $99 \%$ level. Coefficients on continuous covariates (risk perception, concern, confidence, subjective knowledge, and ambiguity aversion) are standardized. All other covariates are indicator variables for the denoted label attributes or experimental conditions. 
Table 3.5 Significant covariates (99\% level), Intersection model fit on full sample

\section{Fillet Choice}

\begin{tabular}{|c|c|c|}
\hline Direct Effects & Coefficient & $\begin{array}{c}\text { Bootstrap } \\
\text { Standard error }\end{array}$ \\
\hline No Purchase (ASC) & -1.65 & 0.12 \\
\hline Fillet Price $(\$)$ & -0.89 & 0.04 \\
\hline Verified Non-GM & 0.45 & 0.17 \\
\hline Fed with GM Soy & -0.49 & 0.09 \\
\hline Norway & -0.06 & 0.02 \\
\hline \multicolumn{3}{|l|}{ Health domain interactions } \\
\hline No Purchase (ASC) x Risk Perception & -0.22 & 0.08 \\
\hline No Purchase (ASC) x Confidence & 0.25 & 0.09 \\
\hline No Purchase (ASC) x Concern & 0.51 & 0.09 \\
\hline Fed with GM Soy x Concern & -0.29 & 0.07 \\
\hline GM x Concern & -0.30 & 0.02 \\
\hline \multicolumn{3}{|l|}{ Environment domain interactions } \\
\hline No Purchase (ASC) x Confidence & -0.23 & 0.09 \\
\hline Balanced x Organic x Confidence & -0.30 & 0.11 \\
\hline Fed with GM Soy x Concern & 0.26 & 0.07 \\
\hline \multicolumn{3}{|l|}{ Subjective knowledge interactions } \\
\hline No Purchase (ASC) & -0.38 & 0.07 \\
\hline \multicolumn{3}{|l|}{ Ambiguity aversion interactions } \\
\hline Fed with GM Soy & 0.27 & 0.07 \\
\hline
\end{tabular}

Notes: Reported coefficients are significant at the $99 \%$ level. Coefficients on continuous covariates (risk perception, concern, confidence, subjective knowledge, and ambiguity aversion) are standardized. All other covariates are indicator variables for the denoted label attributes or experimental conditions. 
Figure 3.1 Example choice set

Please select your most preferred option.

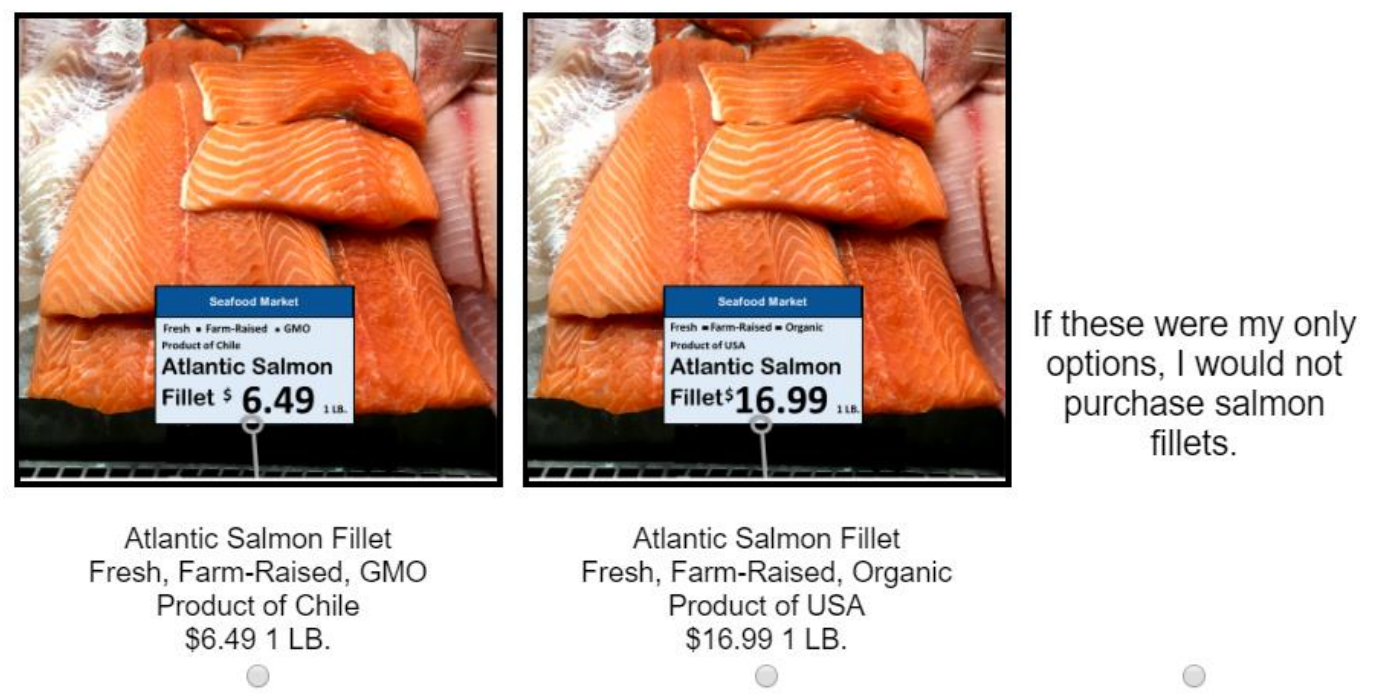


Figure 3.2 Hierarchy of Concern framework

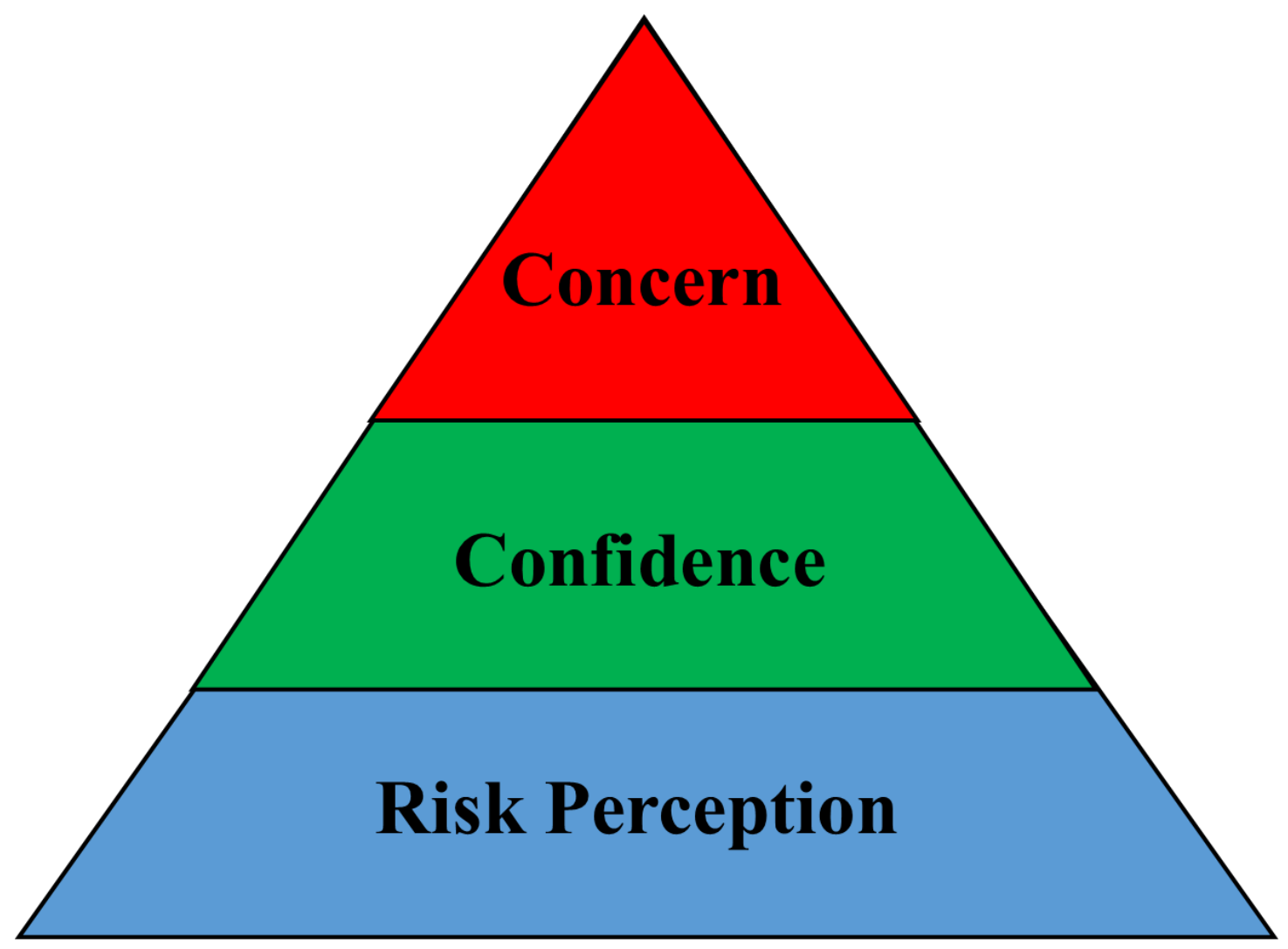

Notes: This framework is adapted from van der Linden (2017). "Risk Perception" is a measure of whether an individual believes there are risk associated with a scenario, e.g. GM food, "Confidence" refers to the perceived likelihood risks will occur, and "Concern" is the level of worry about the potential risks. 
Figure 3.3 Example ambiguity aversion elicitation menu

Please select the fillet of your choice: $\mathrm{U}$ or $\mathrm{K}$. If you think both fillets are equally attractive, you can select "Indifferent".

\section{Fillet U}

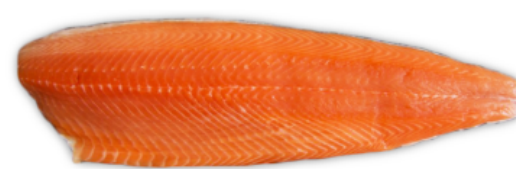

Chance of being GM: ? out of 100

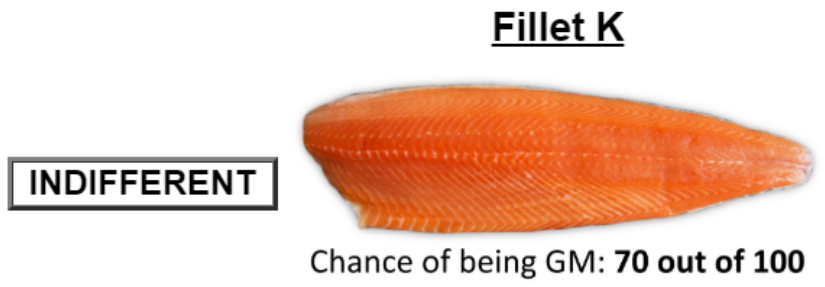


Figure 3.4 Histogram and smoothed density plot of ambiguity aversion parameter

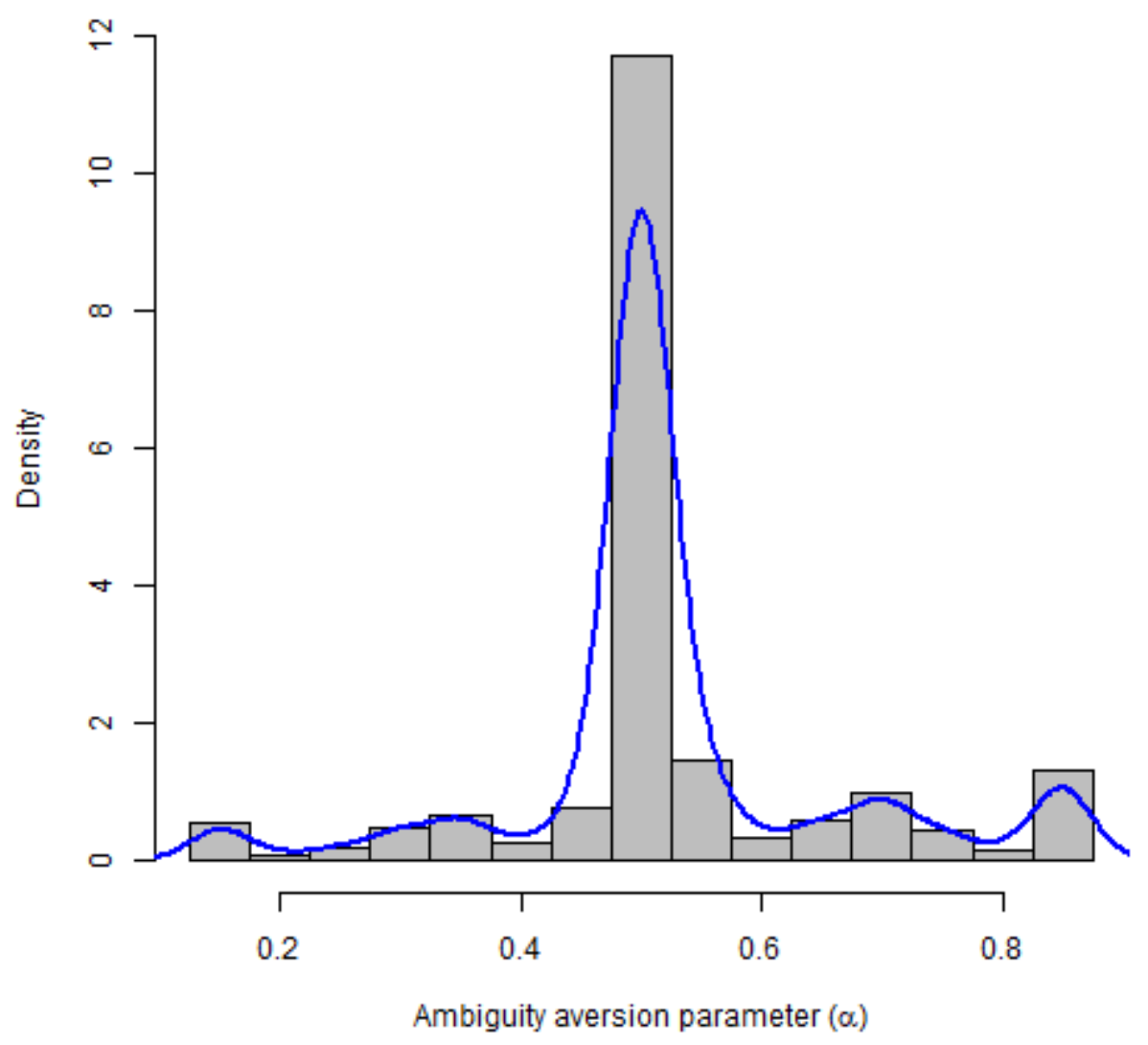


Figure 3.5 Mean out of sample log-likelihood

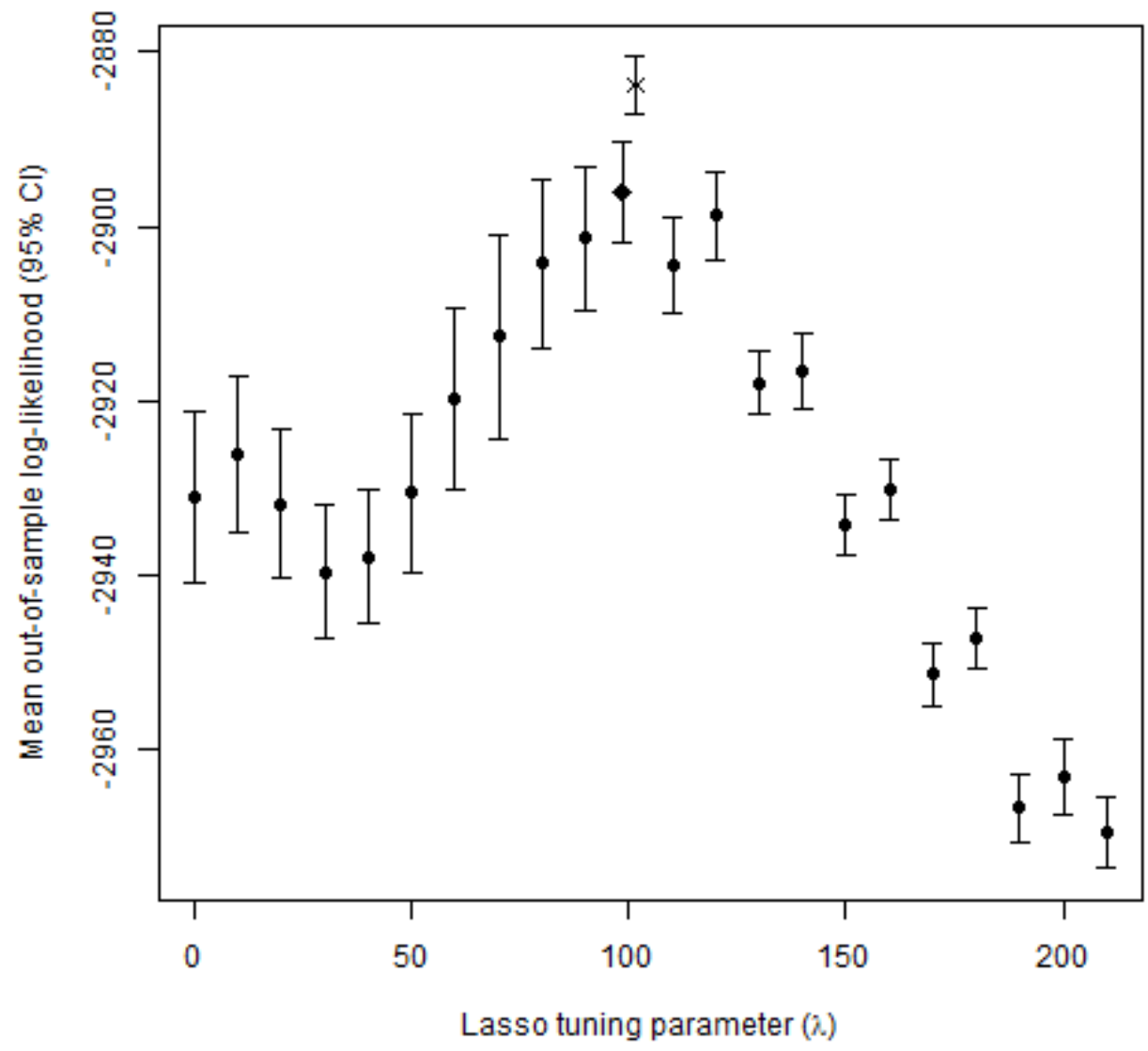

Notes: Diamond denotes mean out of sample log-likelihood of model fit with $\lambda^{*}=100 . x$ denotes mean prediction accuracy of Intersection of $\lambda^{*}$ models from replication analysis. The OOSLL for Lasso* versus intersection are statistically different $(p<0.001)$. 
Figure 3.6 Mean out of sample prediction accuracy

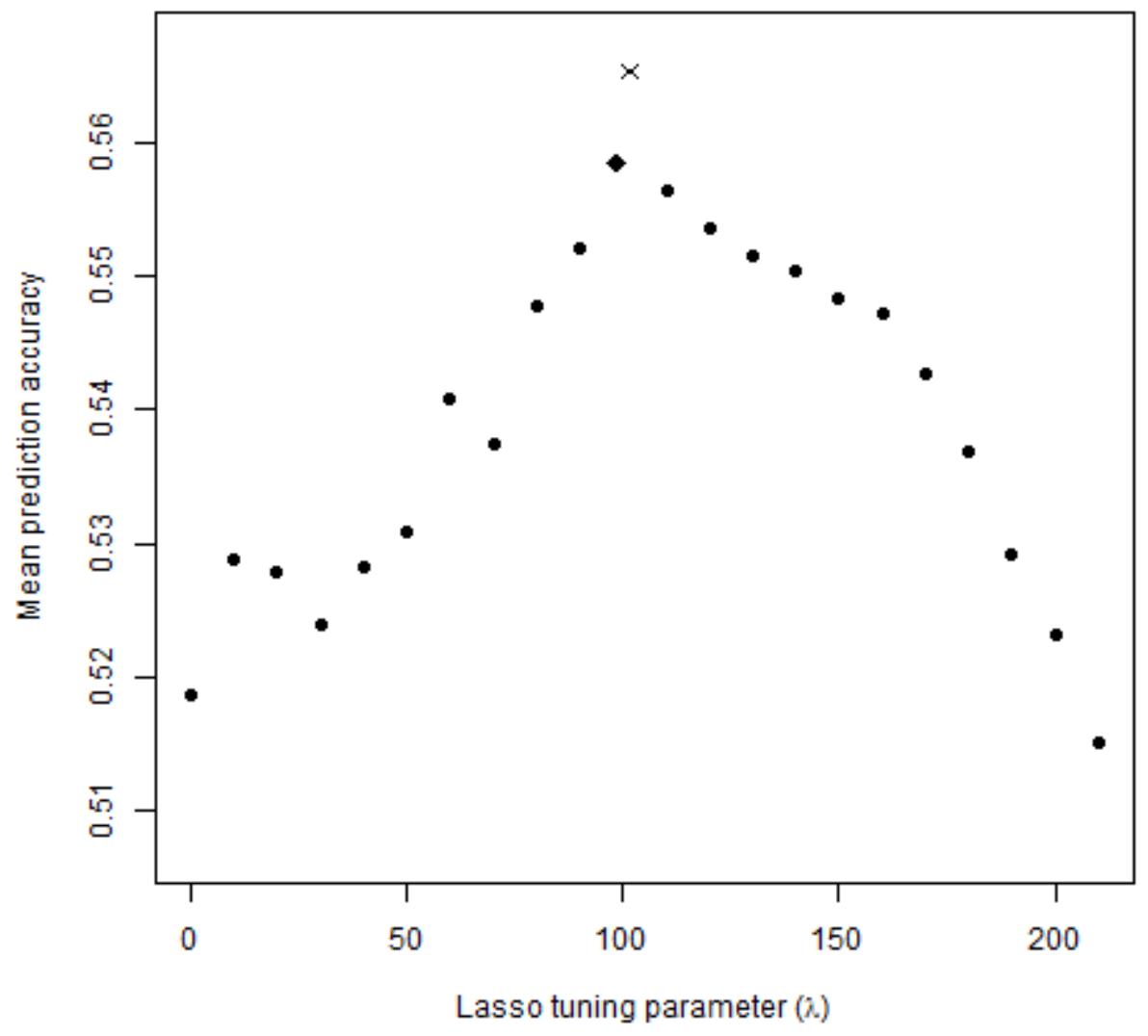

Notes: Diamond denotes mean prediction accuracy of model fit with $\lambda^{*}=100 . \mathrm{X}$ denotes mean prediction accuracy of Intersection of $\lambda^{*}$ models from replication analysis. The prediction accuracy of the Intersection model is significantly different from that of Lasso* $(p<0.001)$. 


\section{BIBLIOGRAPHY}

Abroms, Lorien C., and Edward W. Maibach. 2008. "The Effectiveness of Mass Communication to Change Public Behavior." Annual Review of Public Health 29 (1): 219-34. https://doi.org/10.1146/annurev.publhealth.29.020907.090824.

Afendras, Georgios, and Marianthi Markatou. 2015. "Optimality of Training/Test Size and Resampling Effectiveness of Cross-Validation Estimators of the Generalization Error.” ArXiv:1511.02980 [Math, Stat], November. http://arxiv.org/abs/1511.02980.

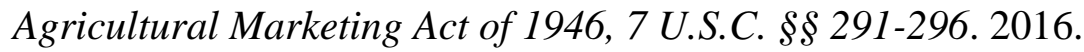
https://www.congress.gov/bill/114th-congress/senatebill/764/text?resultIndex $=1$.

Alfnes, Frode, Atle G. Guttormsen, Gro Steine, and Kari Kolstad. 2006. 'Consumers' Willingness to Pay for the Color of Salmon: A Choice Experiment with Real Economic Incentives." American Journal of Agricultural Economics 88 (4): 1050-61. https://doi.org/10.1111/j.1467-8276.2006.00915.x.

Amin, Latifah, Md. Abul Kalam Azad, Mohd Hanafy Gausmian, and Faizah Zulkifli. 2014. "Determinants of Public Attitudes to Genetically Modified Salmon." PLOS ONE 9 (1): e86174. https://doi.org/10.1371/journal.pone.0086174.

Andini, Monica, Emanuele Ciani, Guido de Blasio, Alessio D’Ignazio, and Viola Salvestrini. 2018. "Targeting with Machine Learning: An Application to a Tax Rebate Program in Italy." Journal of Economic Behavior \& Organization 156 (December): 86-102. https://doi.org/10.1016/j.jebo.2018.09.010.

Belloni, A., D. Chen, V. Chernozhukov, and C. Hansen. 2012. "Sparse Models and Methods for Optimal Instruments With an Application to Eminent Domain." Econometrica 80 (6): 2369-2429. https://doi.org/10.3982/ECTA9626.

Belloni, Alexandre, Victor Chernozhukov, and Christian Hansen. 2014. "HighDimensional Methods and Inference on Structural and Treatment Effects." Journal of Economic Perspectives 28 (2): 29-50. https://doi.org/10.1257/jep.28.2.29.

- 2013. "Inference on Treatment Effects after Selection among HighDimensional Controls $\uparrow$." The Review of Economic Studies 81 (2): 608-50. https://doi.org/10.1093/restud/rdt044.

Berk, Richard, Lawrence Brown, Andreas Buja, Kai Zhang, and Linda Zhao. 2013. "Valid Post-Selection Inference." The Annals of Statistics 41 (2): 802-37. https://doi.org/10.1214/12-AOS1077.

Biernacki, C., G. Celeux, and G. Govaert. 2000. "Assessing a Mixture Model for Clustering with the Integrated Completed Likelihood." IEEE Transactions on 
Pattern Analysis and Machine Intelligence 22 (7): 719-25. https://doi.org/10.1109/34.865189.

Blank, Christine . 2019. "FDA Lifts Import Alert on GE Salmon, Clears Way for AquaBounty." Seafood Source. March 8, 2019. https://www.seafoodsource.com/news/supply-trade/fda-lifts-import-alert-onge-salmon-clears-way-for-aquabounty. (accessed March 8, 2019).

. 2018. "GE Salmon Advancing in the US with FDA's Blessing." Seafood Source. May 1, 2018. https://www.seafoodsource.com/news/aquaculture/gesalmon-advancing-in-the-us-with-fda-blessing. (accessed May 1, 2018).

Blumenstock, Joshua, Gabriel Cadamuro, and Robert On. 2015. "Predicting Poverty and Wealth from Mobile Phone Metadata.” Science 350 (6264): 1073. https://doi.org/10.1126/science.aac4420.

Blumenstock, Joshua. 2016. "Fighting Poverty with Data." Science 353 (6301): 753. https://doi.org/10.1126/science.aah5217.

Bonroy, Olivier, and Christos Constantatos. 2014. "On the Economics of Labels: How Their Introduction Affects the Functioning of Markets and the Welfare of All Participants." American Journal of Agricultural Economics 97 (1): 239-59.

Bouchouicha, Ranoua, Peter Martinsson, Haileselassie Medhin, and Ferdinand M. Vieider. 2017. "Stake Effects on Ambiguity Attitudes for Gains and Losses." Theory and Decision 83 (1): 19-35. https://doi.org/10.1007/s11238-016-95855.

Boudreau, Catherine. 2018. "USDA Eyes Dec. 1 for Final GMO Labeling Rule.” POLITICO Pro (blog). https://subscriber.politicopro.com/agriculture/whiteboard/2018/09/usda-eyesdec-1-for-final-gmo-labeling-rule-1904831 (accessed November 16, 2018).

Bovay, John, and Julian M. Alston. 2018. "GMO Food Labels in the United States: Economic Implications of the New Law." Special Issue on The Economics and Politics GM Food Labeling 78 (July): 14-25. https://doi.org/10.1016/j.foodpol.2018.02.013.

Boxall, Peter C., and Wiktor L. Adamowicz. 2002. "Understanding Heterogeneous Preferences in Random Utility Models: A Latent Class Approach." Environmental and Resource Economics 23 (4): 421-46. https://doi.org/10.1023/A:1021351721619.

Bruhin, Adrian, Helga Fehr-Duda, and Thomas Epper. 2010. "Risk and Rationality: Uncovering Heterogeneity in Probability Distortion." Econometrica 78 (4): 1375-1412. https://doi.org/10.3982/ECTA7139. 
Campbell, Danny, George Hutchinson, and R. Scarpa. 2007. "Using Mixed Logit Models to Derive Individual-Specific WTP Estimates for Landscape Improvements under Agri-Environmental Schemes: Evidence from the Rural Environmental Protection Scheme in Ireland." In Choice Experiments Informing European Environmental Policy.

Carlucci, Domenico, Giuseppe Nocella, Biagia De Devitiis, Rosaria Viscecchia, Francesco Bimbo, and Gianluca Nardone. 2015. "Consumer Purchasing Behaviour towards Fish and Seafood Products. Patterns and Insights from a Sample of International Studies." Appetite 84 (January): 212-27. https://doi.org/10.1016/j.appet.2014.10.008.

Chern, Wen S, Kyrre Rickertsen, Nobuhiro Tsuboi, and Tsu-Tan Fu. 2002. "Consumer Acceptance and Willingness to Pay for Genetically Modified Vegetable Oil and Salmon: A Multiple-Country Assessment." AgBioForum 5: 105-12.

Chern, Wen S. 2006. "Genetically Modified Organisms (GMOs) and Sustainability in Agriculture." In International Association of Agricultural Economists Conference, August 12-18, 2006. Gold Coast, Queensland, Australia.

Colson, Gregory J., Wallace E. Huffman, and Matthew C. Rousu. 2011. "Improving the Nutrient Content of Food through Genetic Modification: Evidence from Experimental Auctions on Consumer Acceptance." Journal of Agricultural and Resource Economics 36 (2): 343-64.

Costa-Font, Joan, and Elias Mossialos. 2005. "Is Dread of Genetically Modified Food Associated with the Consumers' Demand for Information?" Applied Economics Letters 12 (14): 859-63. https://doi.org/10.1080/13504850500365830.

Costello, Anna B, and Jason W Osborne. 2005. "Best Practices in Exploratory Factor Analysis: Four Recommendations for Getting the Most From Your Analysis." Practical Assessment, Research \& Evaluation 10 (7): 9.

Cox, D. R. 1975. "A Note on Data-Splitting for the Evaluation of Significance Levels." Biometrika 62 (2): 441-44. https://doi.org/10.2307/2335385.

Curtis, Kynda R., Jill J. McCluskey, and Thomas I. Wahl. 2004. "Consumer Acceptance of Genetically Modified Food Products in the Developing World." AgBioForum 7 (1 \& 2): 70-75.

Dannenberg, Astrid. 2009. "The Dispersion and Development of Consumer Preferences for Genetically Modified Food - A Meta-Analysis." Ecological Economics 68 (8): 2182-92. https://doi.org/10.1016/j.ecolecon.2009.03.008.

Dimmock, Stephen G., Roy Kouwenberg, Olivia S. Mitchell, and Kim Peijnenburg. 2015. "Estimating Ambiguity Preferences and Perceptions in Multiple Prior 
Models: Evidence from the Field.” Journal of Risk and Uncertainty 51 (3): 219-44. https://doi.org/10.1007/s11166-015-9227-2.

Dolgopolova, Irina, and Ramona Teuber. 2018. "Consumers' Willingness to Pay for Health Benefits in Food Products: A Meta-Analysis." Applied Economic Perspectives and Policy 40 (2): 333-52. https://doi.org/10.1093/aepp/ppx036.

Oster, Emily. Forthcoming. "Diabetes and Diet: Purchasing Behavior Change in Response to Health Information." American Economic Journal: Applied Economics.

Fernandes, Lawrence, and Dr R Srinivasan. 2018. "A Consumer Analysis of Whole Foods Market." International Journal of Latest Engineering and Management Research 03 (02): 5.

"Fresh Salmon in RI." 2019. Dave's Marketplace. http://www.davesmarketplace.com/pages/cfSeafood_Salmon.cfm (accessed January 3 , 2019).

Food and Agricultural Organization of the United Nations. 2016. State of World Fisheries and Aquaculture 2016. Contributing to Food Security and Nutrition for All. Rome. http://www.fao.org/3/a-i5555e.pdf (accessed October 10, 2017).

Food and Agriculture Organization of the United Nations. 2016. "Aquaculture Feed and Fertilizer Resources Information System." Atlantic Salmon - Feed Production. http://www.fao.org/fishery/affris/species-profiles/atlanticsalmon/feedproduction/en/(accessed October 10, 2017).

Fox, Craig R., and Amos Tversky. 1995. "Ambiguity Aversion and Comparative Ignorance*.” The Quarterly Journal of Economics 110 (3): 585-603. https://doi.org/10.2307/2946693.

Fox, John A., Dermot J. Hayes, and Jason F. Shogren. 2002. "Consumer Preferences for Food Irradiation: How Favorable and Unfavorable Descriptions Affect Preferences for Irradiated Pork in Experimental Auctions." Journal of Risk and Uncertainty 24 (1): 75-95. https://doi.org/10.1023/A:1013229427237.

Fox, John A., Jason F. Shogren, Dermot J. Hayes, and James B. Kliebenstein. 1998. "CVM-X: Calibrating Contingent Values with Experimental Auction Markets." American Journal of Agricultural Economics 80 (3): 455-65. https://doi.org/10.2307/1244548.

Frewer, Lynn J., Chaya Howard, and Richard Shepherd. 1998. "The Influence of Initial Attitudes on Responses to Communication about Genetic Engineering in Food Production." Agriculture and Human Values 15 (1): 15-30. https://doi.org/10.1023/A:1007465730039. 
Frewer, Lynn J., Chaya Howard, Duncan Hedderley, and Richard Shepherd. 1997. "The Elaboration Likelihood Model and Communication About Food Risks." Risk Analysis 17 (6): 759-70. https://doi.org/10.1111/j.15396924.1997.tb01281.x.

Friedman, Jerome H., Trevor Hastie, and Rob Tibshirani. 2010. "Regularization Paths for Generalized Linear Models via Coordinate Descent." Journal of Statistical Software; Vol 1, Issue 1 (2010), February. https://www.jstatsoft.org/v033/i01.

Garrett, Elizabeth S., William W. Eaton, and Scott Zeger. 2002. "Methods for Evaluating the Performance of Diagnostic Tests in the Absence of a Gold Standard: A Latent Class Model Approach.” Statistics in Medicine 21 (9): 1289-1307. https://doi.org/10.1002/sim.1105.

Gaskell, G, N Allum, and S Stares. 2003. Europeans and Biotechnology in 2002: Eurobarometer 58.0. Brussels: European Commission.

Gaskell, George, Katrin Hohl, and Monica M. Gerber. 2017. "Do Closed Survey Questions Overestimate Public Perceptions of Food Risks?" Journal of Risk Research 20 (8): 1038-52. https://doi.org/10.1080/13669877.2016.1147492.

Gaskell, George, Nick Allum, Wolfgang Wagner, Nicole Kronberger, Helge Torgersen, Juergen Hampel, and Julie Bardes. 2004. "GM Foods and the Misperception of Risk Perception.” Risk Analysis 24 (1): 185-94. https://doi.org/10.1111/j.0272-4332.2004.00421.x.

Gellynck, Xavier, Wim Verbeke, and Bert Vermeire. 2006. "Pathways to Increase Consumer Trust in Meat as a Safe and Wholesome Food." 52nd International Congress of Meat Science and Technology (52nd ICoMST) 13-18 August 2006 Dublin, Ireland 74 (1): 161-71. https://doi.org/10.1016/j.meatsci.2006.04.013.

Goodman, Joseph K., and Gabriele Paolacci. 2017. "Crowdsourcing Consumer Research.” Journal of Consumer Research 44 (1): 196-210. https://doi.org/10.1093/jcr/ucx047.

Greene, William H. 2012. NLOGIT Version 5.0 Reference Guide. Plainview, NY: Econometric Software, Inc.

Groll, Andreas. 2017. "GlmmLasso: Variable Selection for Generalized Linear Mixed Models by L1-Penalized Estimation" R package version 1.5.1. https://CRAN.R-project.org/package=glmmLasso.

Grunert, Klaus G, Liisa Lähteenmäki, Niels Asger Nielsen, Jacob B Poulsen, Oydis Ueland, and Annika Åström. 2001. "Consumer Perceptions of Food Products Involving Genetic Modification-Results from a Qualitative Study in Four Nordic Countries." Food Quality and Preference 12 (8): 527-42. https://doi.org/10.1016/S0950-3293(01)00049-0. 
Hansen, Janus, Lotte Holm, Lynn Frewer, Paul Robinson, and Peter Sandøe. 2003. "Beyond the Knowledge Deficit: Recent Research into Lay and Expert Attitudes to Food Risks." Appetite 41 (2): 111-21. https://doi.org/10.1016/S0195-6663(03)00079-5.

"Harpoon-Caught Swordfish.” 2019. Whole Foods Market. 2019. https://www.wholefoodsmarket.com/harpoon-caught-swordfish (accessed January 3, 2019).

Hastie, Trevor, Robert Tibshirani, and J. H. Friedman. 2009. The Elements of Statistical Learning: Data Mining, Inference, and Prediction. 2nd ed. Springer Series in Statistics. New York, NY: Springer.

Heath, Chip, and Amos Tversky. 1991. "Preference and Belief: Ambiguity and Competence in Choice under Uncertainty." Journal of Risk and Uncertainty 4 (1): 5-28. https://doi.org/10.1007/BF00057884.

Heiman, Amir, and Oded Lowengart. 2011. "The Effects of Information about Health Hazards in Food on Consumers' Choice Process." The Economics and Econometrics of Risk 162 (1): 140-47. https://doi.org/10.1016/j.jeconom.2010.07.003.

Hensher, David A., and William H. Greene. 2003. "The Mixed Logit Model: The State of Practice." Transportation 30 (2): 133-76. https://doi.org/10.1023/A:1022558715350.

Hensher, David A., John M. Rose, and William H. Greene. 2015. Applied Choice Analysis. Second edition. Cambridge, United Kingdom: Cambridge University Press.

Hess, Sebastian, Carl Johan Lagerkvist, William Redekop, and Ashkan Pakseresht. 2016. "Consumers' Evaluation of Biotechnologically Modified Food Products: New Evidence from a Meta-Survey." European Review of Agricultural Economics 43 (5): 703-36. https://doi.org/10.1093/erae/jbw011.

Hingston, Sean T., and Theodore J. Noseworthy. 2018. "Why Consumers Don't See the Benefits of Genetically Modified Foods, and What Marketers Can Do About It." Journal of Marketing 82 (5): 125-40. https://doi.org/10.1509/jm.17.0100.

Hino, M., E. Benami, and N. Brooks. 2018. "Machine Learning for Environmental Monitoring." Nature Sustainability 1 (10): 583-88. https://doi.org/10.1038/s41893-018-0142-9.

Hoch, Stephen J., and Young-Won Ha. 1986. "Consumer Learning: Advertising and the Ambiguity of Product Experience." Journal of Consumer Research 13 (2): 221-33. https://doi.org/10.1086/209062. 
Hole, Arne Risa. 2015. DCREATE: Stata Module to Create Efficient Designs for Discrete Choice Experiments (version Statistical Software Components S458059). Boston College Department of Economics. https://ideas.repec.org/c/boc/bocode/s458059.html.

Hornik, Robert C., ed. 2002. Public Health Communication: Evidence for Behavior Change. LEA's Communication Series. Mahwah, N.J: L. Erlbaum Associates.

Hossain, Ferdaus, Benjamin Onyango, Brian Schilling, William Hallman, and Adesoji Adelaja. 2003. "Product Attributes, Consumer Benefits and Public Approval of Genetically Modified Foods." International Journal of Consumer Studies 27 (5): 353-65. https://doi.org/10.1046/j.1470-6431.2003.00303.x.

Huffman, Wallace E., Matthew Rousu, Jason F. Shogren, and Abebayehu Tegene. 2007. "The Effects of Prior Beliefs and Learning on Consumers' Acceptance of Genetically Modified Foods." Journal of Economic Behavior \& Organization 63 (1): 193-206. https://doi.org/10.1016/j.jebo.2005.04.019.

Hut, Stefan, and Emily Oster. 2018. "Changes in Household Diet: Determinants and Predictability." w24892. Cambridge, MA: National Bureau of Economic Research. https://doi.org/10.3386/w24892.

International Service for the Acquisition of Agri-biotech Applications. 2018. "Knowledge Center." International Service for the Acquisition of Agri-Biotech Applications. http://www.isaaa.org/kc/default.asp (accessed December 5, 2018).

Jahns, Lisa, Susan Raatz, LuAnn Johnson, Sibylle Kranz, Jeffrey Silverstein, and Matthew Picklo. 2014. "Intake of Seafood in the US Varies by Age, Income, and Education Level but Not by Race-Ethnicity." Nutrients 6 (12): 6060-75. https://doi.org/10.3390/nu6126060.

Jean, Neal, Marshall Burke, Michael Xie, W. Matthew Davis, David B. Lobell, and Stefano Ermon. 2016. "Combining Satellite Imagery and Machine Learning to Predict Poverty." Science 353 (6301): 790. https://doi.org/10.1126/science.aaf7894.

Jedidi, Kamel, Venkatram Ramaswamy, and Wayne S. Desarbo. 1993. “A Maximum Likelihood Method for Latent Class Regression Involving a Censored Dependent Variable." Psychometrika 58 (3): 375-94. https://doi.org/10.1007/BF02294647.

Johnston, Robert J., and Cathy A. Roheim. 2006. "A Battle of Taste and Environmental Convictions for Ecolabeled Seafood: A Contingent Ranking Experiment." Journal of Agricultural and Resource Economics 31 (2): 283300. 
Jung, Hojin. 2019. "Predicting Bid Prices by Using Machine Learning Methods AU Kim, Jong-Min.” Applied Economics 51 (19): 2011-18. https://doi.org/10.1080/00036846.2018.1537477.

Kahan, Dan M., Hank Jenkins-Smith, and Donald Braman. 2011. "Cultural Cognition of Scientific Consensus." Journal of Risk Research 14 (2): 147-74. https://doi.org/10.1080/13669877.2010.511246.

Kahneman, Daniel, Jack L Knetsch, and Richard H Thaler. 1991. "Anomalies: The Endowment Effect, Loss Aversion, and Status Quo Bias." Journal of Economic Perspectives 5 (1): 193-206. https://doi.org/10.1257/jep.5.1.193.

Kaneko, Naoya, and Wen S. Chern. 2005. "Willingness to Pay for Genetically Modified Oil, Cornflakes, and Salmon: Evidence from a U.S. Telephone Survey." Journal of Agricultural and Applied Economics 37 (3): 701-19. https://doi.org/10.1017/S1074070800027188.

Kang, Jun Seok, Polina Kuznetsova, Michael Luca, and Yejin Choi. 2013. "Where Not to Eat? Improving Public Policy by Predicting Hygiene Inspections Using Online Reviews." Proceedings of the 2013 Conference on Empirical Methods in Natural Language Processing, 1443-48.

Kaptan, Gülbanu, Arnout R.H. Fischer, and Lynn J. Frewer. 2018. "Extrapolating Understanding of Food Risk Perceptions to Emerging Food Safety Cases." Journal of Risk Research 21 (8): 996-1018. https://doi.org/10.1080/13669877.2017.1281330.

Kearns, Madelyn. 2017. "US Surimi Supplier Certified as Non-GMO, Announces Weight Watchers Campaign.” Seafood Source, December 14, 2017. https://www.seafoodsource.com/news/foodservice-retail/us-surimi-supplierscores-non-gmo-vetting-announces-weight-watchers-campaign.

Kivi, Paul A., and Jason F. Shogren. 2010. "Second-Order Ambiguity in Very Low Probability Risks: Food Safety Valuation." Journal of Agricultural and Resource Economics 35 (3): 443-56.

Kleinberg, Jon, Himabindu Lakkaraju, Jure Leskovec, Jens Ludwig, and Sendhil Mullainathan. 2017. "Human Decisions and Machine Predictions*." The Quarterly Journal of Economics 133 (1): 237-93. https://doi.org/10.1093/qje/qjx032.

Kleinberg, Jon, Jens Ludwig, Sendhil Mullainathan, and Ziad Obermeyer. 2015. "Prediction Policy Problems." American Economic Review 105 (5): 491-95. https://doi.org/10.1257/aer.p20151023.

Kolodinsky, Jane, and Jayson L. Lusk. 2018. "Mandatory Labels Can Improve Attitudes toward Genetically Engineered Food." Science Advances 4 (6). https://doi.org/10.1126/sciadv.aaq1413. 
Kothiyal, Amit, Vitalie Spinu, and Peter P. Wakker. 2014. "An Experimental Test of Prospect Theory for Predicting Choice under Ambiguity." Journal of Risk and Uncertainty 48 (1): 1-17.

Krinsky, Itzhak, and A. Leslie Robb. 1986. "On Approximating the Statistical

Properties of Elasticities." The Review of Economics and Statistics 68 (4): 715-19. https://doi.org/10.2307/1924536.

Kuznesof, Sharron, and Christopher Ritson. 1996. "Consumer Acceptability of Genetically Modified Foods with Special Reference to Farmed Salmon." British Food Journal 98 (4/5): 39-47. https://doi.org/10.1108/00070709610119874.

Lee, Jason D., Dennis L. Sun, Yuekai Sun, and Jonathan E. Taylor. 2016. "Exact PostSelection Inference, with Application to the Lasso." The Annals of Statistics 44 (3): 907-27. https://doi.org/10.1214/15-AOS1371.

Linden, Sander van der. 2017. "Determinants and Measurement of Climate Change Risk Perception, Worry, and Concern." In The Oxford Encyclopedia of Climate Change Communication, edited by M.C. Nisbet, M. Schafer, E. Markowitz, S. Ho, S. O'Neill, and J. Thaker. Vol. 1. Oxford, UK: Oxford University Press. https://doi.org/10.1093/acrefore/9780190228620.013.318.

Loewenstein, George. 2000. "Emotions in Economic Theory and Economic Behavior." The American Economic Review 90 (2): 426-32.

Loureiro, Maria L., Jill J. McCluskey, and Ron C. Mittelhammer. 2002. “Will Consumers Pay a Premium for Eco-Labeled Apples?" Journal of Consumer Affairs 36 (2): 203-19. https://doi.org/10.1111/j.1745-6606.2002.tb00430.x.

Lusk, Jayson L., and Anne Rozan. 2008. "Public Policy and Endogenous Beliefs: The Case of Genetically Modified Food." Journal of Agricultural and Resource Economics 33 (2): 270-89.

Lusk, Jayson L., and F. Bailey Norwood. 2011. "Animal Welfare Economics.” Applied Economic Perspectives and Policy 33 (4): 463-83. https://doi.org/10.1093/aepp/ppr036.

Lusk, Jayson L., and Keith H. Coble. 2005. "Risk Perceptions, Risk Preference, and Acceptance of Risky Food." American Journal of Agricultural Economics 87 (2): 393-405. https://doi.org/10.1111/j.1467-8276.2005.00730.x.

Lusk, Jayson L., Brandon R. McFadden, and Bradley J. Rickard. 2015. "Which Biotech Foods Are Most Acceptable to the Public?" Biotechnology Journal 10 (1): 13-16. https://doi.org/10.1002/biot.201400561.

Lusk, Jayson L., Jutta Roosen, and John A. Fox. 2003. "Demand for Beef from Cattle Administered Growth Hormones or Fed Genetically Modified Corn: A 
Comparison of Consumers in France, Germany, the United Kingdom, and the United States." American Journal of Agricultural Economics 85 (1): 16-29. https://doi.org/10.1111/1467-8276.00100.

Lusk, Jayson L., Lisa O. House, Carlotta Valli, Sara R. Jaeger, Melissa Moore, J.L. Morrow, and W. Bruce Traill. 2004. "Effect of Information about Benefits of Biotechnology on Consumer Acceptance of Genetically Modified Food: Evidence from Experimental Auctions in the United States, England, and France." European Review of Agricultural Economics 31 (2): 179-204. https://doi.org/10.1093/erae/31.2.179.

Lusk, Jayson L., M. Scott Daniel, Darrell R. Mark, and Christine L. Lusk. 2001. "Alternative Calibration and Auction Institutions for Predicting Consumer Willingness to Pay for Nongenetically Modified Corn Chips." Journal of Agricultural and Resource Economics 26 (1): 40-57.

Lusk, Jayson L., Mustafa Jamal, Lauren Kurlander, Maud Roucan, and Lesley Taulman. 2005. "A Meta-Analysis of Genetically Modified Food Valuation Studies." Journal of Agricultural and Resource Economics 30 (1): 28-44.

Mancino, Lisa, Joanne Guthrie, Michele Ver Ploeg, and Biing-Hwan Lin. 2018. "Nutritional Quality of Foods Acquired by Americans: Findings From USDA's National Household Food Acquisition and Purchase Survey." 188. Economic Information Bulletin. Washington, D.C.: U.S. Department of Agriculture Economic Research Service. https://www.ers.usda.gov/webdocs/publications/87531/eib-188.pdf?utm.

Marette, Stéphan, and Jutta Roosen. 2011. "Bans and Labels with Controversial Food Technologies." Edited by Jayson L. Lusk, Jason F. Shogren, and Jutta Roosen. The Oxford Handbook of the Economics of Food Consumption and Policy. https://doi.org/10.1093/oxfordhb/9780199569441.013.0020.

Marette, Stéphan, Jutta Roosen, Sandrine Blanchemanche, and Philippe Verger. 2008. "The Choice of Fish Species: An Experiment Measuring the Impact of Risk and Benefit Information." Journal of Agricultural and Resource Economics 33 (1): $1-18$.

McFadden, Daniel. 1986. "The Choice Theory Approach to Market Research.” Marketing Science 5 (4): 275-97.

McLachlan, Geoffrey J., and David Peel. 2000. Finite Mixture Models. Wiley Series in Probability and Statistics. Applied Probability and Statistics Section. New York: Wiley.

"Mercury in Seafood FAQ." 2019. Whole Foods Market. 2019. https://www.wholefoodsmarket.com/about-our-products/foodsafety/methylmercury-seafood (accessed January 3, 2019). 
Messer, Kent D., Marco Costanigro, and Harry M. Kaiser. 2017. "Labeling Food Processes: The Good, the Bad and the Ugly." Applied Economic Perspectives and Policy 39 (3): 407-27. https://doi.org/10.1093/aepp/ppx028.

Mizerski, Richard W. 1982. "An Attribution Explanation of the Disproportionate Influence of Unfavorable Information.” Journal of Consumer Research 9 (3): 301. https://doi.org/10.1086/208925.

Mullainathan, Sendhil, and Jann Spiess. 2017. "Machine Learning: An Applied Econometric Approach.” Journal of Economic Perspectives 31 (2): 87-106. https://doi.org/10.1257/jep.31.2.87.

National Fisheries Institute. 2018. "Top 10 List Shows Significant Increase in Seafood Consumption." About Seafood (blog). December 13, 2018. https://www.aboutseafood.com/press_release/top-10-list-shows-significantincrease-in-seafood-consumption/ (accessed December 19, 2018).

—. 2017. "Top 10 List Highlights Seafood Consumption Progress." About Seafood (blog). November 2017. https://www.aboutseafood.com/press_release/top-10-list-highlights-seafoodconsumption-progress/ (accessed December 19, 2018).

—. 2015. “Top Ten Seafood.” About Seafood (blog). November 17, 2015. https://www.aboutseafood.com/resource/top-ten-seafood-3/ (accessed December 19, 2018).

Naylor, Rosamond L., Ronald W. Hardy, Dominique P. Bureau, Alice Chiu, Matthew Elliott, Anthony P. Farrell, Ian Forster, et al. 2009. "Feeding Aquaculture in an Era of Finite Resources." Proceedings of the National Academy of Sciences, August, pnas.0905235106. https://doi.org/10.1073/pnas.0905235106.

Nesheim, Malden C., and Ann L. Yaktine, eds. 2007. Seafood Choices: Balancing Benefits and Risks. Washington, D.C: National Academies Press.

Onozaka, Yuko, Håvard Hansen, and Arne Sørvig. 2014. “Consumer Product Perceptions and Salmon Consumption Frequency: The Role of Heterogeneity Based on Food Lifestyle Segments.” Marine Resource Economics 29 (4): 35174. https://doi.org/10.1086/678928.

Palumbo, Rocco, Paola Adinolfi, Carmela Annarumma, Giuseppina Catinello, Marco Tonelli, Ersilia Troiano, Stefania Vezzosi, and Rosalba Manna. 2019. "Unravelling the Food Literacy Puzzle: Evidence from Italy." Food Policy, January. https://doi.org/10.1016/j.foodpol.2018.12.004.

Peters, Hans Peter. 1998. "Is the Negative More Relevant than the Positive? Cognitive Responses to TV Programs and Newspaper Articles on Genetic Engineering." 
In 5th International Conference on Public Communication of Science and Technology (PCST), Berlin, 17-19.

Petrolia, Daniel R. 2016. "Risk Preferences, Risk Perceptions, and Risky Food." Food Policy 64 (October): 37-48. https://doi.org/10.1016/j.foodpol.2016.09.006.

Pew Research Center. 2016. "The New Food Fights: U.S. Public Divides Over Food Science." http://www.pewinternet.org/2016/12/01/the-new-food-fights/. (accessed January 1, 2017)

Qin, Wei, and J. Lynne Brown. 2006. “Consumer Opinions about Genetically Engineered Salmon and Information Effect on Opinions: A Qualitative Approach." Science Communication 28 (2): 243-72. https://doi.org/10.1177/1075547006294770.

R Core Team. 2018. "R: A Language and Environment for Statistical Computing" R version 3.5.2 (December). http://www.R-project.org/.

Revelt, David, and Kenneth E. Train. 2000. "Customer-Specific Taste Parameters and Mixed Logit: Households' Choice of Electric Supplier.” Working Paper, University of California, Berkeley.

Rickertsen, Kyrre, Geir W. Gustavsen, and Rodolfo M. Nayga Jr. 2017. "Consumer Willingness to Pay for Genetically Modified Vegetable Oil and Salmon in the United States and Norway." AgBioForum 20 (2): 94-104.

Rousu, Matthew C., and Jason F. Shogren. 2006. "Valuing Conflicting Public Information About a New Technology: The Case of Irradiated Foods." Journal of Agricultural and Resource Economics 31 (3): 642-52.

Samoggia, Antonella, and Alessandra Castellini. 2018. "Health-Orientation and SocioDemographic Characteristics as Determinants of Fish Consumption." Journal of International Food \& Agribusiness Marketing 30 (3): 211-26. https://doi.org/10.1080/08974438.2017.1403986.

Scholderer, Joachim, and Lynn J. Frewer. 2003. "The Biotechnology Communication Paradox: Experimental Evidence and the Need for a New Strategy." Journal of Consumer Policy 26 (2): 125-57. https://doi.org/10.1023/A:1023695519981.

Sha, Sha, Julie Insignares Santos, Cathy A. Roheim, and Frank Asche. 2015. "Media Coverage of PCB Contamination of Farmed Salmon: The Response of U.S. Import Demand.” Aquaculture Economics \& Management 19 (3): 336-52. https://doi.org/10.1080/13657305.2015.1057878.

Shimshack, Jay P., Michael B. Ward, and Timothy K.M. Beatty. 2007. "Mercury Advisories: Information, Education, and Fish Consumption." Journal of Environmental Economics and Management 53 (2): 158-79. https://doi.org/10.1016/j.jeem.2006.10.002. 
Shogren, Jason F., John A. Fox, Dermot J. Hayes, and Jutta Roosen. 1999. “'Observed Choices for Food Safety in Retail, Survey, and Auction Markets.” American Journal of Agricultural Economics 81 (5): 1192-99. https://doi.org/10.2307/1244106.

Smith, Martin D., Frank Asche, Atle G. Guttormsen, and Jonathan B. Wiener. 2010. "Genetically Modified Salmon and Full Impact Assessment." Science 330 (6007): 1052. https://doi.org/10.1126/science.1197769.

Snow, Arthur. 2010. “Ambiguity and the Value of Information.” Journal of Risk and Uncertainty 40 (2): 133-45.

StataCorp. 2013. Stata Statistical Software: Release 13. College Station, TX: StataCorp LC.

Steenkamp, Jan-Benedict E.M. 1990. “Conceptual Model of the Quality Perception Process." Journal of Business Research 21 (4): 309-33. https://doi.org/10.1016/0148-2963(90)90019-A.

Tacon, Albert G.J., and Marc Metian. 2008. "Global Overview on the Use of Fish Meal and Fish Oil in Industrially Compounded Aquafeeds: Trends and Future Prospects." Aquaculture 285 (1): 146-58. https://doi.org/10.1016/j.aquaculture.2008.08.015.

Teisl, Mario F., and Brian E. Roe. 2010. "Consumer Willingness-to-Pay to Reduce the Probability of Retail Foodborne Pathogen Contamination." Food Policy 35 (6): 521-30. https://doi.org/10.1016/j.foodpol.2010.07.003.

Tibshirani, Robert. 1996. "Regression Shrinkage and Selection via the Lasso.” Journal of the Royal Statistical Society. Series B (Methodological) 58 (1): 267-88.

Tibshirani, Ryan J., Jonathan Taylor, Richard Lockhart, and Robert Tibshirani. 2016. "Exact Post-Selection Inference for Sequential Regression Procedures." Journal of the American Statistical Association 111 (514): 600-620. https://doi.org/10.1080/01621459.2015.1108848.

Tonsor, Glynn T., and Nicole J. Olynk. 2011. "Impacts of Animal Well-Being and Welfare Media on Meat Demand: Animal Well-Being and Welfare Media on Meat Demand." Journal of Agricultural Economics 62 (1): 59-72. https://doi.org/10.1111/j.1477-9552.2010.00266.x.

Train, Kenneth. 2009. Discrete Choice Methods with Simulation. 2nd ed. Cambridge; New York: Cambridge University Press.

U.S. Department of Health and Human Services, and U.S. Department of Agriculture. 2015. Dietary Guidelines for Americans 2015-2020. 8th ed. United States 
Government Printing Office.

http://health.gov/dietaryguidelines/2015/guidelines/ (accessed June 29, 2018).

-2010. Dietary Guidelines for Americans 2010, 7th Edition. United States Government Printing Office.

https://health.gov/dietaryguidelines/dga2010/dietaryguidelines2010.pdf. (accessed June 29, 2018)

Uchida, Hirotsugu, Cathy A. Roheim, and Robert J. Johnston. 2017. "Balancing the Health Risks and Benefits of Seafood: How Does Available Guidance Affect Consumer Choices?" American Journal of Agricultural Economics 99 (4): 1056-77. https://doi.org/10.1093/ajae/aax025.

Uchida, Hirotsugu, Cathy A. Roheim, Hiroki Wakamatsu, and Christopher M. Anderson. 2014. "Do Japanese Consumers Care about Sustainable Fisheries? Evidence from an Auction of Ecolabelled Seafood." Australian Journal of Agricultural and Resource Economics 58 (2): 263-80. https://doi.org/10.1111/1467-8489.12036.

United States Census Bureau. 2017a. "DP05: ACS Demographic and Housing Estimates.” In 2016 American Community Survey 1-Year Estimates. United States Census Bureau's American Community Survey Office. http://factfinder2.census.gov (accessed June 29, 2018).

_ 2017b. "S1501: Educational Attainment." In 2016 American Community Survey 1-Year Estimates. United States Census Bureau's American Community Survey Office. http://factfinder2.census.gov (accessed June 29, 2018).

_. 2017c. "S2501: Occupancy Characteristics." In 2016 American Community Survey 1-Year Estimates. United States Census Bureau's American Community Survey Office. http://factfinder2.census.gov. (accessed June 29, 2018)

USDA ERS. 2017. "Adoption of Genetically Engineered Crops in the U.S." https://www.ers.usda.gov/data-products/adoption-of-genetically-engineeredcrops-in-the-us/ (accessed July 12, 2017).

Verbeke, Wim, Filiep Vanhonacker, Lynn J. Frewer, Isabelle Sioen, Stefaan De Henauw, and John Van Camp. 2008. "Communicating Risks and Benefits from Fish Consumption: Impact on Belgian Consumers' Perception and Intention to Eat Fish." Risk Analysis 28 (4): 951-67. https://doi.org/10.1111/j.1539-6924.2008.01075.x.

Viscusi, W. Kip, Wesley A. Magat, and Joel Huber. 1999. "Smoking Status and Public Responses to Ambiguous Scientific Risk Evidence." Southern Economic Journal 66 (2): 250-70. https://doi.org/10.2307/1061142. 
Viscusi, W. Kip. 1997. "Alarmist Decisions with Divergent Risk Information.” The Economic Journal 107 (445): 1657-70. https://doi.org/10.1111/j.14680297.1997.tb00073.x.

Visschers, Vivianne H.M., Christina Hartmann, Rebecca Leins-Hess, Simone Dohle, and Michael Siegrist. 2013. "A Consumer Segmentation of Nutrition Information Use and Its Relation to Food Consumption Behaviour." Food Policy 42 (October): 71-80. https://doi.org/10.1016/j.foodpol.2013.07.003.

Visschers, Vivianne HM, Rebecca Hess, and Michael Siegrist. 2010. "Health Motivation and Product Design Determine Consumers' Visual Attention to Nutrition Information on Food Products." Public Health Nutrition 13 (07): 1099-1106. https://doi.org/10.1017/S1368980009993235.

Wakamatsu, Hiroki, Christopher M. Anderson, Hirotsugu Uchida, and Cathy A. Roheim. 2017. "Pricing Ecolabeled Seafood Products with Heterogeneous Preferences: An Auction Experiment in Japan." Marine Resource Economics 32 (3): 277-94. https://doi.org/10.1086/692029.

Wall, Patrick G., and Junshi Chen. 2018. "Moving from Risk Communication to Food Information Communication and Consumer Engagement." Npj Science of Food 2 (1): 21. https://doi.org/10.1038/s41538-018-0031-7.

Wooldridge, Jeffrey M. 2009. Introductory Econometrics: A Modern Approach. $4^{\text {th }}$ ed. Mason, OH: South Western, Cengage Learning.

Zhao, Sen, Ali Shojaie, and Daniela Witten. 2017. "In Defense of the Indefensible: A Very Naive Approach to High-Dimensional Inference." ArXiv:1705.05543 [Math, Stat], May. http://arxiv.org/abs/1705.05543 